\title{
Biochemical parameters in monitoring severity of sarcoidosis
}

Citation for published version (APA):

Rothkrantz-Kos, S. (2003). Biochemical parameters in monitoring severity of sarcoidosis. [Doctoral Thesis, Maastricht University]. Maastricht University Press. https://doi.org/10.26481/dis.20040303sr

Document status and date:

Published: 01/01/2003

DOI:

10.26481/dis.20040303sr

Document Version:

Publisher's PDF, also known as Version of record

\section{Please check the document version of this publication:}

- A submitted manuscript is the version of the article upon submission and before peer-review. There can be important differences between the submitted version and the official published version of record.

People interested in the research are advised to contact the author for the final version of the publication, or visit the DOI to the publisher's website.

- The final author version and the galley proof are versions of the publication after peer review.

- The final published version features the final layout of the paper including the volume, issue and page numbers.

Link to publication

\footnotetext{
General rights rights.

- You may freely distribute the URL identifying the publication in the public portal. please follow below link for the End User Agreement:

www.umlib.nl/taverne-license

Take down policy

If you believe that this document breaches copyright please contact us at:

repository@maastrichtuniversity.nl

providing details and we will investigate your claim.
}

Copyright and moral rights for the publications made accessible in the public portal are retained by the authors and/or other copyright owners and it is a condition of accessing publications that users recognise and abide by the legal requirements associated with these

- Users may download and print one copy of any publication from the public portal for the purpose of private study or research.

- You may not further distribute the material or use it for any profit-making activity or commercial gain

If the publication is distributed under the terms of Article $25 \mathrm{fa}$ of the Dutch Copyright Act, indicated by the "Taverne" license above, 


\section{Biochemical parameters in monitoring severity of sarcoidosis}


(C) Snježana Rothkrantz-Kos, Maastricht 2003 The copyright of articles that have already been published has been transferred to the respective journals.

ISBN: $90-5278-406-X$

Cover: Hens Gardeneers

Lay-out: Tiny Wouters

Production: Datawyse | Universitaire Pers Maastricht

Publication of this thesis was financially supported by Astra Zeneca, Beckman Coulter, GlaxoSmithKline B.V. and Zambon Nederland B.V. 


\title{
Biochemical parameters in monitoring severity of sarcoidosis
}

\author{
PROEFSCHRIFT \\ ter verkrijging van de graad van doctor \\ aan de Universiteit Maastricht, \\ op gezag van de Rector Magnificus, Prof. Mr. G.P.M.F. Mols \\ volgens het besluit van het College van Decanen, \\ in het openbaar te verdedigen \\ op woensdag 3 maart 2004 om 14.00 uur
}

door

Snježana Rothkrantz-Kos

Geboren op 10 april 1973 te Zagreb

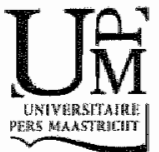




\section{Promotor}

Prof dr. M.P. van Dieijen-Visser

Co-promotor

Dr. M. Drent

\section{Beoordelingscommissie}

\section{Prof. dr. A. Bast (voorzitter)}

Prof. dr. P.M. van den Berg-Loonen

Dr. J.M.M. van den Bosch (St. Antonius ziekenhuis, Nieuwegein)

Prof. dr. R.M. Du Bois (Royal Brompton Hospital \& National Heart and Lung Institute, London, UK)

Prof. dr. E.F.M. Wouters 
Posvećujem mojim roditeljima i Mauriceu (Aan mijn ouders en Maurice) 



\section{Contents}

Abbreviations 9

$\begin{array}{lll}\text { Chapter } 1 & \text { Introduction } & 11\end{array}$

Chapter 2 High-sensitivity C-reactive protein methods examined 31

Chapter 3 Evaluation of two new high-sensitivity $\mathrm{C}$-reactive protein methods

Chapter 4 Analytical evaluation and determination of reference values of soluble interleukin-2-receptor and serum amyloid-A

Chapter 5 Usefulness of inflammatory markers to depict respiratory functional impairment in sarcoidosis

Chapter 6 The relationship between fatigue and clinical parameters in acute pulmonary sarcoidosis

Chapter 7 Decreased redox state in red blood cells from patients with sarcoidosis

Chapter 8 Relationship of myeloperoxidase promotor polymorphism and disease severity in sarcoidosis?

Chapter 9 Generall discussion

Chapter 10 Samenvatting

Chapter 11 Kroatische samenvatting (Sažetak)

Dankwoord

Curriculum vitae

List of publications 



\section{Abbreviations}

\begin{tabular}{|c|c|}
\hline All & angiotensin $\|$ \\
\hline A-IIR & angiotensin II receptor \\
\hline $\mathrm{AaPO}_{2} \max$ & alveolar-arterial oxygen difference at maximal exercise \\
\hline ACE & angiotensine converting enzyme \\
\hline $\mathrm{APC}$ & antigen presenting cell \\
\hline ATS & American Thoracic Society \\
\hline AUC & area under the curve \\
\hline BAL & bronchoalveolar lavage \\
\hline BCGF & B cell growth factor \\
\hline BCDF & B cell differentiation factor \\
\hline CD4/CD8 ratio & ratio of T cells bearing predominantly CD4 or CD8 receptor \\
\hline CSF & colony stimulating factor \\
\hline DLCO & diffusing capacity for carbon monoxide \\
\hline ECG & electrocardiogram \\
\hline EPO & eosinophilic peroxidase \\
\hline ERS & European Respiratory Society \\
\hline FVC & forced vital capacity \\
\hline FEVH & forced expiratory volume in one second \\
\hline Glc-6-P & glucose-6-phosphate \\
\hline GR & glutathione reductase \\
\hline $\mathrm{GR}-\mathrm{Cr}$ & chromate inhibition test \\
\hline $\mathrm{GPx}$ & glutathione peroxidase \\
\hline G6PD & glucose-6-phosphate dehydrogenase \\
\hline GSHIGSSG & $\begin{array}{l}\text { glutathione system (GSH, reduced form; GSSG, oxidized } \\
\text { form) }\end{array}$ \\
\hline $\mathrm{H}_{2} \mathrm{O}_{2}$ & hydrogen peroxide \\
\hline$H L A$ & human-leucocyle-associated \\
\hline HRCTtot & high-resolution computer tomography total score \\
\hline (Hs)-CRP & (high-sensitivity)-C-reactive protein \\
\hline IFN- $\gamma$ & interferon $\gamma$ \\
\hline$\| L$ & interleukin \\
\hline iNOS & inducible nitric oxide synthase \\
\hline MAF & macrophage activating factor \\
\hline MCP-1 & monocyte chemotactic peptide-1 \\
\hline MCF & monocyte chemotactic factor \\
\hline
\end{tabular}




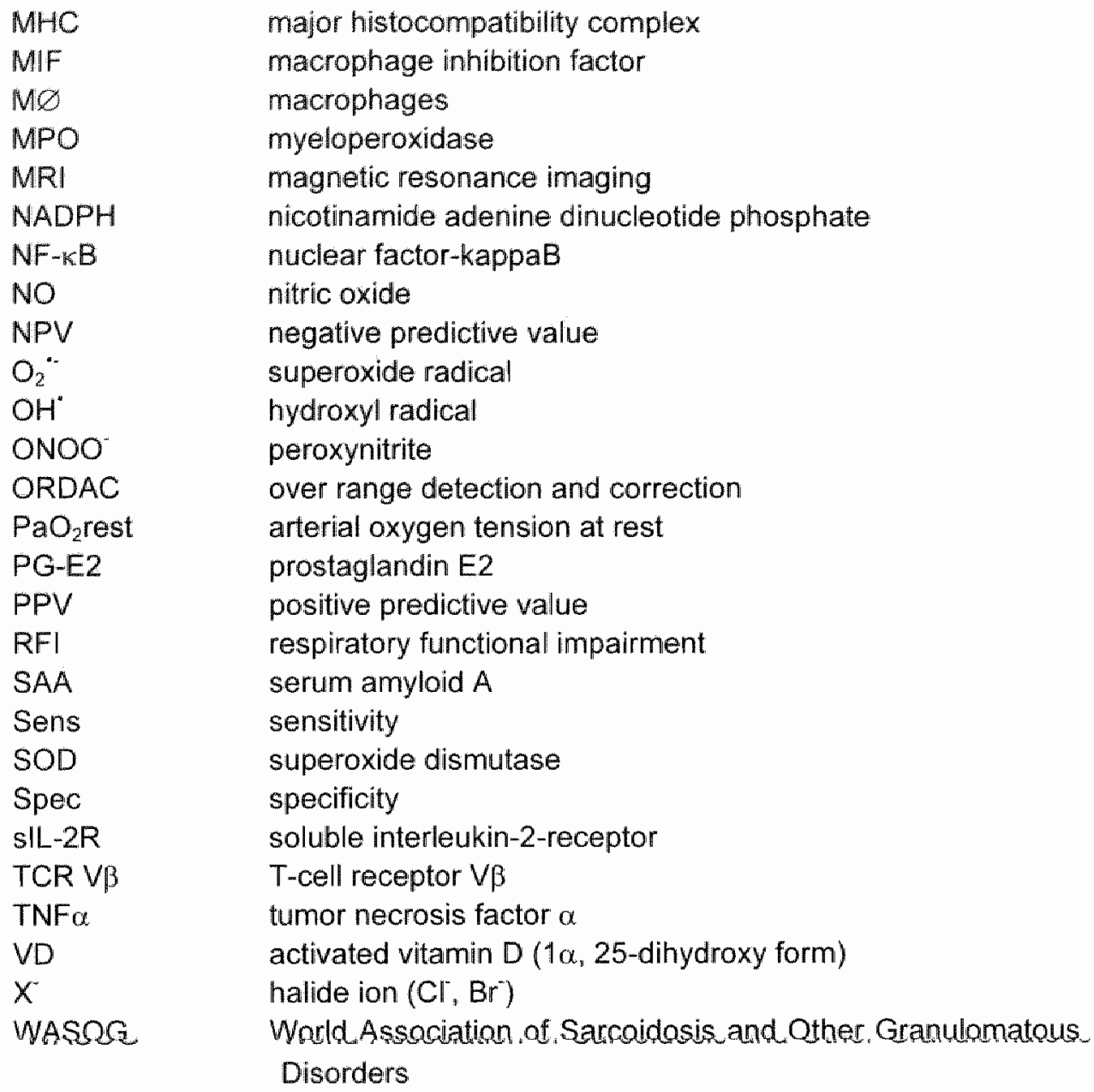


Chapter 1

\section{General introduction}




\section{Introduction}

It is well established that sarcoidosis is a multisystem disorder of unkinown cause(s). To date, no organ is immune to sarcoidosis. Granulomas, usually noncaseating but occasionally necrotizing, are the pathological hallmark of sarcoidosis. Gramulomas are structured masses composed of activated macrophages and their derivates, i.e. epithelioid and giant cells ${ }^{1.2}$. Granulomas are also features of many other (interstivial lung) disorders, e.g. extrinsic allergic alveolitis or hypersensitivity pneumonitis, druginduced pneumonitis, chronic berylliosis, and Crohn's disease. Sarcoidosis subsides in most cases, but it may worsen and become chronic in others. Pulmonary problems may persist, but also devastating extrapulmonary complications may become apparent. Appropriate management of sarcoidosis is mandatory as it predominantly affects fairly young adults (between $20-40$ years). To date, it requires the attention of pulmonologists as well as specialists from other medical disciplines. Therefore, a multidisciplinary approach is recommended that pays attention to the many aspects of this erratic disorder".

\section{Sarcoidosis}

\section{Etiology and epidemiology}

Sarcoidosis is a disseminated, granulomatous disease of unknown etiology that occurs throughout the world. To date, it is the second most common respiratory disease in young adults after asthma. Estimates of prevalence range from 1 to 50 per 100.000 individuals, varying among ethnic and racial groups ${ }^{4}$. The disease is most common among North Americans of African heritage and Northern European Caucasians (The Netherlands and Germany: $40-50$ cases per 100.000). Various infectious, organic, and inorganic agents are considered to be responsible for a granulomatous reaction in susceptible hosts ${ }^{4.7}$. It is highly likely that a genetic susceptibility to the development of sarcoidosis exists ${ }^{8-11}$.

\section{Clinical presentation}

The clinical course of sarcoidosis is highly variable and unpredictable. Virtually every organ can be involved. The lungs are affected in over $90 \%$ of patients with sarcoidosis ". It also frequently affects the lymph nodes, skin, and eyes.

The acute form is known as Lofgren's syndrome, defined by an acute onset of symptoms of fever, erythema nodosum, hilar lymph adenopathy with or without arthralgia. To date, sarcoidosis patients not only suffer from symptoms related to the lungs (e.g. cough, breathlessness), but they may also suffer from a wide spectrum of other symptoms ${ }^{4,12}$. These symptoms include persistent fatigue, arthralgias, muscle pain, weight loss, skin lesions, eye problems, and neurological as well as cardiological problems $4,12,3$. These rather non-specific symptoms are disabling for the patient, may become chronic and causing an impaired quality of life ${ }^{13-19}$. Fatigue, as an integral part 
of the clinical picture of sarcoidosis, has gained some attention in the literature ${ }^{1320-24}$, although the exact mechanism is still unknown.

Generally, spontaneous remission occurs in $75-85 \%$ of the cases within two years. However, the disease can also become chronic and progressive, estimated in up to 15 $25 \%$ of the cases. Failure to regress spontaneously within two years is considered to predict a chronic course of the disease. Overall, the mortality from sarcoidosis is $1-5 \%$. Treatment of sarcoidosis consists largely of immunosuppressive drugs such as steroids, methotrexate, cyclosporin and, more recently, anti- TNFa (Infliximab) ${ }^{25,26:}$.

\section{Diagnostic work-up and follow-up}

A pulmonary physician generally coordinates management of sarcoidosis. However, sarcoidosis can involve any organ. The diagnostic work-up and follow-up of the disease is mainly monitored by assessing clinical features and using auxiliary diagnostic procedures. According to the latest international recommendations, the diagnostic workup includes attention to the medical history, relevant exposures, imaging procedures, laboratory tests, bronchoalveolar lavage ${ }^{27}$ and, if appropriate, evaluation of biopsy specimens ${ }^{4}$. According to the latest recommendations as published by Baughman et al, diagnosis of sarcoidosis can be established by means of the following criteria: ${ }^{28}$

- The presence of granulomas in biopsy specimen without evidence of tuberculosis, fungus, malignancy or other causes of granuloma together with clinical features of sarcoidosis support the diagnosis.

- In the absence of biopsy material, clinical features such as bilateral hilar adenopathy on chest radiography, erythema nodosum, uveitis and macular papular skin lesions are suggestive of sarcoidosis.

If there is no evidence of an alternative diagnosis and additional features highly consistent with sarcoidosis are present such as raised angiotensin-converting enzyme $(A C E)$, bronchoalveolar lavage (BAL) fluid lymphocytosis and/or lupus pernio (cutaneous manifestation of sarcoidosis frequently on the nose), the diagnosis can also be confirmed ${ }^{4.28}$.

The recommended clinical tests in the mangement of sarcoidosis are presented in Table 1.1. Among others, lung function test results are used to guide the therapeutic approach. Depending on the severity of the inflammation in the lung, Iung function tests may reveal restricted lung volumes and/or impaired diffusion capacity and mildly decreased arterial oxygen pressure at exercise. Pulmonary and mediastimal lymph node involvement is found in up to $90 \%$ of patients, which is easily recognizable on chest radiography ${ }^{2 \%}$. Intrathoracic involvement can vary from sole bilateral hilar lymphadenopathy to extensive parenchymal disease and fibrosis. In general, chest radiographic appearances have been divided into four "stages" or types according to the modified Scadding criteria: stage 0, no lung involvement; stage $\mathbb{1}$, bilateral hilar enlargement alone; stage II, hilar enlargement in association with interstitial lung disease; stage III interstitial lung disease alone; and stage IV (a more recent addition to the original classification), requires radiographic evidence of lung fibrosis ${ }^{30}$. 
Table 1. 1. Recommended initial evaluation of patients presenting with sarcoidosis ${ }^{\text {4. }}$.

\begin{tabular}{|c|c|c|}
\hline 1. & History & $\begin{array}{l}\text { Exposure: } \\
\text { - occupational } \\
\text { - environmental } \\
\text { Symptoms }\end{array}$ \\
\hline 2. & Physical examination & \\
\hline 3. & Chest radiography (postero-anterior) & \\
\hline 4. & Pulmonary function tests & $\begin{array}{l}\text { Spirometry } \\
\text { DLCO }\end{array}$ \\
\hline 5. & Peripheral blood counts & $\begin{array}{l}\text { White blood cells } \\
\text { Red blood cellis } \\
\text { Platelets }\end{array}$ \\
\hline 6 & Serum chemistries & $\begin{array}{l}\text { Calcium } \\
\text { Liver enzymes: } \\
\text { - alanine aminotransferase } \\
\text { - aspartate aminotransferase } \\
\text { - alkaline phosphatase } \\
\text { Creatinine } \\
\text { Blood urea nitrogen }\end{array}$ \\
\hline 7. & Urine analysis & \\
\hline 8 & $E C G$ & \\
\hline 9. & Routine ophthalmologic examination & \\
\hline 10 & Tuberculin skin test & \\
\hline
\end{tabular}

* In the initial evaluation of sarcoidosis no ACE measurement was recommended.

\section{Disease activity and severity}

In general the state of a disease can be classified either by activity and/or severity. Unlike other disorders, activity in sarcoidosis does not necessarily indicate a progressive course, a fatal prognosis, or the need for medical treatment"

Moreover, there is a lot of discussion about the definitions of both, as it is very difficult to make a clear distinction between these two entities. Besides, there is overlap between the two. The activity is defined in the latest World Association of Sarcoidosis and other Granulomatous Disorders (WASOG) statement on sarcoidosis (1999). According to the statement, clinical activity is assessed on the basis of onset, worsening, of persistence of symptoms or signs directly related to sarcoidosis. The statement, however, does not give a clear recommendation on how to define the activity (Table 1.2.). Unfortunately, the term "activity" has in the past been used freely and not always systematically".

Inconsistency exists also on how to define severity. Changes in plain chest radiography and lung function tests have traditionally been used as the main indices of change of respiratory function indicating pulmonary severity ${ }^{32}$. Extrapulmonary manifestations such as cardiac, neurological or ocular lesions often also represent a more severe course of the disease. Many new parameters are evaluated as activity parameters, whereas the concept of severity is left out. Recently, some studies evaluated new parameters with the background of severity ${ }^{33-35}$. Moreover, among others one genetic study appeared which showed that human leukocyte antigen (HLA)-DQB I allele*0201 is strongly protective against severe sarcoidosis". 
Unil now, far less attention has been paid to severity of the disease and the appropriateness of the various markers to detect severity. From a clinical point of view, it is of more importance to depict whether the disease is severe, i.e. will have a more or less chronic course than the initial activity. For each appropriate evaluation of the diagnostic accuracy of any marker a clear definition of the condition such as activity or severity is needed. However, a problem arises in case of sarcoidosis.

Therefore, one of the aims of this thesis was to search for new markers, which could possibly reflect disease severity in sarcoidosis. In case of pulmonary sarcoidosis disease severity was defined through the presence of respiratory functional impairment.

The ideal marker(s) of disease severity should be able to predict subsequent organ dysfunction. However, such markers are not identified by now ${ }^{32}$.

Table 1.2. Markers of disease activity in sarcoidosis".

\begin{tabular}{|c|c|c|}
\hline Clinical & Biochemical or instrumental & Imaging \\
\hline Fever & Serum ACE & $\begin{array}{l}\text { Progressiwe changes on } \\
\text { chest radiographs or lung CT } \\
\text { scans }\end{array}$ \\
\hline Eye involvement uveitis & Hypercalcemia & $\begin{array}{l}\text { Ground-glass attenuation on } \\
\text { HRCT scan }\end{array}$ \\
\hline $\begin{array}{l}\text { Skin involvement } \\
\text { - Erythema nodosum } \\
\text { - Lupus pernio } \\
\text { - Changing scar }\end{array}$ & Worsening lung function & $\begin{array}{l}\text { Positive } 67 \text { Ga uptake } \\
\text { (panda/labda sign) }\end{array}$ \\
\hline $\begin{array}{l}\text { Joint involwement } \\
\text { - Polyathralgia }\end{array}$ & $\begin{array}{l}\text { BAL fluid: } \\
\text { lymphocyte alveolitis and high } \\
\text { CD4/CD8 ratio }\end{array}$ & $\begin{array}{l}\text { Fluorescein angiography of } \\
\text { the eyes }\end{array}$ \\
\hline Splenomegaly & $\begin{array}{l}\text { Abnormal ECG, echocardio- } \\
\text { gram or thallium scan }\end{array}$ & $\begin{array}{l}\text { MRI ar CT scan } \\
\text { abnormalities }\end{array}$ \\
\hline \multicolumn{3}{|l|}{$\begin{array}{l}\text { Enlarged lymph nodes } \\
\text { (lymphadianopathy) }\end{array}$} \\
\hline $\begin{array}{l}\text { Salivary and lacrimal gland } \\
\text { enlargement }\end{array}$ & Abnormal liver function tests & Bone cysts \\
\hline \multicolumn{3}{|l|}{ Myocardial disease } \\
\hline \multicolumn{3}{|l|}{$\begin{array}{l}\text { Unilateral facial paralysis or } \\
\text { other neurological } \\
\text { symploms/signs }\end{array}$} \\
\hline $\begin{array}{l}\text { Progressivie respiratory } \\
\text { symptoms (dyspnea, cough) }\end{array}$ & & \\
\hline
\end{tabular}




\section{Molecular changes in sarcoidosis}

Inflammation that does not resolve within a matter of days (by means of "natural immunity"), becomes chronic, as is the case in sarcoidosis. Antigens are than usually presented to the lymphocytes by antigen presenting cells (APC). These APC's (dendritic cells, macrophages and sometimes $\mathrm{B}$ cells) trap antigens, concentrate them, prevent their spread and initiate local immune response.

Before an antigen can be presented to a T cell, it must be processed by an APC. This involves the enzymatic degradation of the antigen and anchoring to highly polymorphic class I (variants of HLA $-A,-B,-C$ ) or class II (variants of HLA -DP, $-D Q$ and $-D R$ ) major histocompatibillity complex (MHC) molecules ${ }^{36-39}$. In sarcoidosis associations with the different HLA molecules have been observed, mainly with the subtypes of HLA-B, HLA-DR and HLA-DQ ${ }^{8-10}$. MHC class I interact with $\mathrm{CDS}^{*} \mathrm{~T}$ cells, whereas MHC class II interact with $C D 4^{+} T$ cells (sce further) ${ }^{36-30}$.

After the presentation of antigen by the APC and reaction with a processed antigen, T cells go through stages of activation, growth and differentiation and secrete a variety of mediators (cytokines). These cytokines are especially important in regulating the function of other lymphocytes. T cells express particular accessory molecules on their cell surface that are important to their function but can also be used to classify them. The T cells expressing CD4 molecules (i.e. T-helper cells) are involved in either cellmediated immunity (Th1 cells, also called delayed hypersensitivity $T$ cells) or promote the activation, growth and differentiation of $B$ cells (Th2 cells). In contrast $T$ cells expressing CD8 molecules, either counterbalance the effects of T-helper cells and suppress immune response (T-suppressor cells) or are involved in the killing of other cells (cytotoxic-T cells). The measurement of T cells expressing either CD4 or CD8 has become clinically important as changes in their balance (CD4/CD8 ratio) may be an indication of a disease ${ }^{36-39}$.

In the sarcoid lung, the earliest pathologic finding is a mononuclear alveolitis composed of increased $\mathrm{CD} 4$ T-helper lymphocytes (with an increased CD4/CD8 helper/suppressor ratio), monocyte-macrophages and some B-lymphocytes ${ }^{\text {, }, 40}$.

Also in sarcoidosis, the consequence of antigen presentation to specific T-lymphocytes is amplification of the immune response through proliferation of T-lymphocytes and their production of cytokines ${ }^{4.28,41}$. The APC-lymphocyte conjugation transduces a signal to the lymphocyte to express IL-2 receptors on T-lymphocyte cell surfaces and release $1 L-2$ (Figure 1.1). The binding of IL-2 to IL-2 receptors causes proliferation of IL-2-responsive lymphocytes. The proliferating T-helper cells command the assembly of the granuloma through production of various molecules ${ }^{4.28,41.42}$. In fact, in the early stage of the disease, the local tissue inflammation in sarcoidosis is dominated by expression of Th1-cytokines (mainly $\mathbb{I L}-2$, interferon- $\gamma$ (IFN- $\gamma$ ) and tumor necrosis factor- $\beta(\mathrm{TNF}-\beta))^{43-49}$. 


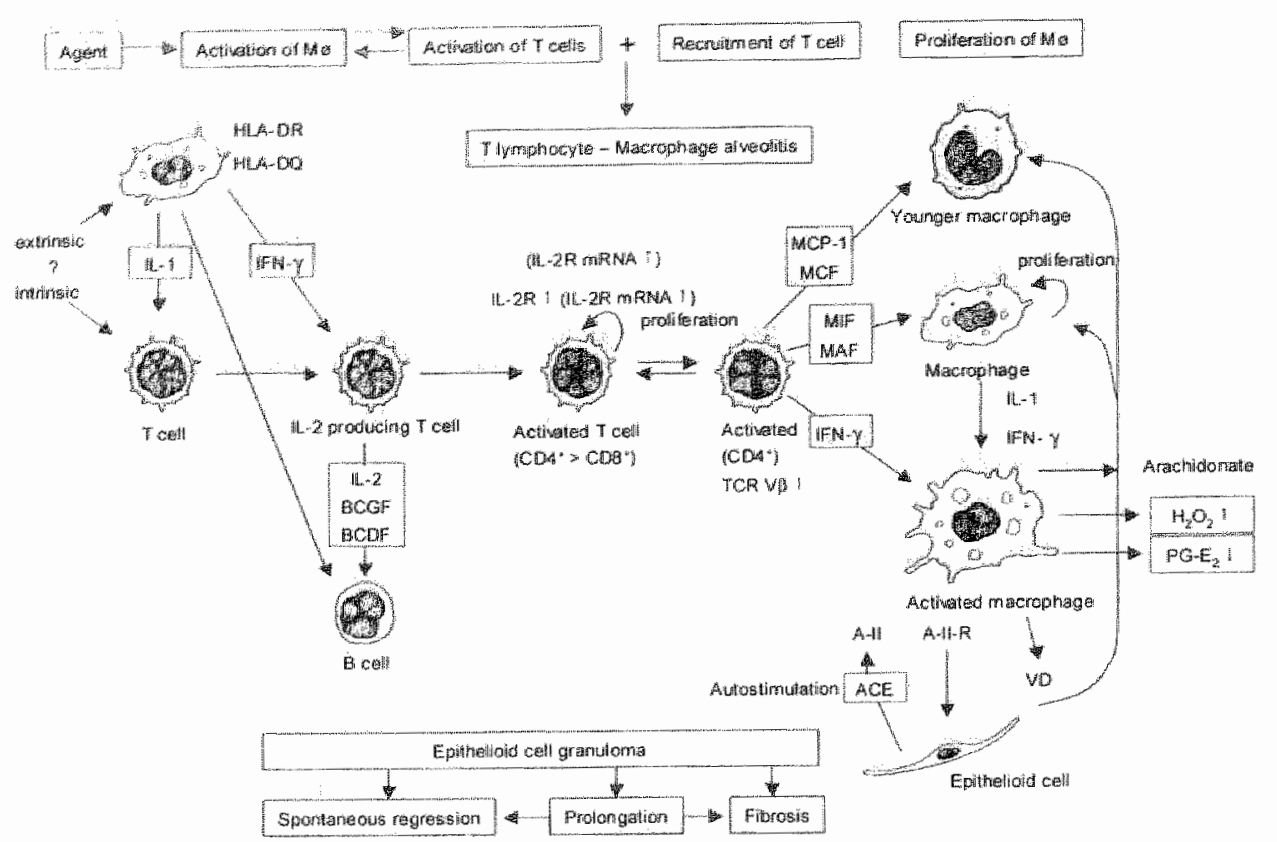

Figure 1.1. Pathophyslological processes in patients with pulmonary sarcoidosis (adapted with permission from Nagai et. at. ${ }^{41}$ ).

$M \varnothing=$ macrophages; $\| L-1=$ interleukin $1 ; 1 L-2 R=I L-2$ receptor; $B C G F=B$ cell growth factor; $\mathrm{BCDF}=\mathrm{B}$ cell differentiation factor; $\mathrm{MCP}-1=$ monocyte chemotactic peptidide-1; MCF = monocyte chemotactic factor; MIF = macrophage inhibition factor; $\mathrm{MAF}=$ macrophage activating factor; $I F N-\gamma=$ interferon $\gamma, \mathrm{PG}-\mathrm{E} 2=$ prostaglandin $E 2$; $A-\|=$ angiotensin $\|; A-\|-R=$ angiotensin $\|$ receptor; $V D=$ activated vitamin $D(1 \alpha$. 25-diOH-form); TCR $V \beta=T$ cell receptor $V / \beta$.

Sarcoid lung T-lymphocytes spontaneously release several cytokines such as soluble monocyte chemoatractant factor (MCF) to attract the monocytes. Monocytes are the predominaint cellular nesource required for granuloma architecture. Recruited monocytes becone activated and sequentially differentiate into macrophages, epithelioid cellis, and giant cells. These granuloma structures (mainly epithelioid cells) are able to produce angiotensin-converting enzyme and the active form of vitamin $D$ as shown in Figure 1.1. An increased production of oxygen peroxide (indicating presence of oxidative stress) and prostaglandin $\mathrm{E2}$ has also been observed (Figure 1.1) (1.50 $^{\text {. }}$

The net eflect of the ThI (IFN-y dominant) response is the organization of the local inflammatory process into the granuloma and an inhibition of fibrogenetic processes ${ }^{46}$. In addition to the $T$ cell activation also some $B$ cell activation occurs which may result in trypergammaglobulinemia ${ }^{51}$.

Nevertheless depending on the host susceptibility, a switch to type 2 (IL-4-dominant) may occur in patients with progressive sarcoidosis who evolve towards lung fibrosis $^{46,52}$. The identity of molecules and receptors that drive the Th1/Th2 balance at sites of disease activity remains controversial ${ }^{46}$. 


\section{Outline of the serum markers evaluated in this thesis}

\section{Acute phase response}

As a consequence of the inflammatory stimuli, $1 L-1$ and $11-6$ are produced, which stimulate liver production of C-reactive protein (CRP) and serum amyloid A (SAA), among other proteins.

\section{C-reactive protein}

C-reactive protein (CRP) is an acute-phase protein featuring a highy conserved structure $^{53}$. Expression of CRP is regulated mainly at the transcriptional level with 1 . -6 being the principal inducer of the gene during the acute phase. It is built up of five identical subunits, aggregated in a symmetric pentameric form by noncovalent binding. between the subumits. Each subunit has the ability to bind two calcium ions so that a calcium-dependent specific binding of a ligand is possible. The most avid ligand is phosphocholine (PCh). The $\mathrm{PCh}$ is widely distributed in pathogens and in cellular membranes ${ }^{53,54}$.

CRP is involved in opsonization and phagocytosis through two routes: activation of the classical pathway of the complement and through the direct binding to the foragment of the IgG receptors. Interestingly, expression of $\mathrm{Fc}$ receptors was shown to be suppressed in alveolar macrophages from patients with sarcoidosis 35.

Clearance of CRP is monoexponential and independent of the serum concentration or pathophysiological circumstances, what normally makes the CRP" a good marker of disease activity.

The measurement of plasma or serum CRP can help differentiate inflammatory from non-inflammatory conditions ${ }^{53}$. In rheumatoid arthritis and pancreatitis CRP measurement has prognostic value ${ }^{53,56}$. Since inflammation is believed to play a role in the pathogenesis of cardiovascular events, measurement of CRP has been proposed for the prediction of the risk of these events ${ }^{57.5 \%}$. Also in sarcoidosis CRP appeared to be increased especially in acute disease ${ }^{34}$.

\section{Serum amyloid $\mathrm{A}$}

Serum amyloid A (SAA) is a polymorphic protein that consists of four genetically determined isotypes. Isotypes SAA1 and SAA2 are synthesized in response to inflammatory cytokines and present together the SAA response measured as a part of the acute phase reaction ${ }^{560}$. The gene encoding SAA3 is not expressed, whereas SAA4 present a constitutive apolipoprotein in $\mathrm{HDL}$, and it does not behave as acute phase reactant.

SAA (SAA1 and SAA2) synthesis is induced primarily in the liver, by the stimulation of inflammation-related cytokines such as $1 L-1, \mathbb{L}-6$ and "TNF $-\alpha^{61.62}$. However, it appears that there is also some extrahepatic SAA synthesis. The plasma concentration of SAA changes can be very large due to inflammatory stimuli (1000x increase). The major nole of SAA appears to be preserving homeostasis by preventing further progress of injuries or by repairing damaged tissues. This mainly because some of the following 
functions have been attributed to SAA: 1. inhibition of antibody production by lymphocytes, 2. inhibition of platelet agglutination; 3 . inhibition of the oxidative burst reaction in newtrophils; 4 . induction of collagenase and 5 . chemotaxis of neutrophils and monocyles ${ }^{5960}$.

Immediately after $\$ A A$ is released from the cells, it binds with high-density lipoproteins (HDL) and circulates throughout the system. The role of HDL is to remove cholestero] from the tissues. Circulating HDL acquires cholesterol by extracting it from cell surface membranes and converts it into cholesterol esters through the action of lecithin cholesterol acyltransferase (LCAT), an enzyme that is activated by the HDL component apoA-I. In the circulation, SAA is rapidly cleared. Inflammatory conditions that are accompanied with high SAA concentrations greatly alter the HDL composition, reducing levels of apoAI, and increasing those of SAA. Reduction of apoAI is due to lowered synthesis in the liver and probably displacement from HDL by SAA ${ }^{59,60}$, which has been stiown in sarcoidosis, $100^{63}$.

In drawn plasma, almost all SAA is present in high molecular form (most in HDL and little in other lipoproteins). Most SAA assays are directed to SAA in HDL, and not to SAA monomer, which reacts with antibodies differently from the lipid-bound form. Furthermore, for measurement of acute phase SAA, cross-reactivity of antibodies with SAA4 must be avoided.

Clinical value of the SAA has been established in various diseases. During viral infections, SAA appeared to increase more intense as compared to $\mathrm{CRP}^{59,64,65}$. In some diseases, such as Crohn's disease and ulcerative colitis, CRP remained even normal, whereas SAA increased ${ }^{6670}$. In sarcoidosis, SAA appeared to be increased in patients with active disease ${ }^{63}$. To date, one of the strongest advantages of SAA above CRP has been demonstrated in kidney transplantation patients on immunosuppressive steroid therapy. In this later population only SAA appeared to be useful in monitoring acute rejection reactions, because in contrast to CRP, SAA expression is not influenced by corticosteroids ${ }^{59,71,72}$.

For neither SAA or CRP, no diagnostic accuracy studies or studies aimed to predict fatigue in sarcoidosis have been reported by now.

\section{High intensity alveolitis}

Activation of $\mathrm{T}$ cells leads to the expression of $\mathrm{IL}-2$ receptors on the cell surface and induces reterse of soluble $\mathbb{1}-2$ receptor $(\mathrm{sIL}-2 \mathrm{R})$ molecules into the circulation. Besides, locally in the lung the redistribution of the cell-types occurs with increase in CD4-cells in the BAL.

\section{Soluble $L-2 R$}

Proliferation of $T$ cells is controlled mainly by $1 \mathrm{~L}-2$ and the recently discovered $1 \mathrm{~L}-15^{7}$. For messages to be transmitted from cell to cell, IL-2 must bind to the IL-2R on the receiving cell. The receptor is expressed only on activated $T$ cells and consists of three transmembrane protein chains: $\alpha(C D 25), \beta(C D 122)$, and $\gamma(C D 132)$. The $\alpha$-subunit must associate with the B-subunit to form the $1 \mathrm{~L}-2$ binding site. Binding of IL-2 with the receptor transduces a signal across the cell membrane and triggers T-lymphocytes to undergo clonal expansion ${ }^{73-7}$. 
The $Q$-subunit of the $I L-2 R$ is expressed on activated $T$ cells and at lower levels on activated $B$ cells, natural killer cells, and tumor cells ${ }^{767}$. The $I L-2 R$ immunoassay is designed as an assay to measure this a(CD25) subunit (sometimes also called anti-Tac assay), as a soluble part of the $I L-2 R$ complex receptor ( $S L-2 R$ ).

Increased levels of $5 I L-2 R$ have been observed in lymphoproliferative disorders, neoplastic diseases and a variety of inflammatory and immunological disorders such as idiopathic pulmonary fibrosis, tuberculosis, leprosy etc. ${ }^{50}$

It has been suggested that sIL-2R might be useful in monitoring pulmonary as well as extrapullmonary involvement in sarcoidosis $34,350.77$ However, no appropriate diagnostic accuracy studies have been performed yet.

\section{Granuloma formation}

\section{Angiotensin converting enzyme}

Angiotensin I-converting enzyme (ACE), is a dipeptidyl-carboxypeptidase, mostly present on the luminal surface of the vascular endothelium.

The product of the enzymatic action of ACE is angiotension II, which is chemotactic for macrophages and may enhance the phagocytosis and accessory function of alveolar macrophages in sarcoidosis ${ }^{50}$.

Physiologically, ACE is the key-enzyme of the renin-angiotensin system. Angiotensin II is a potent vasoconstrictor, which also stimulates adrenal production of aldosterone (sodium ion retention). Furthermore, $\mathrm{ACE}$ is able to cleave vasodilatator bradykinin and some other neuronal peptides, inactivating them thereby ${ }^{50.78}$.

Angiotensin II regulates cellular proliferation, inflammation and endothelial function through the activation of reduced nicotinamide adenine dinucleotide phosphate (NAD(P)H) oxidases ${ }^{79}$. Namely, angiotensin II activates NAD(P)H-dependent oxidases and these form the most important vascular source of superoxide $\left(\mathrm{O}_{2}\right)^{80,81}$, which stimulates nuclear factor- $\mathrm{kB}(\mathrm{NF}-\mathrm{kB})$ to induce proinflammatory cytokines ${ }^{70,80}$. The $N F-\kappa B$ appears also to play a role in sarcoidosis ${ }^{82-84}$.

In sarcoidosis, ACE is mainly produced by activated granuloma cells (epithelioid cells). Therefore, elevated serum ACE concentrations reflect the total body granuloma burden. However, serum ACE correlates only roughly with the number of organs involved and the number of extrapulmonary sites as assessed by gallium seans ${ }^{\text {si }}$. Besides ACE concentrations appeared to have poor predictive value in sarcoidosis ${ }^{34,85-87}$.

There might be several reasons for that. Firstly, its less good performance might, at least for a part, be explained by the fact that $\mathrm{ACE}$ concentrations can be influenced by $\mathrm{ACE}$ polymorphism (I/D polymorphism in intron 16 of the ACE gene) ${ }^{88.89}$ "Therefore, adjustment of the reference values for the ACE polymorphism has been suggested ${ }^{81,90}$. Nevertheless, so far, with respect to ACE polymorphism and susceptibility to disease progression, inconclusive data have been reported ${ }^{96.92}$.

Secondly, ACE increase can be due to familiar ACE increase ${ }^{93-25}$. Thirdly, ACE increase is common in many other diseases, which explains its low specificity for sarcoidosis $^{78}$.

In spite of all of these limitations, ACE ils still the only serologic parameter recommended by $\mathrm{WASOG}$ in sarcoidosis. $\mathrm{ACE}$ is stated to be valuable in several 
aspects: confirmation of suspected diagnosis, estimation of granuloma burden of the organism and follow-up of the disease during treatment ${ }^{*}$.

\section{Oxidative stress and sarcoidosis}

\section{General facts about oxidative stress}

Reactive oxygen and nitrogen spectes (ROS and RNS) are ubiquitous compounds produced by several types of reactions that can cause extensive damage to lung tissue. Enhanced ROS production was also demonstrated in sarcoidosis \% 101,6 ? The ROS include superoxide $\left(\mathrm{O}_{2}{ }^{\circ}\right)$, hydrogen peroxide $\left(\mathrm{H}_{2} \mathrm{O}_{2}\right)$, and hydroxyl radicals $\left(\mathrm{OH}^{*}\right)$. Among various $\mathrm{RNS}$, one of the most toxic species is peroxynitrite (ONOO), derived from the reaction of $\mathrm{O}_{2}$ " and the nitric oxide radical $\left(\mathrm{NO}^{\prime \prime}\right)^{103-105}$. The $\mathrm{NO}^{\circ}$ is produced in high concentrations by the inducible nitric oxide synthase (iNOS), at sites of chronic inflammation.

During inflammation, ROS are produced through the process of so-called respiratory burst. The respiratory burst is an accelerated and increased $\mathrm{O}_{2}$ uptake by neutrophils and macrophages, which can be ten to twenty times the "resting" $\mathrm{O}_{2}$ consumption of neutrophils ${ }^{104}$. The $\mathrm{O}_{2}$ uptake is due to the activation of the NADPH oxidase enzyme complex. The activated complex oxidizes NADPH into NADP in favor of the reduction of $\mathrm{O}_{2}$ into $\mathrm{O}_{2}{ }^{*}$.

In the respiratory burst myeloperoxidase (MPO) and eosinophilic peroxidase (EPO) are important enzymes involved, which produce very potent oxidant hypochlorous acid (HOCl), used for microbial killing.

MPO is an abundant protein of neutrophils, stored in the azurophilic granules of neutrophils and relleased during phagocytosis ${ }^{106.107}$. Important Jung enzymes like acethylcolinesterase, glutathione-S-transferase and alpha-1-antiproteinase can be modified by MPO in a way that they loose their enzymatic properties ${ }^{108}$. An overview of the relationship between the most prominent reactive oxygen or nitrogen species is given in Figure 1.2.A.

Under normal conditions, toxic oxygen metabolites are generated at a low level in lung cells by the transfer of a single electron during aerobic metabolism (respiratory chain for ATP production) in mitochondria.

Enzymatic systens such as NADPH oxidase, cytochrome P-450, nonoamine oxidase, lipooxygenase and arachidonic acid metabolism represent another type of source of toxic oxygen species.

\section{Lung antioxidants}

The lung has to controt the redox-balance in order to maintain nomal cellular function. To be able to do that, it possesses an integrated antioxidant system.

Superoxide-dismutase (SOD) is an ubiquitous enzyme which catalyses conversion of $\mathrm{O}_{2}$ " radicals to $\mathrm{H}_{2} \mathrm{O}_{2}$. The toxic $\mathrm{H}_{2} \mathrm{O}_{2}$ can be converted into $\mathrm{H}_{2} \mathrm{O}$ in an enzymatic reaction by catalase. However, a central mechanism for reduction of $\mathrm{H}_{2} \mathrm{O}_{2}$ is the glutathione system (GSH, reduced form; GSSG, oxidized form of glutathione) in a 
reaction catalyzed by glutathione peroxidase (GPx). The reaction catalyzed by GPx complements catalase as a reducing system for $\mathrm{H}_{2} \mathrm{O}_{2}$ but exceds catalase in its capacity to eliminate additional varieties of toxic peroxides. Therefore, the cells try to mantain a high intracellular GSH:GSSG ratio.

In principle, oxidative stress can result in adaptation or cell injury ${ }^{104}$. The adaptation can result in up-regulation of the synthesis of antioxidant defense systems. Such an adaptation has been shown in sarcoidosis patients reflected through an increased expression of catalase and superoxide dismutase ${ }^{100,10}$.

The enzyme glutathione reductase (GR) maintains high intracellular concentrations of GSH by reducing the oxidized form of glutathione, GSSG, back to the reduced form, GSH. For this reaction, the reducing equivalents are derived from NADPH ${ }^{11-1 / 4}$. The major pathway to generate NADPH is the hexose monophosphate shunt (HMS). In this pathway, glucose-6-phosphate dehydrogenase (G6PD) is the first and rate-limiting enzyme 115,116 . In erythrocytes this is the only pathway to generate the NADPH. An overview of the enzymatic antioxidants is given in Figure 1.2B.

Additional antioxidants present in the lungs include ceruloplasmin, transferrin, ascorbate (vitamin C), alfa-tocoferol (vitamin E), ferritin, other serum proteins, and small molecules such as bilirubin.

A. Generation of reactive oxygen species

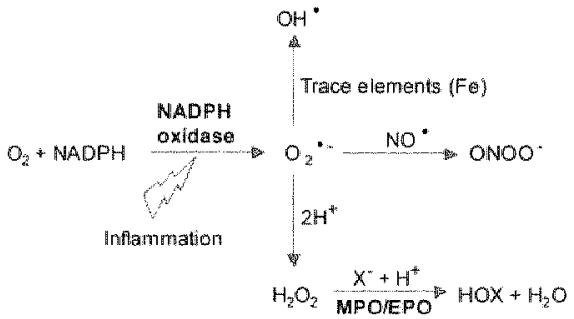

\section{B. Antioxidative enzymatic systems}

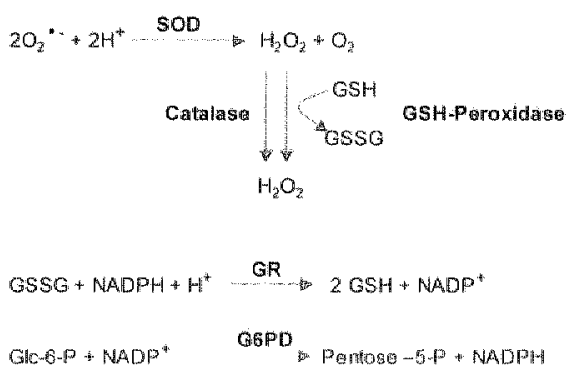

Figure 1.2. Generation of reactive oxidative species and the relation to antioxidative enzymatic systems.

$\mathrm{O}_{2}{ }^{\circ}=$ superoxide, $\mathrm{H}_{2} \mathrm{O}_{2}=$ hydrogen peroxide, $\mathrm{OH}^{\prime \prime}=$ hydroxyl radicals,

ONOO $=$ peroxynitrite, $\mathrm{NADPH}=$ micotinamide adenine dinucleotide phosphate, $\mathrm{MPO}=$ myeloperoxidase,$\quad \mathrm{EPO}=$ eosinophilic peroxidase,$\quad \mathrm{SOD}=$ superoxide dismutase, GSH/GSSG = glutathione system $(G S H$, reduced form; GSSG, oxidized form), $\mathrm{GPx}=$ glutathione peroxidase, $\mathrm{GR}=$ glutathione reductase $N \mathrm{O}^{\circ}=$ nitric oxide radical, $\mathrm{X}=$ halide ion $\left(\mathrm{Cl}^{-}, \mathrm{Br}\right)$, Glo-6-P $=$ glucose-6mphosphate 


\section{Scope and aims of the study}

The studies presented in this thesis were all performed in serum samples or in erythrocytes.

When reatures of sarcoidosis, for example radiological abnormalities and lung function impairment, resolve during treatment, disabling symptoms such as fatigue and pain nay persist. Moreover, consensus about laboratory fundings to depict disease activity or severity in sarcoidosis is still lacking. Overall this thesis concentrates on severity of sarcoidosis and the concept of activity has been left out from the evaluation.

The first aim of the studies presented in this thesis was to evaluate the clinical value of four different enzymatic markers, C-reactive protein (CRP), serum amyloid A (SAA), soluble interleukin-2-receptor (sIL-2R) and angiotensin converting enzyme ( $A C E$ ). Firstly, the diagnostic accuracy of these markers to predict sarcoidosis severity was evaluated (CHAPTER 5). Secondly, the relationship of these markers and other clinical data with one of the major problems of sarcoidosis patients, i.e. fatigue, was studied (CHAPTER 6).

Prior to this, the methods used to measure these markers were evaluated and presented across CHAPTERS 2-4. In CHAPTER 2 and 3 the performance and agreement between the various CRP and hs-CRP methods were examined. In CHAPTER 4 the analytical performance and reference values for $S L L-2 R$ and $S A A$ are presented.

The second aim of the studies presented in this thesis was to study several aspects of oxidative stress and its relationship with sarcoidosis.

Recently, it was hypothesized that oxidative stress might be involved in the pathogenesis of sarcoidosis. Among others, glucose-6-phosphate dehydrogenase (G6PD) and glutathione reductase (GR) are important antioxidant enzymes. These two enzymes are closely related. G6PD is the enzyme responsible for the regeneration of reduced nicotinamide adenine dinucleotide phosphate (NADPH). GR is involved in the regeneration of reduced glutathione (GSH), using the NADPH from the reaction catalyzed by G6PD. Indirectly, NADPH concentration can be measured by chromateinhibition test. The state of these enzymes and indirectly the NADPH concentrations in the erythrocytes of the patients with sarcoidosis were analyzed in CHAPTER 7.

Previously, it was found that polymorphonuclear neutrophils might explain, at least in part, for severity in sarcoidosis. Myeloperoxidase (MPO) is considered as the most abundant enzyme of the neutrophils. Therefore, wo functional polymorphisms, -463 $\mathrm{G} / \mathrm{A}$ and $-129 \mathrm{G} / \mathrm{A}$, able to modify the expression of MPO were examined in sarcoidosis patients. Furthermore, their relationship with the severity of sarcoidosis was examined (CHAPTER \&). 


\section{References}

1. Kataria YP. Holter JF. Sarcoidosis: A Model of Granulomatous Inthammation of Unknown Etiology Associated with a Hyperactive Immune System. Methods 1996;9:268-94.

2. Mullen-Quernheim J. Serum markers for the staging of disease activity of sarcoidosis and other interstitial lung diseases of unknown etiology. Sarcoidosis Pasc Diffase Lung Dis 1998:15:22-37.

3. Drent M. Sarcoidosis: benefits of a multidisciplinary approach. Eu J mern Mad 2003:14:217-20.

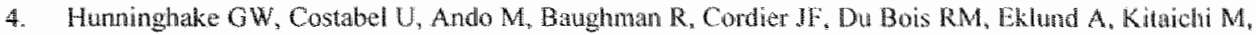
Lynch J, Rizzato G, Rose C, Selroos O. Semenzato G, Shama OP. ATS/ERS/WASOG statement on sarcoidosis. American Thoracic Society/European Respiratory Society/World Association of Sarcoidosis and other Granullomatous Disorders. Sarcordosis Vase Diffuse Lung Dis 1999;16:149-73.

5. MoGrath DS, Goh N, Foley PJ, Du Bois RM. Sarcoidosis: genes and microbes-sail or seed? Sarooidosis: Yaso Diffiuse Lung Dis 2001; 18:149-64.

6. Drent M, Bomans PH, Van Suyten RJ, Lamers RJS, Bast A. Wouters EFM. Association of man-made miryeral fibre exposure and sarcoidlike gramulomas. Respir Med 2000;94:815-20.

7. Verleden GM, Du Bois RM, Bouros D. Drent M, Millar A, Mäller-Quemheim J. Semenzato G, Johnson $S_{\text {, Sourvino }}$, Olivier D, Pietinalho A, Xaubet A. Genetic predisposition and pathogernetic medhanisms of interstitial lung diseases of unknown origin. Ear Respir.J Supp/ 2001,32:175-29s.

8. Sato H, Grutters JC, Pantelidis P, Mizzon AN, Ahraad T, Van Houte AJ, Lammers J-W, van den Bosch MM, Welsh KI, Du Bois RM. HLA-DQB1*0201: A Marker for Good Prognosis in British and Dulch Patients with Sarcoidosis, Am J Respin Cell Mol Biol 2002;27:406-12.

9. Martinetti M, Luisetti M, Cuccia M. HLA and sarcoidosis: new pathogenetic insights. Sarcoidosis Vasc Diffuse Lumg Dis 2002;19:83-95.

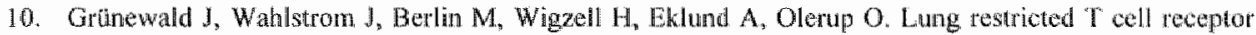
AV2S3+ CD4t $T$ cell expansions in sarcoidosis patients with a shared HLA-DRbeta chain conformation. Thorax 2002;57:348-52.

11. Moller DR, Chen ES. Genetic Basis of Remitting Sarcoidosis: Triumph of the Trimolecular Complex? An J Respir Cell Mol Biol 2002;27:391-5.

12. Janes DG. Complications of sarcoidosis. Chronic fatigue syndrome. Sarcoidosis 1993;10:1-3.

13. Foitsma $\mathrm{E}$, De Vries J, van Santen-Hoeuff $\mathrm{M}$, Faber $\mathrm{CG}_{\text {, Drent } M} \mathrm{M}$. Impact of pain in a Dutch sarcoidosis patient population. Sarcoidosis Vasc Diffuse Lung Dis 2003;20:33-9.

14. Wirnsberger RM, Drent M, Hekelar N, Breteler MHM, Drent S, Wouters EFM, Dekhuijzen PNR. Relationship between respiratory muscle function and quality of life in sarcoidosis. Eur Respir of $1997 ; 10: 1450-5$.

15. Drent M, Wirnsberger RM, Breteler MHM, Kock LM, De Vries J, Woukers EFM. Quallity of lile and depressive symptons in patients suffering from sarcoidosis. Sarcoidosis Fare Diffuse Langy Dis $1998 ; 15: 59-66$.

16. Wirnsberger RM, De Vries J, Breteler MHM, wan Heck GL, Woutters EFM, Dent M. Evaluation of quality of Iffe in sarcoidosis patients. Respir Med 1998:92:750 6 .

17. De Wries J. Drem M. Wan Heck GL, Wouters FFM. Quality of life in sarcoidosis: a comparison between members of a patient organisation and a random sample. Sarcoidosis Vasc Difuse Lamg Dis $1998: 15: 183 \times 8$.

18. Cox CE, Donohue JF, Brown CD, Kataria YP, Judson MA. The Sarcoidosis Health Questionnaire: A New Measure of Health-related Quality of Life. Am y Respir Crit Core Med 2003; 168323-9.

19. Chang B, Steimel J, Moller DR, Baughman RP, Judson MA, Yeager II Jr, Teirstein AS, Rossman MD. Rand CS. Depression in sarcoidosis. Am J Respir Crit Care Med 2001;163:329-34.

20. Wirnsberger RM, De Vries J. Wouters EFM, Drent M. Clinical presentation of sircoidosis in The Netherlands an epidemiological study. Neth J Med 1998,53:53-60.

21. DeRemee RA. Dysphoria and sarcoidosis. Sarcoidosis Wasc Diffuse Lung Dir 1998;15:21.

22. Drent M, Wimsberger RM, De Vries J, van Dieijer-Visser MP, Wouters EFM, Schols AMW. Association of fatigue with an acute phase response in sarcoidosis. Eizt Rexpir \& 1999,13:718-22.

23. Sharma $O P$. Fatigue and sarcoidosis. Eur Respir J 1999:13:713-4. 
24. Drent M, Verbraecken \, van der Grinten CPM. Wouters EFM. Fatigue associated with obstructive sleep apriea in a patient with sarcoidosis. Respiration $2000 ; 67,337-40$.

25. Batughnan RP. Therapeutic optons for sarcoidosis: new and old Cur Opin Pum Mod 2002;8464-9.

26. Baughman RP. Inlluximab for refractory sarcoidosis. Sarcoidosis Vase Diffuse Lang Dis 2001;18.

27. Drent $M$, Jacobs NA, Cobben NAM, Costabel U, Wouters EM. Mulder PGH. Computer program supporting the diagnostic aceuracy of cellular BALF analysis: a new release. Respir Med 2001;,95:781-6.

28. Baughman RP, Lower EE, Du Bois RM. Sarcoidosis. Lancet 2003;361:1111-8.

29. Newman IS Rose CS, Matier LA. Sarcoidosis. N Engl J Med 1997,336:1224-34.

30. Dekemee RA. The wentgenographic staging of sarcoidosis. Historic and contemporary perspectives. Chest $1983: 83: 128-33$.

31. Sharma OP, Alam S. Diagnosís, pathogenesis, and treament of sarcoidosis. Curr Opin Pum Med $1995: 1: 392-400$.

32. Stirling $\mathbb{R G}$, Cullinan $P$, Du Bois RM. Sarcoidasis. In: Schwar $M$, King $T$, eds. Inershitial Lung Disease 1998; Phildelphia, BC Decker Ine:279-323.

3. Drenl M, De Vries J, Lenters M, Lamers RIS, Rothkrantz-Kos S, Wouters EFM, van Dietijen-Visser MP. Verschaketen IA. Sarcoidosis: assegsment of disease severity using HRCT. Eur Radiol 2003;13:2462. 71.

34. Ziegenhagen MW, Rothe ME, Schlaak M, Maller-Quemheim J. Bronchoalveolar and serological parameters reflecting the severity of sarcoidosis. Eur Respir a 2003,21:407-13.

35. Orutters JC. Fellrath J-M, Mulder L, Janssen $R$, wan den Bosch JMM, wan Velzen-Blad H. Serum sIL $2 R$ measurement in sarcoidosis patients: a clinical evaluation. Chest 2003;124:186-95.

36. Delves PJ, Roitt IM. The immune system. First of two parts. N Engl J Med 2000;343:37-49.

37. Delves PJ, Roitt M. The immune system. Second of two parts. N Engl J Med 2000;343:108-17.

38. Playfair JHL. Immunology at a glance. 1996; Oxford, Blackwell Scrence (6th Ed.).

39. Staines $\mathbb{N}$, Brostoff J, James K. Introducing immunology. 1993; London, Mosby (2nd Ed.).

40. Kataria YP. Holter JP. Immunology of sarcoidosis. Clin Chest Med 1997;18:719-39.

41. Nagai $S$, Izumi T. Bronchoalveolar lawage. Still useful in diagnosing sarcoidosis? C/in Chest Med $1997 ; 18: 787-97$

42. Miller-Que:nheim J. Sarcoidosis: inmunopathogenetic concepts and their clinical application. Ew" Respin J1998;12:716-38.

43. Moller DR. Involvement of $T$ cells and alterations in $T$ cell receptors in sarcoidosis. Senwin Respir Infect $1998 ; 13: 174-83$.

44. Agostini C, Semenzato G. Biology and immunology of the granuloma. In: James DG and Zumla A, eds. The granulonatous disorders 1999; Cambridge, Cambridge University Press:3-16.

45. Jones RE, Chatham WW. Update on sarcoidosis. Curr Opin Rhewnato 1999;11:83-7.

46. Agostini C. Adami $F$, Semenzato $\mathrm{G}$. New pathogenetic insights into the sarcold granulona. Cur Opin Rhe whatol $2000 ; 1271-6$.

47. Agostini C, Trentin L, Facco M, Sancetta R. Cerutti A, Tassinari C, Cimarosto L, Adami F, Cipriani A, Zumbello R. Semencato $G$. Role of $\|L-15\| L-$,2 , and their receptors in the development of $T$ cell alveolitis in pulmonary sarcoidosis. J Immumal 1996;157910-8.

48. Agostini C. Semenzato O. Cytokines in sarcoidosis. Semin Respir Hnfecr 1998;13:184-96.

49. Agostini C, Busso U, Semenzato G. Cells and molecules inwolwed in the development of sarcoid gitunulonat d Clin Immonol 1998;18:184-92.

50. Costaluel U. Teshler H. Biochemical changes in sarcoidosis. Chin Chest Med 1997;18:827-42.

51. Babghman RP. Dreni $M$. Role of bronchoalweolar layage in interstitial lung disease. Clin Chest Med $2001: 22: 331-41$.

52. Moller DR. Calts and cytokimes inwolved in the paihogenesis of sarcoidosis. Sarcoidosis Vase Difuse Lung Dis 1999;16:24-31.

53. Gabay C. Kushner I. Acute-phase proteins and other systemic responses to inflanmation. $N$ Engl J Med $1909 ; 340 ; 448-54$.

54. Volumakis fe Humm C-reactive protein: expression, structure, and function. Mol lmmumol $2001,38: 189-97$.

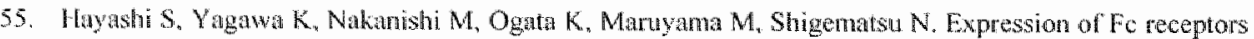
is suppressed in alveolar macrophnges from patients with sarcoidosis. Clin Exp lmmunol 1988;73:495-9. 
56. Werner I. Hartwig W, Uhi W, Muller C. Buchler MW. Useful markers for predicting sewerity and monitoring progression of acute pancreatitis. Pancrearology $2003: 3: 115-27$.

57. Ridker PM. Clinical application of C-reactive protein for cardiovasculat distase detection and prevention. Circulation $2003 ; 107: 363-9$.

58. Ridker PM, Hennekens CH, Buring JE. Rifai N. C-reactive protein and other markers of inflammation in the prediction of cardiowascular disease in women. $N$ Engl w Med $2000,342: 83643$.

59. Yamada $T$. Serum anyloid A (SAA): a concise review of biology, assay methods and elinical usefulness. Clin Chem Lab Med 1999;37:381.8.

60. Steel DM, Whitehead AS. The major acute phase reactursts: C-reactive protein, serum anyloid $P$ component and serum amyloid A protein. Immunhol Todoy 190) 4;15:81-8.

61. Uhlar CM. Whitehead AS. Serum anyloid A, the major vertebrate acuie-plase reactant. Ear of Bird hom 1999:265:501-23.

62. Uhlar CM, Whitehead AS. The kinetics and magnitude of the synergistic activation of the scrum anyloid $\mathrm{A}$ promoter by $\mathrm{I}-1$ beta and $\mathrm{L}-6$ is determined by the order of cytokine addition. Scand, Immwol 1999:49:399-404.

63. Salazar A. Pinto X. Mana J. Serum amyloid A and high density lipoprotein cholesterol: serum markers of inflammation in sarcoidosis and other systemic disorders. Enf . Clin Inwest 2001:31:1070-7.

64. Nakayame T, Sonoda S, Urano T, Yamada T, Okada M. Monitoring bollh seruin anmyloid protein A and C-reactive protein as inflammatory markers in infectious diseases. Chn Chem 1993:39:293 7 .

65. Miwata H, Yanada T, Okada M, Kudo T, Kinusa H, Morishima T. Sarun amyloid A protein in acute viral infections. Arch Dis Child 1993;68:210-4.

66. Raynes JG, Cooper EH. Comparison of serum amyloid A protein and C-reactive protein concentrations in cancet and non-malignant disease. J Clin Pathol 1983;36:798-803.

67. De Beer FC, Mallya RK, Fagan EA, Lanham JG, Hughes GR, Pepys MB. Serum anyloid-A prolein concentration in inflammatory diseases and its relationship to the incidence of resctive systemic amyloidosis. Lancet 1982:2:231-4.

68. Yang $F$, de Villiers WJ, Lee $\mathrm{EY}$, McClain $\mathrm{CJ}$. Varilek $\mathrm{GW}$. Increased nuclear factor-kappaB activation in colitis of interleukin-2-deficient mice. J Lab Chin Med 1999;134:378-85.

69. Niederau C, Backmerhoff F, Schumacher B. Inflammatory mediators and acute phase proteins in patients with Crohn's discase and ulcerative colitis. Heparogastroenterology 1997;44:90-107.

70. de Villiers WJ, Varilek GW, de Beer FC, Guo JT, Kindy MS. Increased serum anyloid A levels refled colitis severity and precede amyloid formation in IL-2 knockout mice. Cyokine 2000;12:1337-47.

71. Casl MT, Bulatovic G, Orlié P, Sabljar-Matovinovic M. The diagnostic capacity of serun amyloid $A$ protein for early recognition of kidney allograft rejection. Nephrol Dial Trapsplarni 1995;10:1901-4.

72. Hartmann A, Eide TC, Fauchald P. Bentdal O, Herbert J, Gallimore JR. Pepys MB. Serum anyloid A protein is a clinically useful indicator of achite renall allograt rejection. Nephrot Dial Transplam $1997,12: 161-6$.

73. Li XC, Demirci G, Werrari-Lacraz \$, Groves C, Coyle A, Malek TR. Strom TB, IL. I5 and II, -2: a mather of the and death for Teells in viwo. Nat Med $2001 ; 7: 114-8$.

74. Smith KA. Intorleukin-2: inception, impact, and implications. Science $1988 ; 240: 1169-76$.

75. Kumar A, Moreau JL, Gibert M. Theze J. Internalization of interleukin 2 (1L-2) by high affinity IL.-2

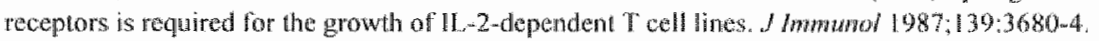

76. Gaffen $S L$, Lai $S Y$, Ha M, et al. Distinet yrosine residues within the interleukin-2 reeptor beta chain drive signal transduction specificity, redundancy, and diversity. I Biol Chem 1996;271:21381 L90.

77. Tartour E, Mosseri V, Jouffroy T, Deneux I., Jaulerry C, Brunin F, Fridman WH. Rodriguex I Serum soluble interleukin-2 receptor concentrations as an independent prognostic marker in head and reek cancer. Lamcer 2001;357:1263-4.

78. Baudin B. New aspects on angiotensin-conwerting enzyme: from gene to disease. Chis Chem Lab Med 2002:40:256 65 .

79. Halkin $\mathrm{A}$, Keren $\mathrm{O}$. Potential indications for angiotensin-converting enzyme inhibitors in atherosclerotic vascular disease. Am J Med 2002;112:126-34.

80. Phillips MI, Kagiyama S. Angiotensin II as a pro-inflammatory mediator. Cure Opin Investig Drags 2002;3:569-77.

81. Griending KK, Minieri CA, Ollerensilaw JD, Alexander RW. Angiotensin II simulates NADH and NADPH oxidase activity in cultured vascular smooth muscle cells. Circ Res 1994;74:1141-8. 
82. Greene CM, Merchery $\mathrm{G}_{*}$ Taggart $\mathrm{CC}_{1}$ et al Role of $1 \mathrm{~L}-18$ in $\mathrm{CD}$ ( $+\mathrm{T}$ T lymphocyte activation in sarcoidossis. IJramunol 2000;165:4718-24.

83. Drent M, wan den Berg. R. Haenen GRMM, wan den Berg H. Wouters EFM, Bast A. NF-KB activation in

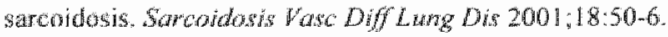

84. Conron M. Bondeson J, Pantelidis P. Beynon HL, Feldmann M, Du Bois RM, Foxwell BM. Alveolar macrophages and Tcells from sarcoid, but not normal fung, are permissive to adenovirus infection and allow analysis of Wf-kappa b-dependem signaling pathways. An J Respir Cell Mol Biol $2001,25: 14$ 1-9.

85. Zlegeniagen MW. Benner UK, Zissel $G$, Zabel P, Schlatk M, Müller-Quernhein J. Sarcoidosis: TNFalpha release from akeolar macrophages and senum level of sIL-2R are prognostic markers. An $J$ Respir Crir Core Med 1997:156:1586-92.

86. Prior C. Barbee RA, Evans PM, P., Primett ZS, Fyhrquist F, Gronhagen-Riska C, Haslam PL. Lavage versus serum measurements of lysocyme, angiotensin converting enzyme and other inflammatory markers in pulmonary sarcoidosis. Etur Rospir J 1990;3:1 46-54.

87. Anslie GM, Poulter L.W, Du Bois RM. Relation between immunocytological features of bronchoalweolar lavage fluid and clinical indices in sarcoidosis. Thorax 1989;44:501-9.

88. Sharma P. Smith I, Maguire G, Stewart $\$$, Shneerson J, Brown M. Clinical value of ACE genotyping in diagnos is of sarcoidosis. Lancet $1997,349: 1602-3$.

89. Tomita $H_{\text {, Ina }} Y_{4}$ Sughura $Y$, Sato $S$. Kawaguchi $H$, Morisinita $M$, Yamamolo M, Ueda R. Polymorphism in the angiolensin-converting enxyme (ACE) gene and sarcoidosis. Am I Respir Crit Care Med $1997 ; 156255-9$.

90. Stokes GS, Monaghan JC, Schrader AP, Glenn CL, Ryan M, Morris BJ. Influence of angiotensin conwerting enzyme (ACE) genotype on inierpretation of diagnostic tests for serum ACE activify. Aws: $N$ Z J Med 1999;29:315-8.

91. Pietinalho $A_{\text {, Furuya }} K$, Yamaguchi $E$, Kawakami $Y$, Sielroos $O$. The angiotensin-converting enzyme DD gene is associated with poor prognosis in Firmish sarcoidos is patients. Exa Respir J 1999;13:723-6.

92. Matliarik MJ, Rybicki BA, Malvilz E, sheffer RG, Majol" M, Popovich d Jr, lannuzzi MC. Angiolensinconverting enzyme gene polymorphism and risk of sarcoidosis. Am I Respir Crit Care Med 1998;158:1566-70.

93. Okabe T, Fujisawa M. Watanabe J, Yotsumalo H, Takaku F. Familial hyper-angiotensin converting enzyme (ACE)-emia: increased production of ACE by monocyte-macrophage. Jph $J$ Med 1987,26: 140-6.

94. Okabe T", Fujisawa M, Yotsumoto H, Takaku F, Lanzillo JJ, Fanburg BL. Familial elevation of serum angiotensin converting enzyme. $Q J$ Med 1985;55:55-61.

95. Kramers C, Danilov SM, Deinum J, Balyasnikova IV. Scharenborg N, Loonan M, Boomsma F, de Keijzer MH, van Duijn C, Martin S, Soubrier F, Adema GI. Point mutation in the stalk of angiotensinconwerting cnayne causes a dramatic increase in serum angiotensin-converting enzyme but wo cardiowascutar disease. Circalotion 2001:104:1236-40.

96. Schaberg T, Rau M. Stephan Ha Lode H. Increased number of alveola macrophages expressing surface molecules of the CDIJCD18 fanily in sarcoidosis and idiopathic pulmonary fibrosis is related to the production of superoxide anions by these cells. Am Rev Respir Dis 1993;147:1507-13.

97. Culhown WI. Salisbury SM. Heterogeneity in cell recovery and superoxide production in buoyant, densityadefined subpopulations of thuman alveolar macrophages from healthy volunteers and sarcoidosis paticnis. ol Lab Cho Med 1989:114:682-90

98. Calhoun W. Salisbury SM, Chosy L.W, Busse WW. Increased alveolar macrophage chemiluminescence and airspace cell superoxide production in active pulmonary sareoidosis. J Lab Clin Med 1988;12: $147-56$.

99. Acts C. Wallaer B. Grosbois JM, Voisin C. Release of superoxide anion by alveolar macrophages in pulmonary sarcoidosis. Ann $N Y$ Acad Sci 1986:465:193-200.

100. Lenz AG, Costabel U, Maler KL. Oxidized BAL fluid proteins in patients with interstitial lung diseases. Ew Respir J 1996;9:307-12.

101. Cassablla MA. Berton G, Agostini C, Zanabello R, Trentin L, Cipriani A, Semenzato G. Generation of superoxide anion by alveolar macrophages in sarcoidosis: evidence for the activation of the oxygen metabolism in patients witly high-intensity alveolitis. Immonology 1989;66:451-8. 


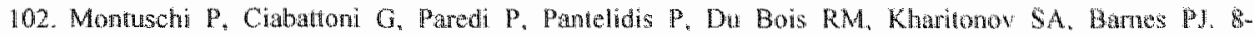

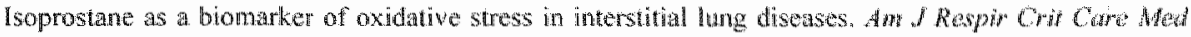
$1998 ; 158: 1524-7$.

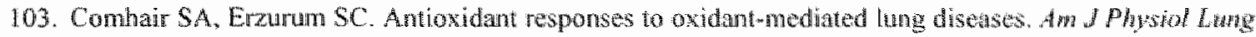
Cell Mol Phy

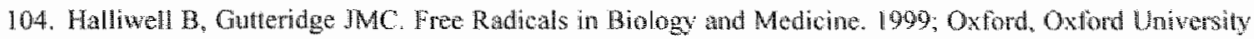
Press.

105. Halliwell B, Gutteridge MM, Cross CE. Foe tadoals, antioxidants, and human disease: where are we now? J Lab CVm Med 1992;119:598-620.

106. Winterbourn CC. Vissers MC. Ketile A. Myeloneroxidasa. Cur Oph Mematol 2000,7:53-8.

107. Klebanoff SI. Myeloperoxidase. Proe Asso Am Physicich 1999;111,383-9.

108. den Hantog GJ. Haenen GRMM, Vegt E, van der Vijgh W. Bast A. Ehreacy of Hocl scanenging by sulfur-contuing compounds. atrioxidant activity of glutathione disulfite? Biol Chen $2002 ; 383 ; 709-13$.

109. Lakari E, Paakko P, Pietarinen-Runtt P. Kinnula VE. Manganese superoxide dismatase and catalase are coordinately expressed in the alveolar ragion in chronic interstitial pneumonias and granalonatous diseases of the lung. An of Respir Crir Care Med 2000;161:615-21.

110. Lakan $\mathrm{E}_{4}$ Patko P, Kinnula VI. Manganese superoxide dismutase, but mot Cuzn superoxide dismutase, is highly expressed in the granulomas of pulmonary sareotiosis and extrinsio allergic alvolitis. Am $J$ Respir Con Cane Med 1998; 158:589-96.

11. Kirkman HW, Rolto M, Ferraris AM, Gatani GF. Mechanisms of protection of cataluse by MAPH. Kineties and stoichiometry, B Biol Chem 1999;274:13908-14.

112. Arscot LD, Veine DM, Wiltians $\mathrm{CH}$. Mixed disulfide with glutathone as an intermediate in the reaction cotalyzed by glutathione reductase from yeast and as a majon form of the enzyme in the cell. Brocherwistry $2000 ; 39: 47 \|:-21$.

113. Schimer R, Krauth-Sieged R, Sclmulz G. Gubathone reductase. In: Dolphin D. Poulson R, Avranovic O, eds. Glanohone, Chemical. Biochemical and Medical Aspects. 1989; New Yom, John Wiley \& Sons Hnc:553-98.

114. Bohme CC, Arscot LD, Becker K, Schirmer RH, Willams CH. Kinetic characturation of glathone reductase from the malarial parasite Plasmodium falcipanum. Comparison with the human encyme. I Biol Chem 2000;275:37317-23.

115. Better E. G6PD deficiency. Blood 1994;84:3613-36.

116. Nicol Cl, Zielenski J, Tisui LC, Wells PG. An embryoprotective role for glucose 6 phosphate dehydrogenase in developmental oxidative stress and chemical teratogenesis. Faseb $J 2000 ; 14: 1 / 1-27$. 


\section{Chapter 2}

\section{High-sensitivity C-reactive protein methods examined}

Snježana Rothkrantz-Kos, Maria PJ Schmitz, Otto Bekers, Paul PCA Menheere, Marja P van Diejen-Visser 


\section{Abstract}

\section{Background}

High sengitivity CRP (hs-CRP) is considered as an important risk factor for coronary heart disease. Until now hs-CRP has primarily been used for research purposes, but implementation, as. a routine laboratory parameter is obvious. In daily practice one CRP method giwing reliable results both in the low and high concentration range is to be preferred.

\section{Methods}

A new hswCRP method developed for the Beckman Coulter IMMAGE measured by near infrared particle immunoassay (NIPIA) was evaluated and compared to the IMMULITE hs-CRP method from Diagnostic Products Corporation and to the BNA hs-CRP method from Dade Behring. In the higher range the hs-CRP methods were also compared to our routinely used CRP method performed by immunoturbidimetry on the Synchron $L X^{2} 20$. Besides, hs-CRP INMAGE method was also compared to the current IMMAGE CRP method (all three from Beckman Coulter).

\section{Results}

In the lower range, $0.2-10 \mathrm{mg} / \mathrm{L}$, the CRPH IMMAGE method was linear down to $0.2 \mathrm{mg} / \mathrm{L}$ and not influenced by turbidity. Total imprecision (CV) was less than $10 \%$ in the range from $0.2-$ $40 \mathrm{mg} / \mathrm{L}$. The CRPH IMMAGE ${ }^{\mathrm{B}}$ method showed good agreement with BNA and IMMULTTE hsCRP methods.

Above $100 \mathrm{mg} / \mathrm{L}$ Bland Altman plots showed highly scattered data for all CRP comparisons.

\section{Conclusion}

The new IMMAGE hs-CRP is a good method for clinical risk stratification. However, for all CRP and hs-CRP methods poor correlations are seen in the upper part of the manufacturers claimed reference ranges. Therefore, at present the use of two different methods, a hs-CRP for risk stratification and a nomial routine CRP method, is required. 


\section{Introduction}

C-reactive protein (CRP) is a valuable laboratory parameter in the clinical evaluation of infection, inflammation or trauma. Several clinical studies have demonstrated that this acute phase protein also has prognostic value in patients with acute coronary syndromes and is moreover a strong independent predictor of future coronary events in apparently healthy subjects. Rifai and Ridker recently reviewed clinical studies on CRP As a prognostic parameter in coronary heart disease'.

In most laboratories CRP measurements are performed by immunoturbidimetry on routine clinical chemistry analyzers, having detection limits for CRP of $2-5 \mathrm{mg} / \mathrm{L}$. For studies on CRP as a risk factor for coronary artery disease, a high-sensitivity CRP (hsCRP) method is required. A variety of methods have now been introduced for measuring hs-CRP and Roberts et al recently compared the different methods ${ }^{2.3}$. In their first study, comparing four different methods, both normal and increased values in the range of $0-250 \mathrm{mg} / \mathrm{L}$, were compared ${ }^{2}$. In their second study, nine hs-CRP methods were compared in 388 apparently heallhy individuals and comparisons were focused on values in the range of $0-10 \mathrm{mg} / \mathrm{L}^{3}$. Hs-CRP assays should indeed distinguish the minor increases from the upper limit of nomal. However, until now hsCRP has primarily been used for research purposes and introduction, as a routine laboratory parameter, is obvious. The laboratory has to be sure to report reliable CRP results regardless of the clinical context; therefore also for the upper part of the manufacturers claimed measuring ranges (varying from 0.2 to 500 or $1000 \mathrm{mg} / \mathrm{L}$ ), agreement between hs-CRP and CRP methods is required.

We report here the evaluation of a new hs-CRP method for the Beckman Coulter IMMAGE. This new method is compared to two hs-CRP methods (IMMULITE and BNA) and in the higher range also to our routine CRP method, on the routine clinical chemistry analyzer LX20 from Beckman Coulter as well as the current IMMAGE CRP method.

\section{Materials and methods}

\section{Samples}

Venous blood samples were collected from 291 ostensibly healthy blood donors, 177 male and 114 female, presenting at the Sanguin Blood Bank in Maastrich. Samples for method comparison were collected from 521 patients in whom a CRP was requested for routine analysis. The Medical Ethical Committee of the Hospital approved the procedure followed.

Serum was separated from the red cells by centrifugation and stored at $-70^{4} \mathrm{C}$ until. analysis ${ }^{4}$. There was no freeze-thawing effect as reported previously". 


\section{Methods}

Hs-CRP on the IMMULITE Automated Analyzer from Diagnostic Product Corporation is a two-site chemiluminescent enzyme immunometric assay, with one ligand labeled anti-CRP monoclonal antibody and an alkaline phosphatase-labeled anti-CRP polyclonal antibody (Diagnostic Product Corporation, Los Angeles, CA, cat no LKCR I).

Hs-CRP on the BNA nephelometer from Dade Behring is performed by particle enhanced immunonephelometry, using a monoclonal antibody coated to polystyrene particles (Dade Behring, Liederbach Germany, $N$ Hs CRP, cat no OQIY G13; supplement reagent OUMU15).

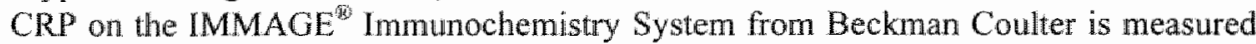
by peak rate nephelometry with a laser diode at $670 \mathrm{~nm}$. A polyclonal anti-CRP antibody is used (Beckman Coulter, cat no 447280).

The new hs-CRP on the IMMAGE ${ }^{\text {B }}$ (called CRPH) is measured by a near infrared particle immunoassay (NIPIA) with a laser diode at $940 \mathrm{~nm}$, using a polyclonal and monoclonal anti-CRP (goat and mouse) antibody coated to latex particles (Beckman Coulter, Inc. Fullerton, CA, US, cat no 474630).

CRP analysis on the Synchron $\mathrm{LX}^{3} 20$ System, a routine clinical chemistry analyzer from Beckman Coulter, is based on immunoturbidimetry, using a polyclonal anti-CRP antibody (Beckman Coulter, Inc. Fullerton, CA, US, cat no 465131). In this study, values below $5 \mathrm{mg} / \mathrm{L}$ are reported as $4.999 \mathrm{mg} / \mathrm{L}$.

Table 2.1 presents the assay characteristics of the different methods used.

Samples for imprecision studies were prepared from five serum pools in the range from $0.2-50 \mathrm{mg} / \mathrm{L}$, and from two serum pools in the range from $100-350 \mathrm{mg} / \mathrm{L}$ as determined on the IMMAGE. Within-run precision was obtained by measuring one sample 20 times within a single run. Between-run precision was obtained by measuring each level on 20 consecutive days, based on a single calibration.

Table 2.1. Characteristics of the different CRP methods.

$\begin{array}{lccccc}\text { Analyzer } & \text { Method } & \text { Dilution } & \text { Assay range } & \begin{array}{c}\text { Manufacturer's claimed } \\ \text { Measuring range }\end{array} \\ \text { Detection limit }\end{array}$

- ORDAC = Over Range Detection And Correction; when a sample is ORDAC-ed, the LX20 uses a smaller sample size for analysis. Values are given in mgíL. 
Linearity studies were performed with two samples containing about $50 \mathrm{mg} / \mathrm{L}$ and $250 \mathrm{mg} / \mathrm{L}$ CRP. Using the manufacturer's diluent eleven dilutions of wach sample were made and measured in five replicates.

The serum index measured on the Synchron LX20 was used to indicate the sample condition in terms of icterus, hemolysis or lipemia. The system monitors the absorbance at $340,410,470,670$ and 700 nanometers and solves a set of equations to determine the response for each index. The response is directly proportional to the sample condition. The lipemia index is indicated in different levels $1-10$. Level 1 is nomal, indicating absence of lipemia. Sample turbidity was also assessed by macroscopic examination.

To assess the agreement between serum and plasma for the hs-CRP IMMAGE method, serum, EDTA and heparin plasma samples were collected from 25 patients.

\section{Statistics}

hs-CRP distributions were skewed rightward and therefore their values are expressed as medians $\pm \mathrm{SD}$. Agreement between methods was assessed visually by the method of Bland and Almans and by means of Deming regression analysis. Furthemore, percentile values were estimated and compared. For determination of reference values, the 0.95 nonparametric interpercentile interval was calculated ${ }^{7}$. Gender differences in samples from blood donors were assessed by the Mann-Whitney U test, while median serum versus plasma comparisons were assessed by the Wilcoxon matched pairs signedranks test.

\section{Results}

\section{Precision and linearity data}

The hs-CRP IMMAGE method appeared to be linear over the whole measured CRP concentration range and comparable to results of BNA (Figure 2.1 A-B). For five pools with mean concentrations of $0.23,1.22,2.18,16.94$ and $44.46 \mathrm{mg} / \mathrm{L}$ between run variations of respectively $4.9,6.7,2.7,2.7$ and $2.1 \%$ and within run wartiations of respectively $5.9,4.3,3.5,2.1$ and $3.0 \%$ were found. So, the total imprecision for the hs-CRP IMMAGE method remained below 7\%. For two additional samples with concentrations of $168 \mathrm{mg} / \mathrm{L}$ and $342 \mathrm{mg} / \mathrm{L}$ within run variations remained bellow $6.2 \%$ for all methods.

\section{Agreement between methods}

Figures 2.2A-F show Bland Altman plots for the different method comparisons. Deming regression analysis in the region from $0-10 \mathrm{mg} / \mathbb{L}$ (Table 2.2) suggests a slightly better agreement of the hs-CRP IMMAGE with BNA $(\mathrm{r}=0.991)$ as compared to TMMULITE $(r=0.986)$. 

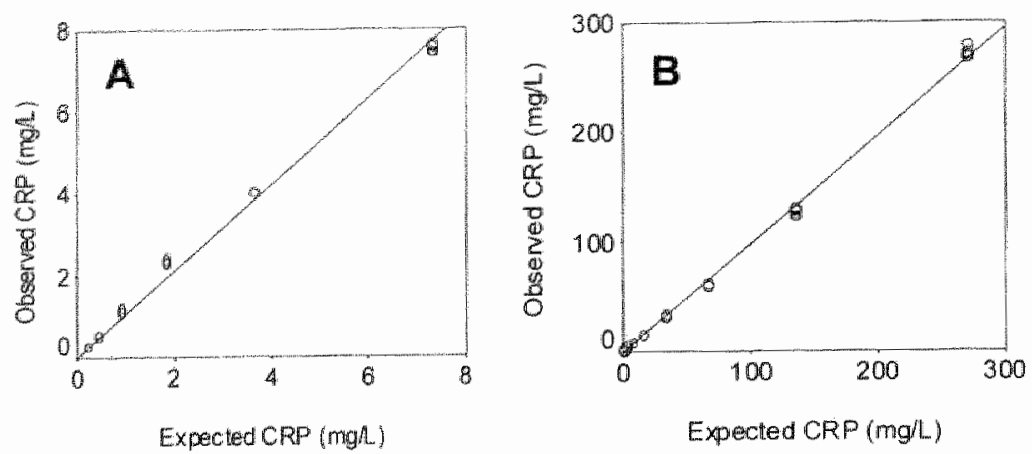

Figure 2.1. Linearity of CRPH IMMAGE up to $10 \mathrm{mg} / \mathrm{L}$ an over the whole measured range. Limearity results for hS-CRP IMMAGE $(A, B)$ in the low $(0-10 \mathrm{mg} / \mathrm{L})$ and high $(0-300 \mathrm{mg} / \mathrm{L})$ CRP concentration range. Dilution samples were run in five replicates. The mean values for each dilution point were plotted vs. expected values and linear regression was performed. Regression analysis results for the respectively low range were: $y=1.012($ SE 0.034$) x+0.201($ SE 0.118$), r=0.998$, SEE 0.207; and for the hight range: $y=0.989($ SE 0.012$) x-1.335($ SE 1.133). $r=0.999$, SEE 3.204

Table 2.2. Deming regression analysis of the hs-CRP IMMAGE method with other hs-CRP mothods.

\begin{tabular}{lcccc}
\hline Anallyzer & Slope \pm SD & Intercept \pm SD & SEE $\left(S_{\text {yix }}\right)$ & $r$ \\
\hline $0-10 \mathrm{mg} / \mathrm{L}$ & & & & \\
IMMAGE vs. BNA & $1.10 \pm 0.18$ & $0.01 \pm 0.17$ & 0.39 & 0.991 \\
IMMAGE vs. IMMULITE & $1.37 \pm 0.25$ & $0.01 \pm 0.18$ & 0.54 & 0.986 \\
IMMULITE vs. BNA & $0.80 \pm 0.11$ & $-0.01 \pm 0.10$ & 0.22 & 0.989 \\
10-300 mg/L & & & & \\
IMMAGE wS. BNA & $1.03 \pm 0.14$ & $0.05 \pm 0.19$ & 8.09 & 0.995 \\
IMMAGE VS. IMMULITE & $1.16 \pm 0.27$ & $0.01 \pm 0.22$ & 12.82 & 0.880 \\
IMMULUTE vS. BNA & $0.89 \pm 0.15$ & $-0.06 \pm 0.18$ & 8.92 & 0.979
\end{tabular}

For the region from $0-10 \mathrm{mg} / \mathrm{L}$, also percentile comparisons of the current CRP and new hS-CRP IMMAGE method to BNA were examined and are shown in the Figures 2.3A-B. The hs-CRP IMMAGE showed excellent agreement with BNA in all quartiles (Figure 2.3A), whereas the current CRP IMMAGE method showed good agreement only with hs-CRP concentrations above $75^{\text {it }}$ percentile (Figure 2.3B). Samples determined on LX20, clear on macroscopic examination, showed no discrepancies with the high-sensitivity methods, whereas this was not the case for turbid samples (data not shown).

Between all hs-CRP methods compared large discrepancies were seen above $100 \mathrm{mg} / \mathrm{L}$ (Figure 2.1). Deming regression results are also presented in Table 2.2. Among the hs-CRP methods (Figure 2.2A-F) also for the whole tested range the best agreement was observed between hs-CRP BNA and hs-CRP IMMAGE. Comparison of the hs-CRP 
methods with our routinely used CRP method (Synchron LX20) only resulted in a good correlation with the BNA (data not shown).
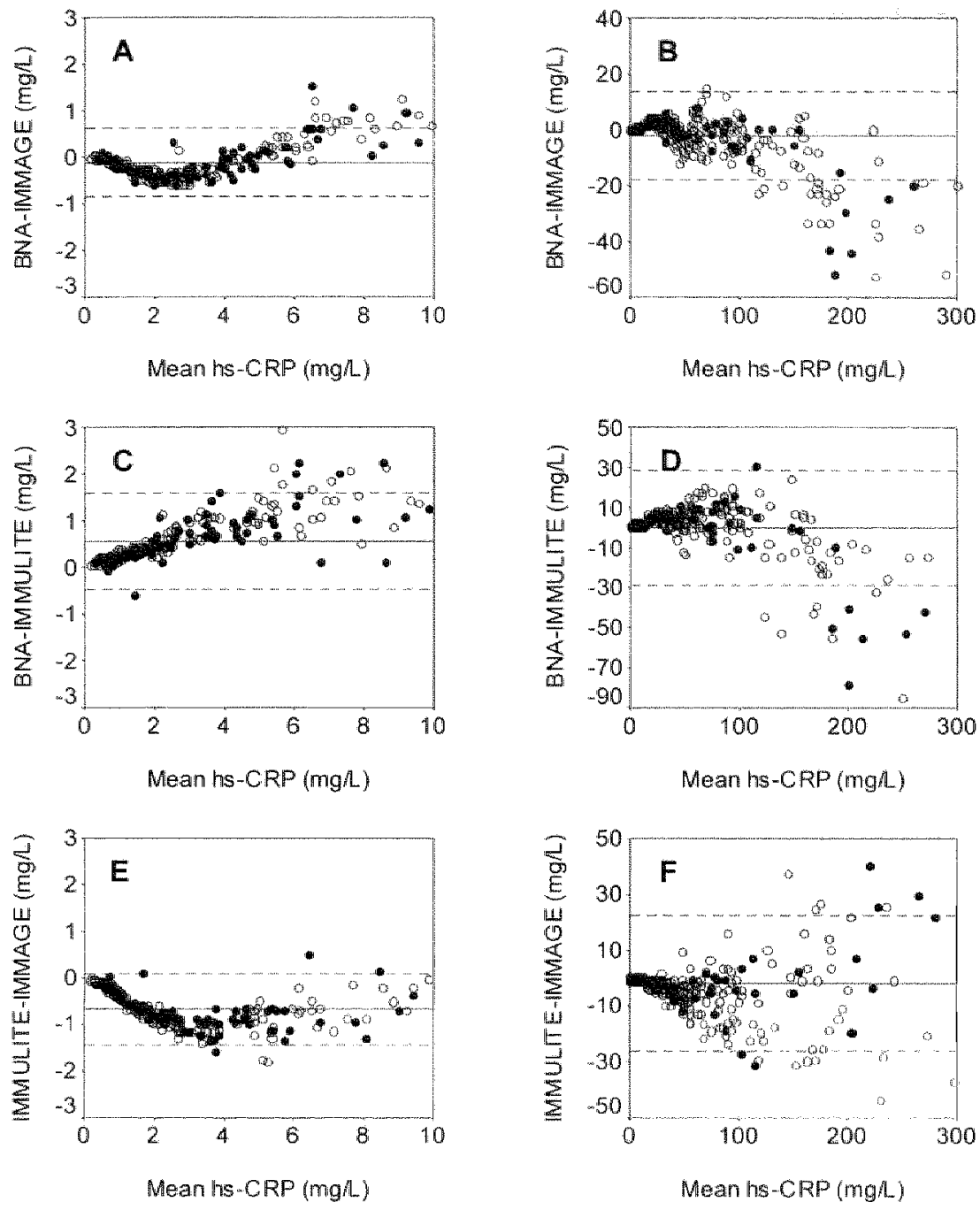

Figure 2.2 Method comparisons in 5.21 samples from patients with normal and increased CRP concentrations.

Bland-Altman analysis for $0-10 \mathrm{mg} / \mathrm{L}(A, C, E)$ and for $0-300 \mathrm{mg} / \mathrm{L}(\mathrm{B}, \mathrm{D}, \mathrm{F})$. The solid line indicates the mean difference between the methods, and the $95 \%$ confidence intervals for the difference are indicated by dashed lines. Mean bias and SD for BlandAltman plats were -0.1 and $0.4 \mathrm{mg} / \mathrm{L}(A), 2.0$ and $7.9 \mathrm{mg} / \mathrm{L}(\mathrm{B}), 0.6$ and $0.6 \mathrm{mg} / \mathrm{L}$ (C), 0.2 and $14.3 \mathrm{mg} / \mathrm{L}(\mathrm{D})-0.7$ and $0.4 \mathrm{mg} / \mathrm{L}(\mathrm{E})$ and 1.8 and $12.1 \mathrm{mg} / \mathrm{L}(\mathrm{F})$.

Closed circles indicate samples showing turbidity assessed by macroscopic examination, whereas open circles indicate completely clear samples. 


\section{Serum versus plasma}

Mean recoveries ( 1 SD) of heparin-and EDTA-plasma related to serum concentrations were: $99.6 \pm 3.6 \%$ and $106.4 \pm 11.2 \%$ respectively. The results of the regression analysis wete as follows: heparin plasma $=0.997$ serum $-0.037, \mathrm{r}=0.9998, \mathrm{SEE} 0.360$; and EDTA-plasma $=0.963^{*}$ serum $-0.725, r=0.996, \mathrm{SEE} 1.429$. No significant differences were found when serum, heparm- and EDTA-plasma were compared for the hs-CRP IMMAGE method (serum versus heparin-plasma, $p=0.52$; serum versus EDTA-plasma, $\mathrm{p}=0.09$ ).

\section{Reference values}

Table 2.3 shows patient characteristics and CRP concentrations measured by the hsCRP IMMAGE in 291 blood donors. The median CRP concentration was $1.57 \mathrm{mg} / \mathrm{L}$ and the 0.95 interpercentile interval was $0.20-11.24 \mathrm{mg} / \mathrm{L}$ for all samples together (males $0.20-14.29 \mathrm{mg} / \mathrm{L}$, females $0.20-9.84 \mathrm{mg} / \mathrm{L}$ ). When values above $10 \mathrm{mg} / \mathrm{L}$ were omitted, the whole group median value was $1.42 \mathrm{mg} / \mathrm{L}$ and the 0.95 interpercentile interval $0.20-7.30 \mathrm{mg} / \mathrm{L}$ (males $0.20-5.40 \mathrm{mg} / \mathrm{L}$, females $0.20-8.89 \mathrm{mg} / \mathrm{L}$ ).
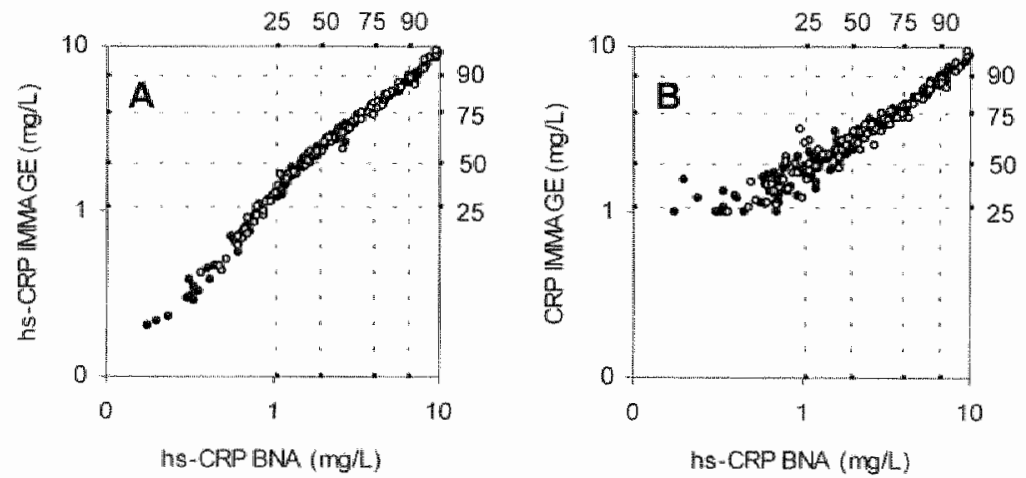

Figure 2.3. Accordance of the current CRP and the new CRPH IMMAGE method.

Samples collected from 521 patients were analyzed by the current and new hs-CRP

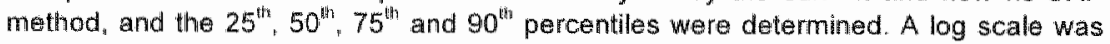
used for both the ordinate and abscissa in each panel. Results $>10 \mathrm{mg} / \mathrm{L}$ were excluded from each plot. (A), comparison of the results of the hs-CRP IMMAGE and hsCRP BNA; (B), comparison of the results of CRP IMMAGE and hs-CRP BNA. Closed circles indicate samples showing turbidity assessed by macroscopic examination. whereas open circles indicate completely clear samples. 
Table 2.3. CRPH IMMAGE and percentiles in blood donors.

\begin{tabular}{llcc}
\hline Parameter & \multicolumn{1}{c}{ All } & Male & Female \\
\hline$N^{\text {a }}$ & $291(282)$ & $177(170)$ & $114(112)$ \\
Age, years & & & \\
Mean & 48.3 & 48.6 & 47.8 \\
SD & 8.10 & 8.25 & 7.87 \\
Median & 49 & 50 & 47 \\
Range & $23-69$ & $25-69$ & $23-68$ \\
CRP, mg/L & & & \\
SD & 2.94 & 3.20 & 2.48 \\
Percentiles & & & \\
$2.5^{\text {th }}$ & $0.20(0.20)$ & $0.20(0.20)$ & $0.20(0.20)$ \\
$25^{\text {th }}$ & $0.67(0.65)$ & $0.64(0.62)$ & $0.83(0.80)$ \\
$50^{\text {th }}$ (median) & $1.57(1.42)$ & $1.25(1.20)$ & $1.86(1.82)$ \\
$75^{\text {th }}$ & $3.06(2.86)$ & $3.03(2.81)$ & $3.18(3.00)$ \\
$90^{\text {th }}$ & $4.98(4.62)$ & $4.89(4.30)$ & $5.87(5.62)$ \\
$95^{\text {th }}$ & $7.71(5.50)$ & $6.41(4.98)$ & $8.11(7.42)$ \\
$975^{\text {th }}$ & $11.24(7.30)$ & $14.29(5.40)$ & $9.84(8.89)$ \\
$99^{\text {th }}$ & $15.70(8.88)$ & $19.94(6.72)$ & $13.12(9.74)$ \\
\hline
\end{tabular}

${ }^{a}$ Values between brackets represent hs-CRP values without samples higher then $10 \mathrm{mg} / \mathrm{L}$.

\section{Discussion}

\section{Precision and linearity}

The new hs-CRP IMMAGE method was found linear in the concentration range of $0.2-$ $10 \mathrm{mg} / \mathrm{L}$, which was in agreement with the requirements for hs-CRP assays. Furthermore, for risk stratification for cardiovascular, cerebrovascular, and peripheral vascular disease, the hs-CRP assay imprecision should be less then $10 \%$ at a concentration of $0.2 \mathrm{mg} / \mathrm{L}^{3.5}$, which was also found for the new method. Given the relatively large within-subject variability of about $40 \%{ }^{5}$, analytical CVs of $10 \%$ or less should be adequate for both clinical and epidemiological studies.

\section{Method comparison and interferences}

In the low CRP range $(0-10 \mathrm{mg} / \mathrm{L})$ the new hs-CRP IMMAGE method showed good agreement with hs-CRP methods on BNA and IMMULITE, based on visual inspection of Bland-Altman plots (Figure 2.2A, C, E, G, I and K). In the concentration range from $0.2-10 \mathrm{mg} / \mathrm{L}$ the new IMMAGE hs-CRP method showed excellent agreement with BNA in all quartiles (Figure 2.3A), whereas the current IMMAGE CRP method showed good agreement only for concentrations above $75^{\text {th }}$ percentile (Figure 2.3B). Roberts et al. performed percentile analysis to allow comparison with a recent study, where the current IMMAGE CRP method was included in the comparison ${ }^{2}$. For the percentile comparison, in our study, BNA was taken as a reference method, whereas Roberts et al. used the BN II N hs-CRP assay?2.

In our study, performed on 521 samples, for all hs-CRP methods good agreement was found for concentrations below $100 \mathrm{mg} / \mathrm{L}$. 
Above $100 \mathrm{mg} / \mathrm{L}$ large discrepancies were seen between the methods, whereas rather good ayreement was observed only between LX20 and BNA. Roberts et al. found excellent agrement berween the compared methods up to $50 \mathrm{mg} / \mathrm{L}$ in 50 patients. Fumbennore, in our study, above $100 \mathrm{mg} / \mathrm{L}$, the scatter observed was more then $2 \mathrm{SD}$, whicl could not be explained solely by proportional bias or imprecision data in the higher range, but is more likely due to assay or system related issues (Figures $2.2 \mathrm{~B}, \mathrm{D}$, F). The scatter that was more then $2 \mathrm{SD}$ (above $100 \mathrm{mg} / \mathrm{L}$ ), was observed for both the CRP IMMAGE (data not shown) and the new hs-CRP IMMAGE method when compared to BNA (reference method in our study).

Visual inspection of Bland-Alman plots revealed that sample turbidity did not interfere in the hs-CRP methods, as no systematic discrepancies were seen. With Synchron LX20, reliable CRP measurements could only be obtained in sera clear on macroscopic examination (data not shown).

\section{Reference values}

The median CRP concentration was $1.57 \mathrm{mg} / \mathrm{L}$ and the 0.95 interpercentile interval was $0.20-11.24 \mathrm{mg} / \mathrm{L}$ for all samples together (males $0.20-14.29 \mathrm{mg} / \mathrm{L}$, fernales $0.20-$ $9.84 \mathrm{mg} / \mathrm{L}$ ). When values above $10 \mathrm{mg} / \mathrm{L}$ were omitted, the whole group median value remained higher then median vallues reported by others $(0.58-1.13 \mathrm{mg} / \mathrm{L})^{2,4}$. This is probably due to the already observed weak positive correlation between age and hs-CRP concentration (median age of healthy blood donors in our study was 49 years compared to 32 years reported in previous studies) ${ }^{2}$. It might also be due to eventually unreported episodes of cold within the prior 90 days. The gender difference in hs-CRP was not found significant, neither before $(p=0.15)$ not after omitting of the values $(p=0.06)$ figher then $10 \mathrm{mg} / \mathrm{L}$, as is in accordance with previous studies ${ }^{2.8}$.

\section{Conclusion}

In conclusion, evaluation of the hs-CRP method on the IMMAGE yolded good imprecision results and satisfying linearity as required for hs-CRP methods. The method correlated well with the other two compared hs-CRP metlods in the range from 0.2 $100 \mathrm{mg} / \mathrm{L}$. However, above $100 \mathrm{mg} / \mathrm{L}$ poor correlations were found between all different methods, both hs CRP and CRP. Therefore, the use of two different methods, a hs-CRP for risk stratification and a normal routine CRP method, seems still required.

As we are convinced that for the clinical laboratory it is most practical to use one CRP method for the complete measuring range, further investigation to improve agreement between the different methods also in the higher range is tequired. 


\section{References}

1. Rifai N, Ridker PM. High-sensitivity C-reactive protein: a novel and promising nather of coronary het disease. Chin Chew 2001:47:403-11.

2. Roberts WL, Sedrick R, Moulton L, Spencer A, Rifai N. Exaluation of four automated high-sensitivity Creactive protein methods: implications for clinical and epidemological applications. Cin Chem $2000 ; 46: 461-8$.

3. Roberts WL, Moulton $\mathrm{L}$, Law TC, Farrow $G$, Coopet-Anderson $M$, Savory $\mathrm{J}_{n}$ Rifai $N$. Evaluation of nine automated thigh-sensitivity C-reactive protein methods: implications for clinical and epidemiological applications. Part 2. Clin Chem 2001;47:418-25.

4. Hutchinson WL, Koenig W, Frohlich M. Sund M. Lowe GD. Pepys MB. Inmunoradiometric assay of circulating C-reactive protein: age-related values in the adult general population. Clin Cham 2000;46: $934-8$.

5. Macy EM, Hayes TE, Tracy RP. Variability in the measurement of C-reactive protein in healthy subjects: implications for reference intervals and epidemiological applications. Chin Chem 1997;43:52-8.

6. Bland JM. Altman DG. Statistical methods for assessing agreement between two methods of alinical measurement. Lancet 1986;1:307-10.

7. Martin RF. General Deming regression for estimating systematic bias and its confidence inlerval in method-comparison studies, Clin Chem 2000:46:100-4.

8. Solberg H. Establishment and use of teference walues. In: Burtis CA, Ashwood ER, eds. Thetz raxbook of Clinical Chemistry. 1994; Philadelphu, W. B. Saunders Company :470-6.2nd Ed.)

9. Ockene IS, Matthews CE, Rifai N, Ridker PM, Reed G, Stanek E. Variability and elassification accuracy of serial high-sensitiwity C-reactive protein measurements in healthy adults. Chin Chem 2001;47:444-50. 


\section{Chapter 3}

\section{Evaluation of two new high- sensitivity C-reactive protein methods}

Snježana Rothkrantz-Kos, Otto Bekers, Armand Gubbels, Marjalein Drent, Maria PJ Schmitz, Marja P van Dieijen-Visser 


\section{Abstract}

\section{Background}

The implementation of a high-sensitivity C-reactive protein (hs-CRP) assay as a routine Iaboratory parameter may be necessary. It would be most practical to use one CRP method giving reliable results for the whole concentration range. We report here the evaluation of two new hsCRP methods, which cover both the low and the high concentration ranges.

\section{Methods}

The BN ProSpec ts-CRP (Dade Behring) and Synchron LX20 PRO hs-CRP methods were compared with the existing hs-CRP IMMAGE method (taken as a reference) and, for the high concentration range, also with the routine Synchron LX20 CRP method (all from Beckman). Agreement anong methods was examined in 521 samples. Reference walues were estimated in 291 blood donors. Additionally, the influence of sample turbidity, a major problem of the present Synchron LX20 CRP method, was evaluated.

\section{Resuits}

Measurements of CRP by the BN ProSpec were linear down to $0.2 \mathrm{mg} / \mathrm{L}$, whereas the linearity of Synchron LX20 PRO showed some systematic discrepancies. Over the whole measured range $(0.2-250 \mathrm{mg} / \mathrm{L})$, precision (coefficient of variation, $C V)$ was $\leq 3.7 \%$ for the BN ProSpec and $\leq 6.1 \%$ for LX20 PRO. The Synchron LX20 PRO hs-CRP method was found to be superior to the current routine Synchron LX20 CRP method with regard to precision in the low concentration range and the influence of sample turbidity. Both in the low concentration range and especially in the high concentration range, large discrepancies between methods were obserwed.

\section{Conclusion}

Although acceptable performance was found for the Synchron LX20 PRO hs-CRP method, overall the perfomance of the $B N$ ProSpec hs-CRP method was superior. However, standardization among assays needs further improvement in both the low and the high concentration ranges. 


\section{Introduction}

C-reactive protein (CRP), an acute-phase protein, is a valuable laboratory parameter in the clinical evaluation of inflammatory disease. Although CRP is a classical acute-phase reactant, in the absence of infection or trauma its concentration is biologically stable over a long period of time ${ }^{\prime}$ CRP has been introduced as a strong independent predictor of future coronary events in apparently healthy subjects as demonstrated in several clinical studies ${ }^{1-3}$. Recently, a cardiovascular risk assessment algorithm has been proposed, using high-sensitivity CRP (hs-CRP) in the concentration range 0.7 $3.9 \mathrm{mg} / \mathrm{L}$ as determined with a nephelometric immunoassay (BN II, from Dade Behring) '. Although in some studies the limited clinical utility has been discussed ${ }^{4}$. there is still a need for more sensitive assays. Furthermore, implementation of hs-CRP as a routine laboratory parameter is to be expected.

In most clinical laboratories CRP measurements are performed by immunoturbidimetry on a routine clinical chemistry analyzer, with detection limits for CRP of about 2 $5 \mathrm{mg} / \mathrm{L}$. These methods are primarily suitable for detection of active inflammation. For studies on CRP as a risk factor for coronary artery disease, a hs-CRP method with a detection limit of about $0.2 \mathrm{mg} / \mathrm{L}$ is required". A variety of methods have now been introduced for measuring hs-CRP and their analytical performance has been evaluated and compared ${ }^{5-7}$. These studies were mainly focused on comparing different methods in the low concentration range of $0-10 \mathrm{mg} / \mathrm{L}$, taking BNII from Dade Behring as the reference method. It was apparent that standardization between the assays still needs improvement in the low range ${ }^{5.8}$. However, large discrepancies between different hs-CRP methods were also observed in the high concentration range (above $100 \mathrm{mg} / \mathrm{L}$ )". The aim of the present study was to evaluate two new hs-CRP methods (Synchron LX20 PRO and BN ProSpec) and compare them to the existing hs-CRP IMMAGE method and also (in the higher range) to our routine Synchron LX20 CRP method. For the laboratory it is most practical to use one CRP method for both the low and the high concentration ranges. Therefore, to find out whether the hs-CRP methods can be used for both risk stratification and detection and monitoring of inflammation, their evaluation was performed over the whole measuring range.

In addition, the influence of sample turbidity, a known major problem of the routine Synchron $L \times 20$ method, was examined.

\section{Materials and methods}

\section{Samples}

Samples for method comparisons were collected from 521 persons either for whom CRP was requested for routine analysis or from a donor population (42 sampleg). Furthemore, venous blood samples were separately collected from 291 ostensibly healthy blood donors, (177 men and 114 women), who were selected according to the selection criteria of the Sanguin Blood Bank in Mastricht. The medical ethical committee of the hospital approved the procedure that was followed. Serum was 
directy separated from the red cells after centrifugation and stored at $-80^{\circ} \mathrm{C}$ unti]. analysis ${ }^{30}$.

\section{Methods}

The hs-CRP assay on the BN ProSpec from Dade Behring is based on particle-enhanced immunonephelometry (N HS CRP, cat no OQIY G13; supplement reagent OUMU15; Dade Behring, Liederbach, Germany).

The IMMAGE hs-CRP (trade name: IMMAGE CRPH) and the LX20 hs-CRP (trade name Synchron $L X^{20}$ PRO) are both turbidimetric methods based on the peak rate principle, measured by a near-infrared particle immunoassay, with a laser diode at 940 nm (cat no. 474630 and 378020 ; Beckman Coulter, Fullerton CA, USA).

CRP was measured on a routine clinical chemistry analyzer, the Synchron $L X 20$ (trade name Synchron $\mathrm{LX}^{20}$, cat no 465131 ; Beckman Coulter, Fullerton CA, USA): the method is based on immunoturbidimetry.

All the methods were calibrated to CRM 470/RPPHS. According to the manufacturers, the CRP target for CRM 470 is $39.2 \mathrm{mg} / \mathrm{L}$, which was recovered by all instruments within $5 \%$ of that target. Table 3.1 presents the assay characteristics of the different methods used.

Table 3.1. Assay characteristics of the methods used.

\begin{tabular}{|c|c|c|c|c|c|}
\hline \multirow[b]{2}{*}{ Analyzer } & \multirow[b]{2}{*}{ Methad } & \multirow[b]{2}{*}{$\begin{array}{l}\text { Dilution } \\
\text { (mg/L) }\end{array}$} & \multirow[b]{2}{*}{$\begin{array}{c}\text { Assay range } \\
(\mathrm{mg} / \mathrm{L})\end{array}$} & \multicolumn{2}{|c|}{ Manufacturer's claimed } \\
\hline & & & & $\begin{array}{c}\text { Measuring range } \\
\text { (mg/L) }\end{array}$ & $\begin{array}{l}\text { Detection limit } \\
(\mathrm{mg} / \mathrm{L})\end{array}$ \\
\hline IMMAGE & hs-CRP & $\begin{array}{l}\text { neat } \\
1: 6 \\
1: 24\end{array}$ & $\begin{array}{c}0.20-60 \\
1.2-360 \\
4.8-1440\end{array}$ & $0.20-1440$ & 0.20 \\
\hline BN Praspec & hs-CRP & $\begin{array}{l}1: 20 \\
1: 100 \\
1: 400 \\
1: 2000\end{array}$ & $\begin{array}{c}0.18-11 \\
0.88-55 \\
3.5-220 \\
17.5-1150\end{array}$ & & 0.18 \\
\hline SynchronLX20 PRO & hs-CRP & $\begin{array}{l}\text { neat } \\
\text { ORDAC }\end{array}$ & $\begin{array}{l}0.2-80 \\
60-380\end{array}$ & $0.20-380$ & 0.20 \\
\hline Synchron $L \times 20$ & CPP & $\begin{array}{l}\text { neat } \\
\text { ORDAC }\end{array}$ & $\begin{array}{r}5-200 \\
150-488\end{array}$ & $5.0-488$ & 5.0 \\
\hline
\end{tabular}

"ORDAC, over range detection and correction; the LX20 uses a smaller sample size for analysis of such samples. lhs-CRP, high-sensitivity C-reactive protein.

The serum index measured on the Synchron LX20 was used to indicate the sample condition in terms of lipemia. A lipemic index above 1 was used to indicate turbidity. Sample turbidity was also assessed by macroscopic examination and by measuring triglycerides. Samples with triglyceride concentration above $3 \mathrm{mmol} / \mathrm{L}$ were classified as turbid samples.

Samples for precision studies were prepared from 11 serum pools in the concentration range from $0.2-250 \mathrm{mg} / \mathrm{L}$, as determined on the $\mathrm{BN}$ ProSpec, taking into account cardiovascular risk assessment algorithm cut-off points. Within-run precision was obtained by measuring one sample 20 times within a single run. Between-run precision 
was obtained by measuring each concentration on 20 consecutive days, based on a single calibration (one lot number). Since the method agreement experiment was performed on the basis of one lot number (four calibrations), no lot-to-lot stability investigations during the between-run precision experiment were performed.

\section{Statistics}

Agreement between methods was assessed visually by the method of Bland and Altman ${ }^{11.12}$ and by Deming regression analysis ${ }^{13}$. For evaluation of blood donor samples, the 0.95 non-parametric inter-percentile interval was calculated ${ }^{\text {lit }}$. Gender differences in samples from blood donors were assessed by the Mann-Whitney $U$ test. Median serum versus plasma comparisons was assessed by Wilcoxon matched pairs signed-ranks test.

\section{Results}

\section{Precision and linearity studies}

Precision data for BN ProSpec and $\mathrm{LX} 20$ PRO are presented in Table 3.2. The mean value of the lowest pool $(0.25 \mathrm{mg} / \mathrm{L})$ as measured on the BN ProSpec was below the detection limit of the LX20 PRO and therefore these data cannot be reported. In the hsCRP concentration range 0.7 to $3.9 \mathrm{mg} / \mathrm{L}$, which has been proposed for cardiovascular risk assessment, between-run coefficients of variation (CVs) ranged from 1.1 to $3.3 \%$ for the BN ProSpec and from 2.5\% to $5.4 \%$ for LX20 PRO. Precison of BN ProSpec was better $(\mathrm{CV} \leq 3.7 \%)$ than that of the $\mathrm{LX} 20 \mathrm{PRO}(\mathrm{CV} \leq 6.1 \%)$ over the measured range $(0.2-250 \mathrm{mg} / \mathrm{L}$, as measured on the $\mathrm{BN}$ ProSpec).

Linearity results are presented as percentage deviation from expected values (Figure 3.1). Expected values were calculated from two initial pools containing 60 and $310 \mathrm{mg} / \mathrm{L} \mathrm{CRP}$. No systematic deviation from expected values for the BN ProSpec could be detected over the whole tested range. However, for ILX20 PRO, the linearity of the method was less good (below $10 \mathrm{mg} / \mathrm{L}$ ). Deviation from expected values changed from positive $(0-10 \mathrm{mg} / \mathrm{L}$ ) to negative (above $10 \mathrm{mg} / \mathrm{L}$ ) values. No specific discrepancies in linearity were observed at concentrations for which automatic dilution is performed (Table 3.1).

\section{Influence of sample turbidity on the CRP and hs-CRP methods on the $\mathrm{LX} 20$}

To evaluate whether the hs-CRP LX20 PRO method is less sensitive to sample turbidity than the present LX20 CRP method, lipemic index, triglycerides and sample turbidity assessed by macroscopic examination were determined in all samples. Both methods were compared to the hs-CRP IMMAGE method (Figure 3.2). Below $20 \mathrm{mg} / \mathrm{L}$ $(\mathrm{n}=270), 12(4.4 \%), 29(10.7 \%)$ and $100(37 \%)$ samples were classified as turbid by means of lipemic index, triglycerides and macroscopic examination, respectively. Therefore, assessment of sample turbidity by means of macroscopic examination 
appeared to be more sensitive than the use of either lipemic index or measurement of riglycerides.

Because a good relation was found between $L X 20$ PRO and IMMAGE, LX20 PRO appears insensitive to sample turbidity, whereas on the $L X 20$ a reliable CRP analysis seems possible only for clear serum samples.

Table 3.2 summary of precision data.

\begin{tabular}{|c|c|c|c|c|c|c|}
\hline \multirow[b]{2}{*}{ Pool } & \multicolumn{3}{|c|}{ Synchron LX20 PRO } & \multicolumn{3}{|c|}{ BN Prospec } \\
\hline & $\begin{array}{c}\text { Mean hs-CRP } \\
\text { concentration (mg/L) }\end{array}$ & $\begin{array}{l}C W_{E}^{a} \\
(\%)\end{array}$ & $\begin{array}{l}\mathrm{CV}_{\psi}^{6} \\
(\%)\end{array}$ & $\begin{array}{c}\text { Mean hs-CRP } \\
\text { concentration (mg/L) }\end{array}$ & $\begin{array}{l}C V_{B} \\
(\%)\end{array}$ & $\begin{array}{l}\mathrm{CV}_{\mathrm{w}} \\
(\%)\end{array}$ \\
\hline 0 & -0 & - & - & 0.25 & 3.1 & 3.7 \\
\hline 1 & 0.36 & 4.5 & 6.1 & 0.40 & 3.3 & 3.5 \\
\hline 2 & 0.77 & 5.4 & 4.8 & 0.64 & 2.5 & 2.7 \\
\hline 3 & 1.65 & 3.8 & 3.4 & 1.30 & 1.5 & 1.5 \\
\hline 4 & 2.67 & 3.1 & 1.8 & 2.18 & 1.1 & 0.6 \\
\hline 5 & 4.35 & 2.5 & 1.6 & 3.86 & 1.4 & 0.9 \\
\hline 6 & 7.06 & 5.5 & 1.7 & 6.74 & 1.6 & 1.0 \\
\hline 7 & 14.7 & 2.1 & 2.1 & 15.0 & 1.6 & 1.0 \\
\hline 8 & 51.4 & 2.1 & 2.0 & 45.1 & 1.4 & 1.0 \\
\hline 9 & 162 & 2.5 & 2.9 & 133 & 2.3 & 0.8 \\
\hline 10 & 318 & 3.1 & 2.0 & 246 & 1.4 & 1.0 \\
\hline
\end{tabular}

a. the concentration of high-sensitivity C-reactive protein (hs-CRP) are based on between-run results.

a $C V_{0}$, between-run coefficient of variation $(n=20)$.

b $C V_{w}$, within-run coefficient of variation $(n=20)$.

c -, buelow detection limit.

\section{Agreement between methods}

Bland-Altman plots are presented in Figure 3.3, and the statistics are summarized in Table 3.3. The percentage plots ${ }^{15}$ were used, as the method differences appeared comelated with their mean values. Large discrepancies were observed both in the low and high concentration ranges.

For the BN ProSpec method, the observed bias was negative across the whole concentration range. However, in the low concentration range average bias was approximately 2.5 times higher than in the high concentration range $(-19.3 \%$ versus $-7.1 \%$ ). As can be seen from percentage plots for the range $0-10 \mathrm{mg} / \mathrm{L}$, a change in the slope occurs at $1.6 \mathrm{mg} / \mathrm{L}$. Thus bias and limits of agreement were calculated for the range 1.6 to $10 \mathrm{mg} / \mathrm{L}$ (Table 3.3). Very broad limits of agreement were found, indicating poor agreement ( -40 to $1.8 \%$ ). Because of the proposed cardiovascular assessment algorithm, a separate Deming regression analysis was performed for concentrations below $1.6 \mathrm{mg} / \mathrm{L}$. Deming comparison $(0-1.6 \mathrm{mg} / \mathrm{L}$ range $)$ of the $\mathrm{BN}$ ProSpec and IMMAGE methods gave a mean (standard deviation, SD) slope of $1.37(0.22)$, an intercept of $-0.09(0.11)$ and an $S_{y x}$ of $0.06(r=0.979)$.

For $\mathrm{L} \times 20$ PRO method, in the range from $0-10 \mathrm{mg} / \mathrm{L}$, the observed bias was negative $(-12.6 \%)$, whereas above $10 \mathrm{mg} / \mathrm{L}$ the observed bias was positive $(8.9 \%)$. Again, very broad limits of agreement $(-30$ to $5 \%$ ) were observed in the low concentration range. 
Above $10 \mathrm{mg} / \mathrm{L}$, the bias for $L X 20$ PRO versus IMMAGE was higher and positive $(8.9 \%)$ compared with BN ProSpec versus MMAGE $(-7.1 \%)$. Overall, the plots in Figure 3.3 suggest better agreement with the BN ProSpec. Moreover, above $100 \mathrm{mg} / \mathrm{L}$ there were $23 \%$ BN ProSpec samples, compared with $38 \% \mathrm{LX} 20$ PRO samples hawing absolute differences with the reference method of more than $30 \mathrm{mg} / \mathrm{L}$.

Comparison of the hs-CRP methods with our routinely used CRP method (Synchron LX 20 ) above $15 \mathrm{mg} / \mathrm{L}$, resulted in a good agreement only with BN ProSpec: less good agreement was found with both MMMAGE and LX20 PRO (data not shown).
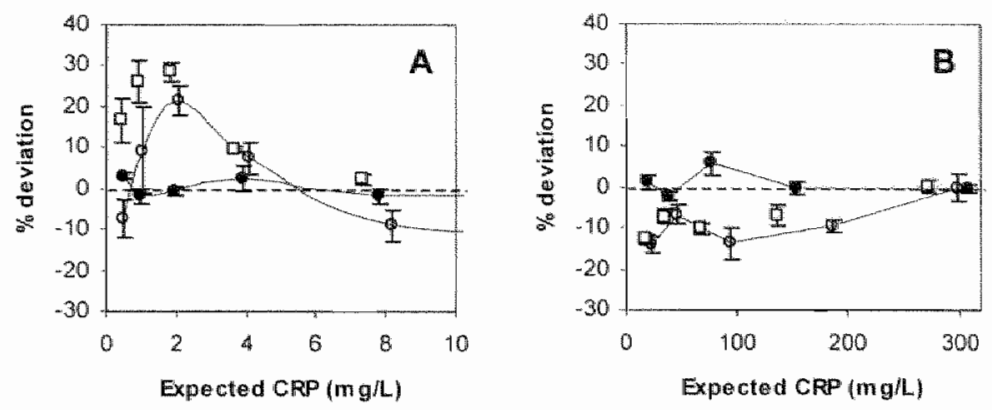

Figure 3.1. Linearity of the evaluated high sensitivity $C$-reactive protein (hs-CRP) methods for the CRP range $0-10 \mathrm{mg} / \mathrm{L}(\mathrm{A})$ and $10-300 \mathrm{mg} / \mathrm{L}(\mathrm{B})$.

Linearity is presented as the average percentage deviation together with standard deviation: deviation $(\%)=[($ measured - expected $) / e x p e c t e d] \times 100$. Open circles indicate $L X 20$ PRO results, closed circles the BN ProSpec hs-CRP results and square open symbols the hs-CRP IMMAGE results. The linearity data for the hs-CRP IMMAGE method were published previously".

\section{Evaluation of blood donor samples}

The hs-CRP concentrations of 291 serum samples collected from apparently healthy" adult blood donors were measured on the $\mathrm{L} \times 20 \mathrm{PRO}$ and the $\mathrm{BN}$ ProSpec. A frequency histogram with percentile values is shown in Figure 3.4. On the LX20 PRO, the median CRP concentration was $1.81 \mathrm{mg} / \mathrm{L}$ with a 0.95 inter percentile interval of 0.26 $12.72 \mathrm{mg} / \mathrm{L}$, whereas for the BN ProSpec a median CRP concentration of $1.35 \mathrm{mg} / \mathrm{L}$ and a 0.95 inter-percentile interval of $0.26-12.51 \mathrm{mg} / \mathrm{L}$ were found. No signilicant gender differences were found ( $p<0.053$ for $\angle X 20$ PRO, $p<0.132$ for BN ProSpec). In Figure 3.4 percentile values are reported for samples with CRP concentration $<10 \mathrm{mg} / \mathrm{L}$ $(3.4 \%$ of cases omitted). The inter-percentile intervals found were $0.26-7.42 \mathrm{mg} / \mathrm{L}$ for LX20 PRO and $0.26-7.24 \mathrm{mg} / \mathrm{L}$ for BN ProSpec. 

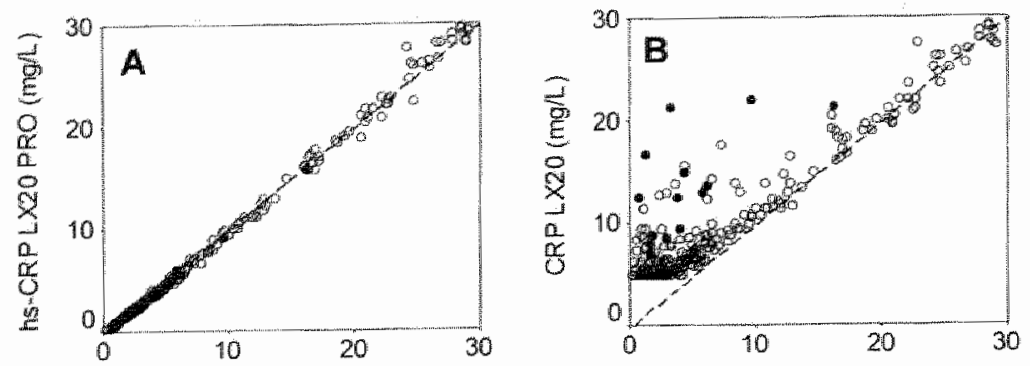

hS- CRP WMMGE (MVIL)
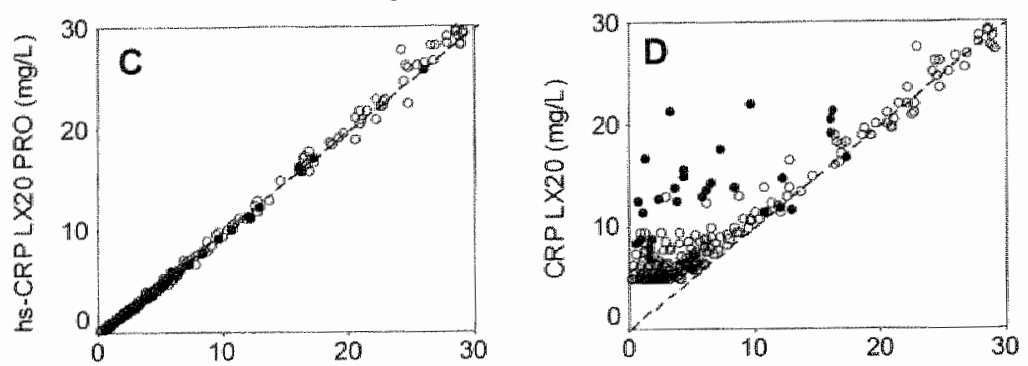

hS-CRP IMMAAGE (mg/L)
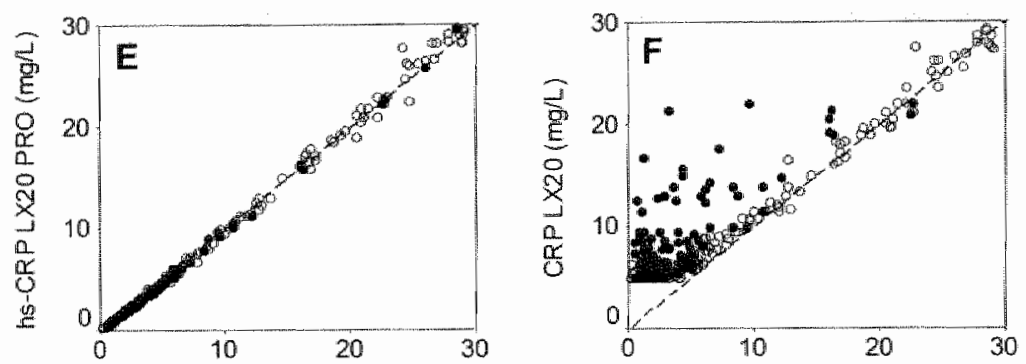

h⿻ $-C R$ P IMMAGIE (ing/L)

MS.CRP IMMAGE (mg/)

Filgure 3.2. Influence of sample turbidity on C-reactive protein (CRP) and high sensitivity CRP (hs-CRP) measurements using the LX20 and LX20 PRO, respectively.

Samples with a lipemic index $<1(A, B)$, triglycerides concentrations $<3$ mmoll $L, C, D)$ or turbicity assessed by macrascopic examination $(\mathbb{E}, F)$ are indicated by closed circles. The dashed line indicates unity.

\section{Serum versus plasma comparison}

To compare sample types, serum, heparin- and EDTA-plasma hs-CRP concentrations for 25 patients were compared for the two new methods. Only slight differences were seen between serum and plasma samples. For BN ProSpec, mean (SD) recoveries in heparin- and EDTA-plasma were $98.3(3.4) \%(\mathrm{p}<0.02)$ and $99.9(10.5) \%(\mathrm{p}<0.18)$, respectivaly, $100.4(5.0) \%(\mathrm{p}<0.90)$ and $108.5(10.4) \%(\mathrm{p}<0.04)$, respectively, for the hs-CRP LX2O PRO. 

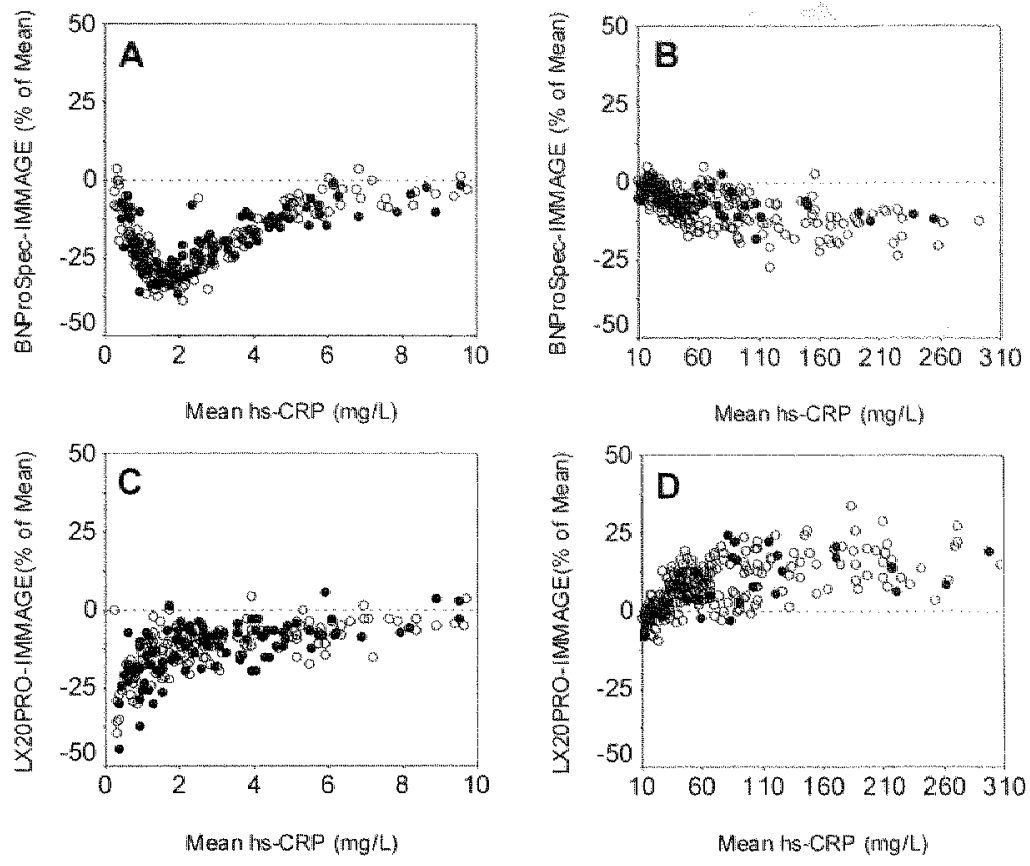

Figure 3.3. Method comparison in 521 patient samples by means of Bland-Altman analysis for the high-sensitivity $C$-reactive protein (hs-CRP) concentration ranges 0 $10 \mathrm{mg} / \mathrm{L}(A, C)$ and $10-300 \mathrm{mg} / \mathrm{L}(B, D)$.

The dashed lines indicate zero difference between the methods. Closed symbols indicate samples showing turbidity assessed by macroscopic examination, open symbols indicate completely clear samples.

Table 3.3. Comparison of the LX20 PRO and BN ProSpec methods with the IMMAGE method.

\begin{tabular}{cccc}
$0-10 \mathrm{mg} / \mathrm{L}$ & \multicolumn{2}{c}{$10-350 \mathrm{mg} / \mathrm{L}$} \\
LX20 PRO $(y)$ & BN ProSpec $(y)$ & LX20 PRO $(y)$ & BN PloSpec $(y)$ \\
versus & versus & versus & versus \\
IMMAGE $(x)$ & IMMAGE $(x)^{2}$ & IMMAGE $(x)$ & IMMAGE $(x)$
\end{tabular}

Deming regression analysis

\begin{tabular}{|c|c|c|c|c|}
\hline SlopetSD & $1.15 \pm 0.17$ & $0.96 \pm 0.11$ & $1.16 \pm 0.12$ & $1.11 * 0.00$ \\
\hline IntercepteSD & $-0.10 \pm 0.17$ & $0.73 \pm 0.03$ & $-2.75+3.42$ & $-4.52 \pm 2.49$ \\
\hline$r$ & 0.995 & 0.996 & 0.995 & 0.997 \\
\hline$s_{y \mid \not}$ & 0.23 & 0.19 & 7.59 & 5.10 \\
\hline \multicolumn{5}{|c|}{ Bland-Altman analysis } \\
\hline Bias (in \%) & -12.6 & -19.3 & 8.9 & -7.1 \\
\hline $\begin{array}{l}\text { Limits of } \\
\text { agreements (in } \%)\end{array}$ & -30 to 5 & -40 to 1.8 & -7.410 .2 .4 & -18 to 4 \\
\hline $\begin{array}{l}\text { Wilcoxon's test } \\
(z, p)\end{array}$ & $\begin{array}{c}-12.6 \\
p<0.0001\end{array}$ & $\begin{array}{c}-13.0 \\
p<0.0001\end{array}$ & $\begin{aligned} &-13.7 \\
& p<0.0001\end{aligned}$ & $\begin{array}{c}-11.0 \\
p<0.0001\end{array}$ \\
\hline
\end{tabular}

a Deming regression and Bland-Altman analysis were performed on data for $1.6-10 \mathrm{mg} / \mathrm{L}$ (results for $0-1.6 \mathrm{mg} / \mathrm{L}$ are presented in the text). SD, standard deviation. 


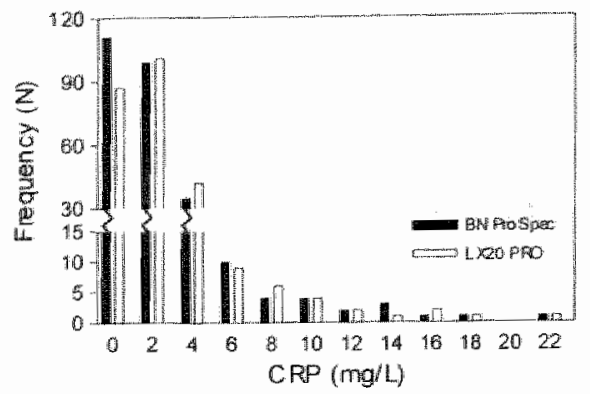

Figure 3.4. Evaluation of blood donor samples.

C-reactive protein (CRP) walues were quantified in 291 blood donors (177 men and 114 womenl of median age 49 years. Percentile values are based on samples with CRP concentrations of less than $10 \mathrm{mg} / \mathrm{L} .25^{\text {th }}, 25^{\text {th }}, 50^{\text {th }}, 75^{\text {th }}$ and $97.5^{\text {th }}$ percentile values for the BN ProSpec were $0.26,0.67,1.35,2.64$ and 7.24 respectively and for the $L \times 20$ PRO they were $0.26,0.77,1.81,3.12$ and 7.42 respectively.

\section{Discussion}

\section{Agreement among the methods}

Two distinct populations of data could be identified from the Bland-Altman plots (i.e. those below and above $10 \mathrm{mg} / \mathrm{L}$ ). Regression analysis and bias estimates were therefore performed separately for these two measuring ranges. In the percentage plots, mean bias (mean of relative differences) appeared to be larger in the low concentration range $(-12.6 \% \mathrm{LX} 20 \mathrm{PRO},-19.3 \% \mathrm{BN}$ ProSpec) than in the higher concentration range $(8.9 \%$ LX20 PRO, $-7.1 \%$ BN ProSpec) when comparing the methods to the hs-CRP IMMAGE method. Moreover, in the low concentration range BN ProSpec (nephelometric assay) showed a non-linear relationship with the IMMAGE (turbidimetric assay), with a slope change at around $1.6 \mathrm{mg} / \mathrm{L}$, probably caused by lack of linearity of the LX20 PRO (see Figure 2.1). Hamwi et al. noticed similar disagreement when comparing four turbid metric assays to the BN II method?

However, in the higher range, regardless of the lower percentage bias, the differences found are clinically significant. Above $100 \mathrm{mg} / \mathrm{L}$ as measured by the hs-CRP IMMAGE method, there were $23 \%$ of BN ProSpec samples and $38 \%$ of LX20 PRO samples for which the absolute differences with the reference method was $>30 \mathrm{mg} / \mathrm{L}$. These results suggest that, above $100 \mathrm{mg} / \mathrm{L}$ there is better agreement between the BN ProSpec and the IMMAOE methods compared with that between the LX20 PRO and the IMMAGE methods. The observed results are in accordance with previous studies, in which at concentrations above $100 \mathrm{mg} / \mathrm{L}$, the same large discrepancies were observed between the compared methods ${ }^{5,9}$.

Since all method agreement studies were performed using reagents of only one lot number, influence of lot-to-lot instability could a priori be excluded. The differences between the methods might also have been caused by improper automatic dilution, but 
this does not appear to be the case (Table 3.1). Furthemore, poor linearity might also cause poor agrement. Inspection of linearity results reveals that the $L \times 20$ PRO method is not linear, whereas the BN ProSpec appears linear cross the whole concentration range. To be able to follow the infuence of linearity on the agreement among the methods, previously published linearity results of the IMMAGE method were presented as percentage deviation from expected values in the same graph (Figure 3.1). The same trend in deviation from linearity seen for the $L \times 20$ PRO was seen for the IMMAGE. This deviation does not appear to be dependent on precision. Although slightly higher CVs were obtained below $1 \mathrm{mg} / \mathrm{L}$, good precision data were observed for $L \times 20$ PRO and BN ProSpec across the whole range examined. Although the performance of $B N$ ProSpec is better with respect to precision, the hs-CRP assay precision for risk stratification of vascular disease should be less than $10 \%$ at a concentration of $0.2 \mathrm{mg} / \mathrm{L}^{5}$, which was achieved for both methods.

All methods were calibrated to CRM 470/RPPHS. However, even assays calibrted to the same reference material may yield different results. The difference may be related to suboptimal value transfer. Alternatively, inappropriate curve-fitting or matrix differences between the system specific calibrators may be responsible for the observed bias". It is obvious that standardization among assays should be improved not only in the low range, but also for the whole measuring range.

From our results it is clear that agreement between methods needs further improvement. Moreover, for clinical risk stratification, concordance between assays is needed, especially at cut-off values separating risk groups".

\section{Samples from blood donors}

Samples from blood donors appeared to have higher median values $(1.81 \mathrm{mg} / \mathrm{L}$ on the LX20 PRO, $1.35 \mathrm{mg} / \mathrm{L}$ on BN ProSpec) than those reported by others (range $0.58-$ $1.13 \mathrm{mg} / \mathrm{L}^{5.16}$, but were similar to the findings reported previously". Methodologyrelated differences cannot be excluded. Besides, a weak positive correlation between age and hs-CRP concentration has been observed ${ }^{10.16}$. Since in our population the median age was 49 years, compared to 32 years reported in the earlier study, this might allso contribute to the higher values found". The hs-CRP values higher than $10 \mathrm{mg} / \mathrm{L}$ (3.4\% of blood donors) might be due to existence of some subclinical inflanmatory disease ${ }^{5,1017}$.

\section{Influence of sample turbidity}

In this study, parallel comparison of the hs-CRP LX20 PRO method and the routine CRP turbidimetric method with the IMMAGE method revealed that turbidity of samples results in considerable overestimation of CRP concentrations measured with our routine CRP LX20 method. The samples that were used were randomly taken from hospital population (mostly fasting) and from donor samples (non fasting), the latter group to obtain more samples in the low range $(<10 \mathrm{mg} / \mathrm{L})$. As a consequence, there are relatively more donor samples (non-fasting), and thus turbid samples, in the lower concentration range $(16.3 \%$ lower than $10 \mathrm{mg} / \mathrm{L}$ compared with $0.8 \%$ above $10 \mathrm{mg} / \mathrm{L}$ ). An effect of turbidity is of course present for the whole concentration range, but in our study this was more pronounced in the lower range caused by the sample population. 
Althugh the reagent insert from Beckman indicates that turbidity can interfere in the test and ultracentrifugation of turbid samples is required, we showed that the influence of non-specific interferences with the Synchion LX20 CRP is greatly underestimated. This is very important, assuming that in order to allow stat analysis, CRP is still measured in many laboratories using the immunoturbidimetric Synchron $L \times 20$ method, which according to the manufacturer is reliable for clear samples with values above $5 \mathrm{mg} / \mathrm{L}$. Besides, lipemic index, the automatic screening procedure for selection of turbid samples on the $L \times 20$, appeared inadequate.

\section{Conclusion}

Use of hs-CRP as a routine laboratory parameter appears inevitable. Therefore, for the laboratory, it would be most practical to use one CRP method giving reliable results for the whole measuring range. The BN Prospec method appears superior to the Synchron $1 \times 20$ PRO method and suitable for the whole measuring range. The Synchron $L \times 20$ PRO is to be preferred to the current Synchron $L \times 20$ CRP method, regarding precision. in the low concentration range and influence of sample turbidity. However, the Synchron LX20 PRO needs some improvement with respect to linearity. Furthermore, better standardization among hs-CRP assays is still needed. 


\section{References}

1. Ridker PM, Cushman M. Stampfer MI, Tracy RP. Hennekens CH. Inthammation, aspirin, and the risk of cardiovascular disease in apparently healthy men. $N$ Engt I Med 1997,336:973-9.

2. Ridker PM, Henryekens CH, Buring JE, Ritai N. Careactive protein and other matkers of inflammation in the prediction of eardiovascular disease in women. $N$ Eng/ J Med 2000;342:836-43.

3. Rifai $N$, Ridker PM. Proposed cardiovaseular risk assessment algorithm using high-sensitivily C-reactive protein and lipid screening. Clin Chem 2001:47:28-30.

4. Campbell $B$, Badrick $T$, Flatman $R$, Kanowsti D. Limited clinical utlity of high-sensitivity plasma $C$ reactive protein assays. Ann Clin Biochem 2002,39:85-8.

5. Roberts WL., Sedrick R, Moulton L, Spencer A, Rifui N. Evaluation of four automated high-sensitivity C. reactive protein methods: implications for clinical and epidemiological applications. Clin Chem $2000: 46: 461-8$

6. Roberts WL, Moulton L. Law TC. Farrow G, Cooper-Anderson M, Savory 1, Rifai N. Exaluation of nine automated high-sensitivily C-reactive protein methods: implications for clinical and epidemiological applications. Part 2. Clin Chem 2001;47:418-25.

7. Hamwi A, Vukovich $T$, Wagner $O$, Rumpold $H$, Spies $R$, Stich M, Langecker C. Evaluation of turbidimetric high-sensitivity C-reactive protein assays for cardiovascular risk estimation. Clin Chem $2001 ; 47: 2044-6$

8. Ledue TB, Rjäi $\mathrm{N}$. High sensitivity immunoassays for $\mathrm{C}$-reactive protein: promises and pitfalls. Clin Chem Lab Mad 2001;39:1171-6.

9. Rothkrantz-Kos S, Schmitz. MP, Bekers O, Menheere PPCH, wan Dieijen-Visser MP. High-sensitivity Creactive protein methods examined. Clin Chem 2002;48:359-62.

10. Hutchinson WL, Koeñg W, Fröhlich M, Sund M, Lowe GD, Pepys MB. Immunoradiometric assay of circulating C-reactive protein: age-related values in the adult general population. Clin Chem 2000;46: 934.8 .

11. Bland JM, Altman DG. Statistical methods for assessing agrement between two methods of elinical measurement. Lancet 1986;1:307-10.

12. Pollock MA, Jefferson SG, Kane JW, Lomax K, Mackinnon G, Winnard CB. Method comparison-at different approach. Ann Clin Biochem 1992;29:556-60.

13. Martin RF. General Deming regression for estimating sysiematic bias and its confidence interval in method-comparison studies. Clin Chem 2000;46:100-4.

14. Solberg H. Establishment and use of reference walues. In: Burtis CA, Ashwood ER, eds. Tiezz rexibook of Clinjecol Chemistry. 1994; Philadelphia, W.B. Saunders Company :470-6.(2nd Ed.)

15. Hollis $\mathrm{S}$. Analysis of method comparison studies. Ann CYin Biochem 1996;33:1-4.

16. Macy EM, Hayes TE. Tracy RP. Variability in the measurement of Creative protein in hailly subjects: implications for reference intervals and epidentological applications. Clin Chem 1997:43:52.8.

17. Ockene IS. Matthews CE, Rifäi N, Ridker PM, Reed G. Stanek E. Variatbility and classification accuracy of seriall high-sensitivity C- reactive protein measurements in healthy adulls. C/in Chem 2001:47:444-50. 


\section{Chapter 4}

\section{Analytical evaluation and determination of reference values of soluble interleukin-2-receptor and serum amyloid-A}

Snježana Rothkrantz-Kos, Marjolein Drent, Maria P Schmitz, Paul PPC Menheere, Marja P van Dieijen-Visser 


\section{Abstract}

\section{Background}

There is a growing interest in both, serum amyloid $A$ (SAA) as an acute phase reactant and soluble $1 L-2$ receptor ( $S L-2 R$ ) as a T cell activation parameter. In this study, we evaluated the analytical performance of $S A A$ and $S L-2 R$ assays and we report the reference values in an adequate rerence population.

\section{Materials and methods}

SAA was determined by particle-enhanced immunonephelometry on the BN Prospec from Dade Behring, whereas sIL-2R was determined on the IMMULITE Automated Analyzer, by means of a two-site chemiluminescent enzyme immunometric assay. Reference intervals were established in 282 adult blood donors

\section{Results}

For $\mathrm{s} / \mathrm{L}-2 \mathrm{R}$ the coefficients of variation $(\mathrm{CV})$ for within- $(\mathrm{n}=20)$ and between-run $(\mathrm{n}=20)$ assay precision were $<3.8 \%$ and $\angle 7.3 \%$, respectively, and for the $\mathrm{SAA}<9.2 \%$ and $<10.8 \%$ Both methods were linear, slL-2R below $1000 \mathrm{kU} / \mathrm{L}$ and SAA below $854 \mathrm{mg} / \mathrm{L}$. For sIL2R reference interwals were found to be $241-846 \mathrm{kU} / \mathrm{L}\left(2.5^{\text {th }}-97.5^{\text {th }}\right.$ percentile). For SAA sex differences were observed and the reference values in males were $0.99-9.87 \mathrm{mg} / \mathrm{L}$ and in females $0.84-$ $11.4 \mathrm{mg} / \mathrm{L}$. The sLL-2R concentration appeared not related to age. However, SAA concentrations tended to a moderate increase with age.

\section{Conclusions}

Both assays, SAA on the BNProSpec and sIL-2R of the IMMULITE appeared to be useful in clinical practice. 


\section{Introduction}

Serum amyloid A (SAA) is an acute phase protein. The liver is mainly responsible for the production upon stimulation by interleukins $1 \mathrm{~L}-1$ and $I L-6$, respectively. Like Creactive protein (CRP), SAA belongs to the quick responding acute phase proteins.

The diagnostic value of these two different acute phase proteins is influenced by the underlying disorder. For example, during viral infections, SAA appeared to increase more intense as compared to CRP ${ }^{1-3}$. In some diseases, such as rheumatoid arthritis. Crohn"s disease and ulcerative colitis, CRP remained even nomal, whereas SAA increased $^{4 \%}$. Increased CRP was shown to be associated with inflammation in sarcoidosis" whereas SAA appeared to be increased in patients with active sarcoidosis" $^{10}$. To date, one of the strongest advantages of SAA above CRP has been demonstrated in kidney transplantation patients on immunosuppressive steroid therapy. In this later population only SAA, but not CRP appeared to be useful in monitoring acute rejection reactions $2,11.12$.

Another inflammatory parameter of clinical importance is soluble interleukin-2-receptor (sIL-2R). Interleukin-2 stimulates activation of $T$ cells through a complex interleukin-2 receptor molecule ${ }^{13}$. It concerns a heterodimeric receptor, which is partly released as a soluble form of the $55 \mathrm{kD}$ chain, the so called soluble IL-2 receptor ${ }^{14}$ is sIL-2R was found to be a good prognostic marker, related to pulmonary as well as extrapulmonary manifestations of sarcoidos is ${ }^{16-19}$. Recently, it has been demonstrated by various groups that sIL-2R appeared to be more useful as compared to the traditionally used angiotensin-converting enzyme and might even replace it ${ }^{18-20}$.

Before an assay can be used for clinical evaluation, a critical examination of assay performance is required. In this paper we report an extensive evaluation of the new SAA assay on the BNProSpec, from Dade Behring. Although evaluation of SIL-2R on the TMMULITE is available, no reference values were reported until now ${ }^{21}$. Therefore, the reference values estimated in a population of healthy blood donors for both, SAA, determined on the BN ProSpec from Dade Behring, and for $\$ L-2 R$, determined on the IMMULITE are presented.

\section{Materials and methods}

\section{Study population}

To allow determination of reference values, between $1999-2002$ venous blood samples were collected from 282 ostensibly healthy blood donors presenting at the Sanguine Blood Bank in Maastricht. The Medical Ethical Committee of the Hospital approved the procedure followed. 


\section{Serological measurements}

Samples were obtained by venipuncture in serum tubes and clotted blood was centrifuged $\left(2500 \mathrm{~g}\right.$ at $\left.20^{\circ} \mathrm{C}\right)$ for 15 minutes to obtain serum. Serum was separated and stored at $-70^{\circ} \mathrm{C}$ for further analysis. The whole procedure took less than an hour.

Soluble IL-2 receptor (SIL-2R) was determined on the IMMULITE Automated. Analyzer, by means of a two-site chemiluminescent enzyme immunometric assay, with a detection limit of $50 \mathrm{kU} / \mathrm{L}$, and a measuring range $50-7500 \mathrm{kU} / \mathrm{L}$ (Diagnostic Product Corporation, Los Angeles, CA, cat no LKIP1). L-2R reagent (LIP2) consists of alkaline phosphatase conjugated to rabbit polyclonal anti-IL-2R antibody.

Serum amyloid A. (SAA) was determined on the BN Prospec from Dade Behring, by particle-enhanced immunonephelometry. The detection limit for $S A A$ was $3 \mathrm{mg} / \mathrm{L}$, with a measuring range of $3-1000 \mathrm{mg} / \mathrm{L}$, depending on dilution (Dade Behring, Liederbach Germary, N SAA reagent, cat no OQMP 11). N SAA reagent (OQMP 11) consists of lyophilised polystyrene particles coated with sheep antibodies to human SAA.

For both assays, within-run precision was obtained by measuring one sample 20 times within a single run. Between-run precision was obtained by measuring each level on 20 consecutive days, based on a single calibration.

For sIL-2R, samples for precision studies were prepared from two serum pools in the range from $200-1000 \mathrm{mg} / \mathrm{L}$. The linearity studies were performed with one sample containing about $1000 \mathrm{kU} / \mathrm{L}$ of sJL-2R. Using the manufacturer's diluent (IL-2R Sample Diluent (LIPZ)) eleven dilutions of each sample were made in two replicates and measured.

With respect to SAA, samples for precision studies were prepared from nine serum pools in the range from $0.98-821 \mathrm{mg} / \mathrm{L}$, as determined on the $\mathbb{B N}$ ProSpec. The linearity studies were performed with two samples containing about $854 \mathrm{mg} / \mathrm{L}$ and $150 \mathrm{mg} / \mathrm{L}$ SAA. Using the manufacturer's diluent (N Diluent (OUM T65)) nine dilutions of each sample were made in five replicates and measured.

\section{Statistical analysis}

Statistical analysis was performed using the SPSS10.0 for Windows (SPSS, Chicago, IL. USA). The distributions of the SAA and SIL-2R were positively skewed. Therefore, the reference values are presented as an interpercentile interval $\left(2.5^{\text {th }}-97.5^{\text {th }}\right.$ range ) Linear regression was used to test the relationship with age. Sex-differences were tested by means of Mann-Whitney $U$ test. All p-values were two-tailed, and $p<0.05$ was considered statistically significant.

\section{Results}

\section{Imprecision and linearity of sIL2R assay}

In two pools with mean concentrations of sll-2R of 193 and $978 \mathrm{kU} / \mathrm{L}$ between run variations of respectively 3.6 and $7.2 \%$ and within run variations of respectively 2.7 and $3.7 \%$ were found. The IMMULITE sIL-2R assay appeared to be linear below $1000 \mathrm{kU} / \mathrm{L}$. The results of the regression analysis are presented in Figure $1 \mathrm{~A}$. The 
percentage deviation of the observed values as compared to expected values varied from $-2.3 \%-13.6 \%$ (mean: $4.8 \%$ ).

\section{Imprecision and linearity of SAA assay}

Since to the best of our knowledge this report concerns, the first evaluation of the SAA assay on the BN ProSpec, slightly more extensive evaluation was performed as compared to the sIL-2R evaluation. For nine pools with mean concentrations of 0.98 , $4.31,7.40,14.7,21.64,85.44,134,452$ and $821 \mathrm{mg} / \mathrm{L}$ between run variations of respectively $10.7,9.3,4.4,4.3,4.1,4.8,4.7,6.9$ and $6.6 \%$ and within run variations of respectively $8.9,9.2,5.1,6.3,2.6,3.3,7.4,5.0$ and $5.2 \%$ were found. So, the total imprecision for the SAA BN ProSpec method remained below 10.7\%. The method appeared to be linear below $854 \mathrm{mg} / \mathrm{L}$. Linearity results are presented in Figure 4.1B. The percentage deviation of the observed values as compared to expected values varied from $-21.8 \%-17.6 \%$ (mean: $2.4 \%$ ).
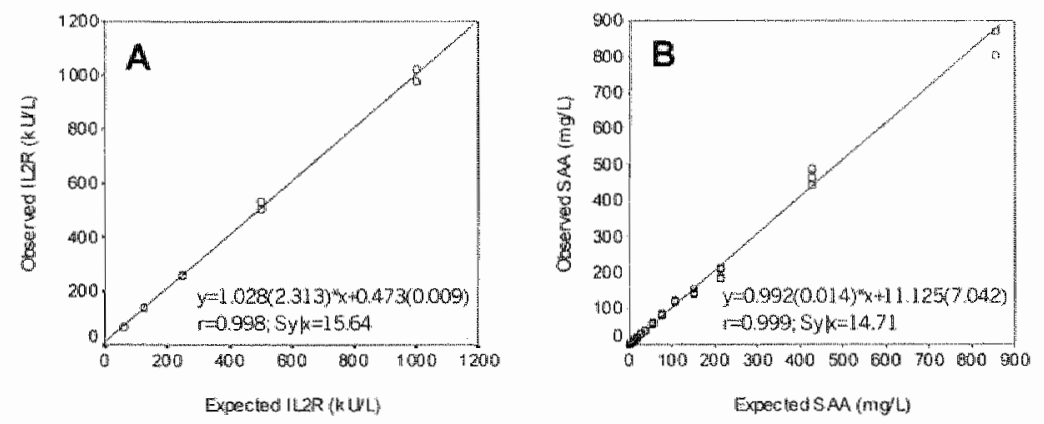

Figure 4.1. Linearity of sIL-2R (IMMULITE) and SAA (BN ProSpec) assays.

The values for each dilution point are plotted vs, expected values and linear regression was performed. Linearity results of sIL-2R IMMULITE (A) and SAA BN ProSpec (B) method are presented for the whole tested range. For $s / L-2 R$, dilution samples were run in duplicate in 2 independent experiments and the results of the one of these experiments are plotted, whereas the SAA linearity was determined in single experiment in foul replicates (SAA). The linearity equation is presented with the standard errors for the intercept and the slope within parentheses.

\section{Determination of blood donor samples}

The sIL-2R and SAA concentrations of 282 serum samples collected from apparently healthy adults are presented in Table 4.1. Overall, the median sIL-2R concentration was $448 \mathrm{kU} / \mathrm{L}$ with a 0.95 interpercentile interval of $241-846 \mathrm{kU} / \mathrm{L}$. The median SAA concentration $(0.95$ interpercentile interval) was $2.49(0.90-10.22 \mathrm{kU} / \mathrm{L})$. For sll $-2 \mathrm{R}$ no gender differences were found (Mann-Whitney $U=8665, p=0.23$ ), whereas for SAA significant gender differences were found (Mann Whitney $U=7285, p=0.013$ ) as shown in Table 4.1. Furthermore, no relationship with age was found for $s[L-2 R$ $(\mathrm{p}=0.91)$. However, the SAA showed a moderate relationship with age $(r=0.14$, $p=0.02$ ), as visible from Figure 4.2 . 


\section{Analytical performance of the two evaluated assays}

With respect to $\mathrm{sll}-2 \mathrm{R}$, the results were comparable to a previous study on imprecision and linearity ${ }^{2 !}$. As the assay performance was previously evaluated, we performed only a limited evaluation. Ledue et al reported for slL-2R concentrations of ca. $850 \mathrm{kU} / \mathrm{L}$ and $2000 \mathrm{kU} / \mathrm{L}$, between run variations of respectively $3.7 \%$ and $7.0 \%$ and within run vartations of respectively $3.3 \%$ and $5.1 \%$. In the present study, we additionally reported the imprecision for a pool with mean concentration of $193 \mathrm{kU} / \mathrm{L}$. In line with the previous study ${ }^{2 *}$, our analyses also revealed a low imprecision $(<4 \%)$.

To the best of our knowledge, this is the first study reporting imprecision and linearity results on the BN Prospec for SAA. As shown in the section Results we extensively evaluated the measuring range. Below $4.5 \mathrm{mg} / \mathrm{L}$, the imprecision (both within- and between run) was ranging from 8.9-10.7\%. However, the imprecision between $4.5-$ $821 \mathrm{mg} / \mathrm{L}$ SAA, remained below $7.4 \%$, suggesting a good performance of the assay. In an earlier study SAA was evaluated on the Behring nephelometer II (BNII), a previous generation of Dade Behring assays. The coefficients of variation (CV) found, for intraand inter-assay precision were below $5.2 \%$ and $8.5 \%$, respectively, for the three samples at concentrations representing low, normal and high ${ }^{22}$. Linearity for each method was within $5 \%$ of the expected values throughout the calibration range. These results are in agreement with our findings, suggesting that the performance of the SAA assay on the BN ProSpec is comparable to the same assay on the BNII. However, the agreement studies are needed to confirm the accordance between the methods, as shown in case of $\mathrm{CRP}^{23,24}$.

Table 4.4. Evaluation of soluble interleukin-2-receptor (sIL2R) and serum amyloid A (SAA) in blood donor samples.

\begin{tabular}{|c|c|c|c|c|c|c|c|}
\hline & \multicolumn{3}{|c|}{ sIL-2R (KU/L) $)^{\nexists}$} & \multicolumn{3}{|c|}{$\mathrm{SAA}(\mathrm{mg} / \mathrm{L})$} \\
\hline & & All & Males & Females & All & Males & Females \\
\hline Mean & & 468 & 475 & 456 & 3.22 & 2.96 & 3.60 \\
\hline $\mathrm{SD}$ & & 150 & 148 & 153 & 2.31 & 2.13 & $2.5 \%$ \\
\hline Minimuim & & 189 & 189 & 208 & 0.77 & 0.77 & 0.78 \\
\hline Maximum & & 1058 & 944 & 1058 & 13.80 & 12.20 & 13.80 \\
\hline \multirow[t]{6}{*}{ Percentiles } & 2.5 & 241 & 246 & 226 & 0.90 & 0.99 & 0.84 \\
\hline & 25 & 354 & 368 & 341 & 1.65 & 1.58 & 2.00 \\
\hline & 50 & 448 & 451 & 440 & 2.49 & 2.27 & 2.76 \\
\hline & 75 & 557 & 551 & 563 & 4.03 & 3.51 & 4.84 \\
\hline & 95 & 744 & 745 & 749 & 7.94 & 7.66 & 8.67 \\
\hline & 97.5 & 846 & 860 & 812 & 10.22 & 9.87 & 11.4 \\
\hline
\end{tabular}

sIL-2R values were quantified in $282(172$ males and 1110 females) blood donors with median age of 49 years. 

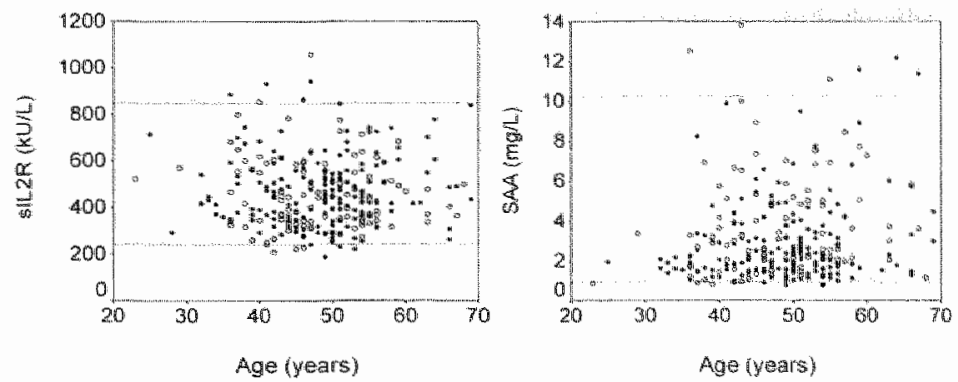

Figure 4.2. SIL-2R and SAA reference values in relation with age.

Open symbols present female values, whereas closed symbols present male values. The horizontal lines present reference walues in the whole group.

\section{Discussion}

\section{Reference values of sIL-2R and SAA}

With respect to sIL-2R we found no sex differences and no relationship with age. The latter is in accordance with a previous study in Japanese patients ${ }^{25}$. As far as we know, this is the first study reporting sIL-2R values in a large population. Previous studies, often clinical trials, all used small populations (sample size $<40$ ) to define the control group values ${ }^{26-29}$. Moreover, mostly no clear definition on the criteria used to select the control patients were given.

The reference values observed for SAA were comparable with the results of the previous studies ${ }^{22,30}$. The upper level of the reference interval (97.5th percentile) found in this study was $10.22 \mathrm{mg} / \mathrm{L}$, whereas the median value of $2.49 \mathrm{mg} / \mathrm{L}$ is slightly higher as compared to the study of Ledue $e t$ al. $^{22}$. For SAA, significant sex differences were found ( $\mathrm{p}=0.013)$, which were not reported previously. Ledue et al established reference intervals on BNII in 261 adult blood donors (aged $36.2+1-9.0$ years) with 2.5th, 50th, and 97.5th percentiles of $<0.84,2.10$ and $9.70 \mathrm{mg} / \mathrm{L}$ for $\mathrm{SAA}^{22}$. Yamada $e$ t al. reported the normal range of $0.17-10.0 \mathrm{mg} / \mathrm{L}$ with a self developed method based on the measurement of SAA by kinetic nephelometry ${ }^{30}$.

In accordance with a previous study of Ledue et al., we observed a weak relationship of SAA with age ${ }^{22}$. However, in the present study this relationship appeared to be only present in males. One could argue that the sex differences observed and the sexdependent relationship with age are simply sample related. Nevertheless, we used a large sample to establish the reference values in healthy blood-donors, in accordance to the requirements for the establishment of reference values ${ }^{31,32}$. The donor population was selected according to the criteria used by the Sanguine Blood Bank in Maastricht. The participants were asked to fill in a questionnaire consisting of questions considering the presence of acute or chronic illness or trauma, medication, pregnancy etc. Accordingly, donors meeting any of these criteria were excluded. The same reference population was used to establish the CRP reference values. The results were highly 


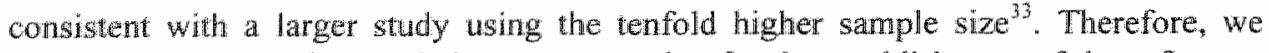
considered our sample population representative for the establishment of the reference walues.

In conclusion, evaluation of the SIL-2R method on the IMMULITE and SAA method on the BN ProSpec yielded good imprecision results and satisfying linearity. The reference values established in 282 ostensibly healthy blood donors for sIL-2R were 241 $846 \mathrm{kU} / \mathrm{L}$. Moreover, these latter values appeared to be sex and age independent. The reference walues for $\mathrm{SAA}(0.99-9.87 \mathrm{mg} / \mathrm{L}$ in males and $0.84-11.4 \mathrm{mg} / \mathrm{L}$ in females) on BN ProSpec were sex dependent and showed relationship with age. 


\section{References}

1. Nakasyana T, Sonoda S, Urano T, Yamada T, Okada M. Monitoring both serum amyloid protein A and $\mathrm{C}$ reactive protein as inflammatory markers in infectious diseases. Cin Chem 1993;39:293\%7.

2. Yamada T. Serum anyloid A (SAA) a concise review of biology, assay methods and clinical usefuness, Clin Chem Lab Med 1999;37,381-8.

3. Miwata H, Yamada T, Okada M, Kudo T, Kimura H, Morishima 'T. Serum amyloid A protein in acute viral infections. Arch Dis Child 1993;68:210-4

4. Raynes $\mathrm{JG}_{\mathrm{G}}$, Cooper EH. Comparison of serum amyloid A protein and $\mathrm{C}$-reactive protein concentrations in cancer and non-malignant disease. I Clin Pathol 1983;36:798-803.

5. De Beer FC, Mallya RK, Fagan EA, Lanham JG, Hughes GR, Pepys MB. Serum amyloid-A protein concentration in inflammatory diseases and its relationship to the incidence of reactive systemic anyloidosis. Lancet 1982;2:231-4.

6. Yang F, de Villiers WI, Lee EY, McClain CJ, Varilek GW. Increased nuclear factor-kappaB activation in colitis of interleukin-2-deficient mice. J Lab Clin Med 1999;134:378-85.

7. Niederau $\mathrm{C}$, Backmerhoff $\mathrm{F}$, Schumacher $\mathrm{B}$. Inflanmatory mediators and acute phase proteins in patients with Crohn's disease and ulcerative colitis. Hepatogastroenterology 1997;44:90-107.

8. de Villiers WI, Varilek GW, de Beer FC, Guo JT, Kindy MS. Increased serum amyloid A levels rellect colitis severity and precede amyloid formation in IL-2 knockout mice. Cytokine 2000;12:13:37-47.

9. Drent $M$, Wirnsberger RM, De Vries J, van Dieijen-Visser MP, Wouters EFM, Schols AMW, Assaciation of fatigue with an acute phase response in sarcoidosis. Eur Respir J 1999;13:718-22.

10. Salazar A, Mana J, Fiol C, Hurtado I, Argimon JM, Pujol R, Pinto X. Influence of serum amyloid A on the decrease of high density lipoprotein-cholesterol in active sarcoidosis. Atherosclerosis 2000;152:497-502.

11. Cas MT. Bulatovic G, Orlic P, Sabljar-Matovinovic M. The diagnostic capacity of serum anyloid A protein for early recognition of kidney allograft rejection. Nephrol Dial Transplant 1995:10:1901-4.

12. Hartmann A, Eide TC, Fauchald $P$, Bentdal $O$, Herbert J, Gallimore JR, Pepys MB. Serum amyloid A protein is a clinically useful indicator of acute renal allograft rejection. Nephrol Dial Transplant $1997 ; 12: 161-6$.

13. Vink A, Uyttenhove C. Wauters $\mathbb{P}$, Van Snick J. Accessory factors involved in murine $T$ cell acliwation. Distinct roles of interleukin 6, interleukin 1 and tumor necrosis factor. Eur J llmmunol 1990;20:1-6.

14. Rubin LA, Nelson DL. The soluble interleukin-2 reeeptor: biology, function, and clinical application. Ann Intern Med 1990;1 13:6.19-27.

15. Ellery JM, Nicholls PJ. Alternate signalling pathways from the interleukin-2 receptor. Cytokine Growth Factor Rev 2002;13:27-40.

16. Lawrence EC. Brousseau KP, Berger MB, Kurman CC, Marcon L, Nelson DL. Elevated concentrations of soluble interleukin-2 receptors in serum samples and bronchoalweolar tavage fluids in active sarcoidosis. Am Rev Respir Dis 1988;137.759-64

17. Ziegenhagen MW. Benner UK, Zissel G, Zabel P, Schlaak M, Müller-Quemheim I. Santicoidosis: WMValpha release from alveolar macrophages and serum level of sI L $-2 R$ are prognostic numkers. Am I Respir Crit Care Med 1997;156:1586-92.

18. Grutters JC, Fellrath J-M, Mulder L, Janssen R, wan den Bosch JMM, van Vedren-Blad H. Serum sll.21R measurement in sarcoidosis patients: a clinical evaluation. Chest 2003:124:186-95.

19.Ziegenhagen MW, Rothe ME, Schlaak $M$, Maller-Qwernheim J. Bronchoalwolar and serolugicall parameters reflecting the severity of sarcoidosis. Eur Respir $\mathrm{J} 2003 ; 21: 407-13$.

20. Rothkrantz-Kos S, van Diejen-Visser MP. Mulder PGH. Drem M. Usefulness of inflammatory markers to depict respiratory functional inpairment in sarcoidosis. Clin Chem 2003:49:1510-7.

21. Berthier F, Lambert C, Genin C. Bienveru J. Evaluation of an automated immunoassay medliod for gytokine measurement using the Immulite Immunoassay system. Clin Chem Lab Med 1999; 37.593-4).

22. Ledue TB, Weiner DL, Sipe JD, Poulin SE, Collins MF, Rifai N. Analytical evaluation of particleenhanced immunonephelometric assays for C-reactive protein, serum amyloid $A$ and mannose-binding protein in buman serum. Ann Clin Biochem 1998;35:745-53.

23. Rothkrantz-Kos S, Schmitz MPJ, Bekers O, Menheere PPCH, van Dieijen-Visser MP. High-sensitivity C. reactive protein methods examined. Clin Chem $2002 ; 48: 359-62$ 
24. Roberts WL, Moulton L, Law TC, Farrow G, Coper Anderan M, Savory J Rifai N. Evaluation of nine automated high-sensinitity C-reactive protein methods: implications for clinical and epidemiological applications. Part 2. Clin Chem $2001,47,418-25$.

25. Gotoh $Y$, Okamoto $Y$, Uemura $O$. Mori $N$, Tanaka $\$$, Ando $T$, Nishida M. Determination of agerelated changes in human solubte interleukin 2 receptor in body fuids of normal subjects as a control value against disease states. Clin Chim Acta 1996;289:89-97.

26. Jones AC, Besley $C R$, Warner JA, Warner JO. Variations in serum soluble IL-2 receptor concentration. Pediatr Altergy Immunol 1994;5:230-4.

27. Lemmer $B$, Schwelera U, Thrun A, Lissner R. Circadian rhytha of soluble interfeukin-2 receptor in healthy indiwiduals. Eur Cytokine Netw $1992,3,355-6$

28. Owens $\mathrm{O}$, Taggart $\mathrm{C}$, wilson $\mathrm{R}$, Walker $\mathrm{JJ}$, McKillop JH, Kennedy JH. Interleukin-2 receptor and ovarian cancer. Br J Cancer 1993;68:364-7.

29. MacLean MA, Wilson R, Jenkins C, Miller HA, Walker J. Interleukin-2 receptor concentrations in pregnant women with a history of recurrent miscartiage. Hum Reprod 2002;17:219-20.

30. Yamada $T$, Nomata $Y$, Sugita $O$, Okada $M$. A rapid method for measuring serum amyloid A protein by katex agglutination nephelometric immunoassay. Ann Clin Biochem 1993;30:72-6.

31. Henny I, Petitelerc C, Fuentes-Arderiu X, Petersen PH, Queralto JM, Schiele F, siest G. Need for rewisiting the concept of peference values. Clin Chem llab Med 2000;38:589-95.

32. Solberg H. Establishment and use of reference values. In: Burtis $\mathrm{CA}$, Ashwood ER, eds. Tietz textbook of Clinical Chemistry. 1994; Philadelphia, W.B. Saunders Compary :470-6.(2nd Ed.)

33. Hutchinson WL, Koenig W, Frohlich M, Sund M, Lowe GD. Pepys MB. Immunoradiometric assay of circulating C-reactive protein age-related values in the adult general population. Clin Chem 2000;469348. 


\section{Chapter 5}

\section{Usefulness of inflammatory markers to depict respiratory functional impairment in sarcoidosis}

Snježana Rothkrantz-Kos, Marja P van Dieijen-Visser, Paul GH Mulder, Marjolein Drent 


\section{Abstract}

\section{Background}

Sarcoidosis is a multiotgan inflammatory gramulomatous disorder of unknown origin for which adequate markers to monitor disease severty are lacking. The aim of this study was to evaluate the clinical usefulness of serological markers of inflammation I(high-sensitivity C-reactive protein (hs-CRP) and serum amyloid $\mathrm{A}$ (SAA)], T cell activation [soluble interleukin-2 receptor $(\mathrm{s}, \mathrm{L}-2 \mathrm{~K})$, and granuloma formation [angiotensin-converting enzyme (ACE) for monitoring pulmonary severity.

\section{Methods}

Of the 185 sarcoidosis patients who visited the Sarcoidosis Management Center between 19992002, we selected 144 non-smoking patients: 73 untreated (group I) and 71 treated (group II). Subgroups of the untreated patients lgroup la (non-chronic group with time since diagnosis $\leq 2$ years) and group $\mathrm{Ib}$ (chronic group with time since diagnosis $>2$ years)] were evaluated separately. ROC-curves and logistic regression analyses were used to compare the diagnostic accuracy of different markers to assess disease severity. Pulmonary disease severity was defined by lung function test results.

\section{Results}

In untreated subgroup la and the total untreated group (group 1), sIL-2R had the largest areas under the curves (AUCs: 0.891 and 0.799 , respectively), and the highest sensitivity ( $82 \%$ and $64 \%)$, specificity $(94 \%$ and $88 \%)$, and positive $(82 \%$ and $70 \%)$ and negative $(94 \%$ and $88 \%)$ predictive values among the evaluated markers in both untreated groups. Nevertheless, the confidence intervals for SIL-2R AUC, sensitivity, and specificity were broad and partly overlapped those of ACE, hs-CRP, and SAA. In the treated group (group II), all four markers appeared to have comparable AUCs ranging from 0.645 for $S A A$ to 0.711 for $S L-2 R$.

\section{Conclusion}

sll. $2 \mathrm{R}$ appears to be useful for monitoring respiratory disease severity in sarcoidosis. We recommend sL-2R measurement in the follow-up of patients with sarcoidosis. 


\section{Introduction}

In young adults, pulmonary sarcoidosis is the second most common respinatory disease after asthma. Sarcoidosis is a systemic granulomatous inflammatory disease that primarily affects the lungs and lymphatic system of the body ${ }^{1.2}$.

Sarcoidosis is characterized by a hyperimmune response to an unknown agent at the lesion sites ${ }^{13}$. In sarcoidosis, inflammatory stimuli generally lead to activation of monocyte-macrophages, which in turn produce cytokines, e.g., tumor necrosis factor- $\alpha$, and interleukins, e.g., interleukin-1 (IL-1) and $1 L-6^{4,5}$. As a consequence, IL- 1 and IL-6 concentrations increase and stimulate hepatic production of acute-phase proteins such as C-reactive protein (CRP) and serum amyloid A (SAA). CRP has been shown to be a rather stable marker of systemic inflammation?. Recently, Drent et $a l^{*}$, using a traditional, less sensitive CRP method, demonstrated that a moderate increase in serum CRP is implicated in sarcoidosis. High-sensitivity CRP (hs-CRP) methods have recently been introduced to accurately monitor minor increases in serum CRP ${ }^{9}$, but no studies evaluating hs-CRP in sarcoidosis have been reported. Increased SAA has also shown been shown to be independently associated with sarcoidosis activity ${ }^{\text {th }}$. SAA appears to be less sensitive to immunosuppressive drugs, such as corticosteroids, and therefore has been recommended in the follow-up of patients to whom such drugs have been administered ${ }^{6}$.

Cytokines produced by activated monocytes-macrophages, mainly $I L-\mathbb{I}$ and $I L-6$, also stimulate the production of IL2. Production of 112 leads to T cell activation ${ }^{11}$. Activated $T$ cells express an $I L-2$ receptor $(55-\mathrm{kDa} / 75-\mathrm{kDa}$ heterodimer) on their cell surface and release a soluble form of the $55 \mathrm{kDa}$ chain, the so called soluble IL-2 receptor $(\mathrm{sIL}-2 \mathrm{R})^{12}$. sIL-2R was found to be increased in patients with active sarcoidosis ${ }^{13.14}$.

In sarcoidosis, inflammation does not resolve, but leads to granuloma formation. Angiotensin-converting enzyme (ACE) is a product of granuloma (of epithelioid cells that are derivatives of the activated macrophages). Despite its shortcomings, $A C E$ is mostly used in the assessment and the follow-up of sarcoidosis ${ }^{15}$.

All of the above markers have been shown to be related to sarcoidosis activity relationships with the severity of this disease have not yet been fully established. A relationship between $s L-2 R$ and severity of sarcoidosis has recently been suggested ${ }^{16 n_{2}}$, but ROC curve analysis was lacking in both studies.

From a clinical point of view it is even more important to know whether sarcoidosis is severe, rather than active. Lung function tests provide information about the presence of respiratory functional impaiment (RFI), which is one of the indicators of disease severity ${ }^{\text {is }}$. Furthermore, RFI is one of the reasons to initiate treatment, which is aimed at preventing irreversible fibrotic changes'.

The aim of the present study was to determine the diagnostic accuracy of SIL-2R, ACE, hs-CRP, and SAA to predict the severity of pulmonary sarcoidosis, as indicated by RFI. 


\section{Materials and Methods}

\section{Study population}

Between 1999 - 2002, 185 sarcoidosis patients visited the Sarcoidosis Management Centre of the University Hospital Maastricht, a Dutch referral center for sarcoidosis. Out of these patients, 144 non-smoking patients were prospectively included in this study. The diagnosis of sancoidosis was based on consistent clinical features and bronchoalveolar lavage nuid analysis, according to the American Thoracic Society/European Respiratory Society/World Association of Sarcoidosis and other Granulomatous Disorders (ATS/ERS/WASOG) guidelines ${ }^{1 \%}$. The diagnosis was confirmed histologically in $85 \%$ of the cases. No comorbidity was present in any of these patients. Informed consent was obtained from all participants.

In sarcoidosis, spontaneous remissions without treatment can occur. For that reason, a period of observation of 2 years is justified if patient is relatively asymptomatic. Hence, sarcoidosis is generally considered chronic if present for more than 2 years ${ }^{20}$. Accordingly, subgroup analyses were performed with the untreated group divided in two groups: a subgroup with a time since diagnosis $\leq 2$ years (group Ia, non-chronic group) and a subgroup with a time since diagnosis $>2$ years (group Ib, chronic group).

To determine reference values, we collected venous blood samples (serum) from 282 ostensibly healthy blood donors presenting at the Sanguin Blood Bank in Maastricht. The Medical Ethical Committee of the Hospital approved the procedure followed.

\section{Serological measurements}

Simultaneously with lung function tests, blood samples were taken, and serum was stored at $-20^{\circ} \mathrm{C}$ until actual measurement, which occurred for all samples within 2 months after storage. In addition, frozen aliquots of control sera were always checked. No influence on the stability of the evaluated markers was found for the samples that were treated in this way.

Soluble IL-2R was determined by a two-site chemiluminescent enzyme immunometric assay (cat. no. LKIPI; Diagnostic Product Corporation) on the IMMULITE Automated. Analyzer. The detection limit of the assay in $50 \mathrm{kU} / \mathrm{L}$, and the measuring range is 50 $7500 \mathrm{kU} / \mathrm{L}$. "The within- and between run imprecision of the assay was $<7.2 \%$, and the reference interval for $\mathrm{SIL}-2 \mathrm{R}$ was $241-846 \mathrm{kU} / \mathrm{L}$.

his-CRP and SAA were measured by particle enhanced immunonephelometry on the BN Prospec (Dade Behring). The detection limit for hs-CRP is $0.175 \mathrm{mg} / \mathrm{L}$, and the measuring range is $0.175-1100 \mathrm{mg} / \mathrm{L}$, depending on dilution (N Hs CRP; cat. no OQIY 13; supplement reagent OUMU; Dade Behring). The detection limit of SAA is 3 $\mathrm{mg} / \mathrm{L}$, with a measuring range of $3-1000 \mathrm{mg} / \mathrm{L}$, depending on dilution $\mathrm{N}$ SAA reagent, cat no OQMP 11; Dade Behring). The imprecision of the SAA BN ProSpec method was $<11 \%$ and the reference interval was $0.90-1.0 .22 \mathrm{mg} / \mathrm{L}$.

Evaluation of the hs-CRP assay on the BN ProSpec has been reported previously"2. The reference interval was $0.26-7.24 \mathrm{mg} / \mathrm{L}$. 
Serum ACE (ACE) was measured by colorimetric method (cat. nr. FU 1 16; Fujirebio Inc.). ACE acts on a substrate pwydroxybenzoyl-glycyl-L-hystidyl-L-leucine and separates p-hydroxybenzoylglycine, which is converted in two subsequent reactions into quinoneimine dye. The absorbance of the quinoneimine dye is measumed at 505 nm 10 evaluate $\mathrm{ACE}$ activity. The imprecision of the $\mathrm{ACE}$ assay was $<5.6 \%$, an the reference interval for $\mathrm{ACE}$ was $9-25 \mathrm{U} / \mathrm{L}$.

The tests and the measurements in sarcoidosis patients were evaluated by one professional analyst or a $\mathrm{PhD}$ student trained by this analyst; both were blinded to the patients" histories.

\section{Evaluation of severity of Sarcoidosis Pulmonary Disease}

Chest radiographs were graded according to the radiographic staging of DeRemee (0 to III), with stage IV, the end stage of lung fibrosis, added ${ }^{1,2 ?}$.

Lung function indices, including the forced expiratory volume in $\mathbb{s}(\mathrm{FEV})$ and forced vital capacity ( $F V \mathrm{C}$ ), were measured with a pneumotachograph. The diffusing capacity for carbon monoxide (DLCO) was measured by the singlembreath method. Both measurements were performed on a Masterlab (Jaeger, Würburg, Germany). The intrasession $\mathrm{CV}$ for DLCO was $4-6 \%$, and the intersession $\mathrm{CV}$ was $9 \%$. Values were expressed as a percentage of those predicted ${ }^{23}$.

Both the radiographic staging and pneumotachography tests were performed and interpreted by two professionals who were blinded to the patients" histories.

\section{Statistical analysis}

Statistical analysis was perfomed with SPSS10.0 for Windows (SPSS). For all selected patients, non-missing and interpretable results were obtained for both the laboratory tests and the lung function tests. The distributions of the explanatory variables CRP. $S A A, A C E$, and $S I L-2 R$ were positively skewed, therefore, the data are presented as medians and interquartile ranges. A $\log$ transformation was applied to normalize the data before further analysis, if appropriate. Logistic regression was used to test the discriminatory effect of the (log-transformed) explanatory variables simultaneously by use of likelihood ratio tests. A weighted sum of explanatory variables with the estimated $\mathrm{log}$ odds ratios as weights served as linear predictor score in a ROC analysis. Areas under the ROC curves were compared using a paired nonparametric test described by DeLong et $a^{24}$. The optimal cut-off point (for the predictor) coincides with the point on the ROC curve where the sum of sensitivity and specificity was maximal. At this point the slope to the ROC curve equals unity, which is under certain conditions the result of minimization of the total costs attributable to false-positive and false-negative outcomes $^{25}$. All p-values were two-tailed, and $p<0.05$ was considered statistically significant. 


\section{Results}

\section{Definition of severity criteria and group description}

Clinical characteristics of the study group are presented in Table 5.1. Only non-smoking patients were included in the study because smoking can cause, or at least worsen, lung inflammation. Sarcoidosis patients were divided in two groups, untreated (group I) and treated (group II).

Table 5.1. Clinical characteristics of the studied sarcoidosis population $(n=144)^{*}$

\begin{tabular}{|c|c|c|}
\hline & Groulup 1 & Group II \\
\hline $\mathrm{n}$ & 73 & 71 \\
\hline Gender ${ }^{\mathrm{H}}, \mathrm{M} / \mathrm{F}$ & $33 / 40$ & $46 / 25$ \\
\hline Age, years & $40.8 \pm 11.0$ & $43.8 \pm 10.4$ \\
\hline \multicolumn{3}{|c|}{ Seralogic markers ${ }^{\circ}$} \\
\hline$\$ L-2 R^{6}, K U / L$ & $733(464-1244)$ & $584(400-832)$ \\
\hline$A C E, U / L$ & $20.0(16.0-27.0)$ & $20.0(16.0-27.0)$ \\
\hline hs-CRP, mig/L & $3.60(1.68-8.36)$ & $3.03(1.28-6.79)$ \\
\hline SAA, mg/L & $5.33(2.28-9.13)$ & $5.90(3.14-11.70)$ \\
\hline \multicolumn{3}{|c|}{ Lung function tests } \\
\hline $\mathrm{RFI}^{\circ}, \mathrm{n}(\%)$ & $22(30)$ & $39(55)$ \\
\hline $\mathrm{DLCO}^{\circ}, \%$ & $87.5 \pm 18.6$ & $82.3 \pm 18.0$ \\
\hline FVC $\%$ & $99.2 \pm 21.5$ & $91.0 \pm 20.4$ \\
\hline FEV $1 \%$ & $92.2 \pm 23.2$ & $81.7 \pm 23.1$ \\
\hline \multicolumn{3}{|c|}{ Chest radiographic staging, $n(\%)$} \\
\hline Stage $<\| I$ & $33(45)$ & $22(31)$ \\
\hline Stage $\geq 11$ & $40(55)$ & $49(69)$ \\
\hline
\end{tabular}

* Patients were selected according to the criteria described in Materials and methods: Group I, all untreated patients; Group II, all treated patients.

thac Group I vs. group It: ${ }^{\text {bi }} p<0.05 ;{ }^{\text {eq }} p<0.01$.

d Variables presented as mean (SD) follow a gaussian distribution.

a Serologic markers are presented as median with range $\left(25^{\text {th }}-75^{\text {th }}\right.$ percentiles) within parentheses.

RFI was defined as DLCO $<80 \%$, FVC $<80 \%$, or FEVI $<80 \%$ (percentage of predicted). Patients without RFI were those for whom all three indices were $\geq 80 \%$, according to standard recommendationl. A cross-tabulation of the rest results with respect to the reference standard (RFI) is presented in Figure 5.1. Treated patients appeared to have significantly lower sIL-2R concentrations compared with the untreated patients $(\mathrm{p}<0.05)$. The differences in sIL-2R between the treated and untreated group also remained significant after correction for pulmonary function tests, i.e. presence of RFI $(\mathrm{p}<0.05$ ). Moreover, $55 \%$ of the treated patients presented with RFI compared with only $30 \%$ of untreated patients $(p<0.0 \|)$.

The untreated group was further divided into two subgroups: a subgroup with time since diagnosis $\leq 2$ years (group Ia, non-chronic group) and a subgroup with time since diagnosis $>2$ years (group $\llbracket b$, chronic group). Clinical characteristics of the two subgroups are presented in Table 5.2. There was no relationship of inflammatory 
markers with time since diagnosis, but we observed significant difference in DLCO and FVC between the two groups $(\mathrm{p}<0.05)$.

\section{Diagnostic accuracy of evaluated inflammatory markers}

The ROC analysis results of the untreated and treated groups are presented in Figure 5.2. Overall, the areas under the curves (AUCs) were significantly different from the null-hypothesis, true area $=0.5$ (meaning no discrimination). In the group of untreated patients (group $1, n=73$ ), the AUC for slL $2 \mathrm{R}$ was significantly larger than the AUC for ACE $(p=0.033)$, but we found no significant differences for sIL-2R compared with hs-CRP $(p=0.236)$ or SAA $(p=0.180)$. The AUC's for hs $-C R P$ and SAA were comparable $(\mathrm{p}=\mathrm{NS})$, and athough smaller, both were not significantly different from the AUC for ACE (Figure 5.2A).

In treated patients (group $\mathrm{II}, \mathrm{n}=71$ ), the evaluated inflammatory markers had comparable AUCs, which were all $<0.720$ (Figure 5.2B). However, in all three tested groups, the AUC for sIL-2R was the largest. All ROC curves were significantly different from the $A U C$ of 0.5 .
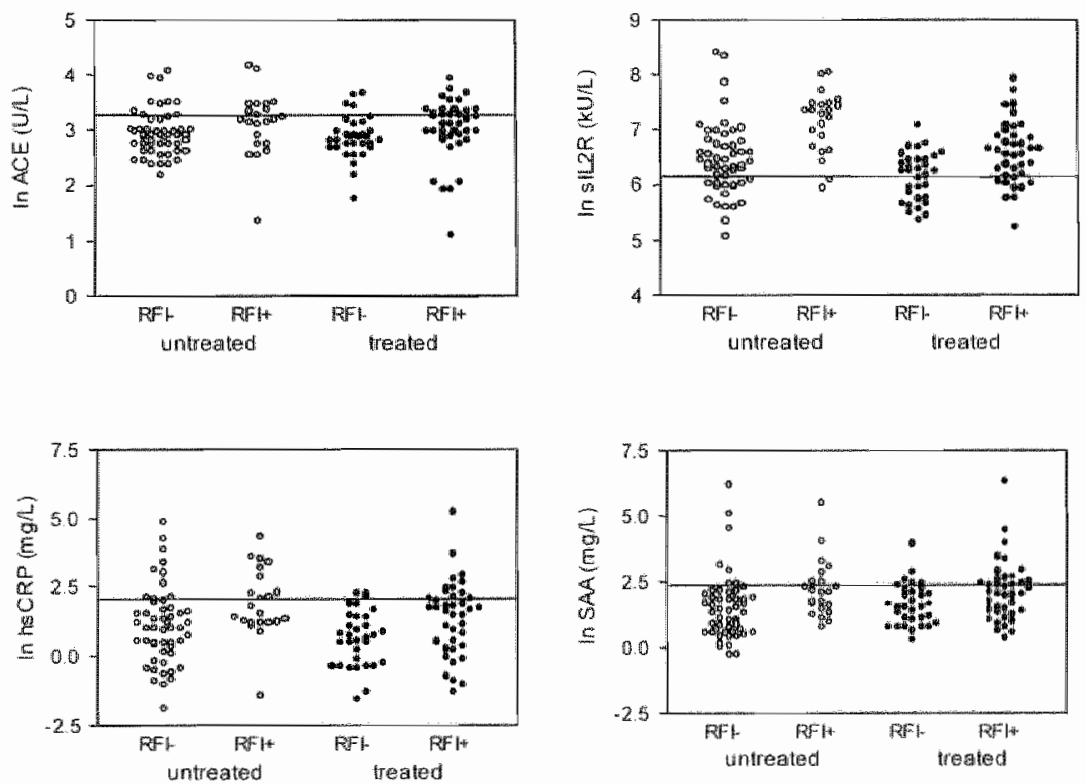

Figure 5.1. Distribution of In-transformed test results with respect to the reference standard. RFI was used as a reference standard (RFI", RFI present, RFI, RFI absent). RFI was defined as present if DLCO was $<80 \%$, or FEV 1 was $<80 \%$, or FVC wes $<80 \%$ of the predicted value and as absent if DLCO was $\geq 80 \%$, FEV 1 was $\geq 80 \%$, or FVC was $\geq 80 \%$ of the predicted value. Open circles indicate untreated patients; closed circles indicate treated patients. In each group, the horizontal tine represents the upper limit of the reference interval $\left(97.5^{\frac{1 / p}{6}}\right.$ percentile). 
In addition, the logistic regression was used to test the discriminatory effect of explanatory variables simultaneously. The various combinations of markers yielded different logistic regression models giving different linear prediction scores for the construction of AUCs.

The linear prediction score based on the combination of all four markers ylelded AUCs (SE) of $0.812(0.055)$ for group I and $0.744(0.058)$ for group II. The combinations of SIL-2R and hs-CRP, sIL-2R and SAA, and sIL-2R and ACE yielded AUCs (SE) of $0.812(0.054), 0.803(0.056)$, and $0.803(0.057)$, respectively, for group I and 0.733 $(0.059), 0.732(0.059)$, and $0.708(0.061)$ for group II. However, none of these models appeared to be significantly different from the AUCs for sIL-2R alone $[(0.799(0.058)$ for group I and $0.711(0.061)$ for group $\mathrm{m})]$.

Table 5.2. Clinical characteristics of the subgroups of untreated sarcoidosis patients $(n=73)^{3}$.

\begin{tabular}{|c|c|c|}
\hline & Group la & Group ib \\
\hline$n$ & 42 & 31 \\
\hline Gender, M/F & $21 / 21$ & $12 / 19$ \\
\hline $\mathrm{Age}^{\mathrm{B}}$, years & $41.1 \pm 11.8$ & $40.3 \pm 10.1$ \\
\hline \multicolumn{3}{|c|}{ Serologic markers ${ }^{\mathrm{C}}$} \\
\hline slL-2R, KU/L & $825(520-1437)$ & $618(454-1203)$ \\
\hline ACE, U/L & $19.5(16.0-27.0)$ & $20(14-27)$ \\
\hline$h s-C R P, m / L$ & $3.55(1.62-7.29)$ & $3.90(1.68-8.68)$ \\
\hline SAA, mg/L & $5.50(2.33-9.29)$ & $4.67(2.16-9.16)$ \\
\hline \multicolumn{3}{|c|}{ Lung function tests ${ }^{d}$} \\
\hline$R F I, n(\%)$ & $\| 1(26 \%)$ & $11(36 \%)$ \\
\hline DLCO $\%$ & $89.6 \pm 14.7$ & $84.8 \pm 22.7$ \\
\hline FVC $\%$ & $101.4 \pm 16.5$ & $96.2 \pm 26.9$ \\
\hline FEVI,$\%$ & $94.7 \pm 19.1$ & $88.8 \pm 27.8$ \\
\hline \multicolumn{3}{|c|}{ Chest radiographic stagie, $n(\%)$} \\
\hline Stage < ll & $22(53 \%)$ & $11(35 \%)$ \\
\hline Stage $\geq 11$ & $20(48 \%)$ & $20(65 \%)$ \\
\hline
\end{tabular}

a Pattients were selected according to the criteria described in Materials and methods. Group la, untreated patients with time since diagnosis $\leq 2$ years, Group $\mathrm{l} b$, untreated patients with time since diagnosis $>2$ years.

Variables are presented as mean $\pm \mathrm{SD}$, as they follow a gaussian distribution.

cThe values of serological parameters are presented as median with range $\left(25^{\text {th }}-75^{\text {th }}\right.$ percentiles $)$ within parentheses.

" $p<0.05$ for group la vis. Ib.

\section{Subgroup analysis}

The ROC results for the subgroups of untreated patients are presented in Figure 5.3 . In the gromp la (non-chronic group, $n=42)$, only sIL-2R $(p<0.0001)$ and ACE $(p<0.04)$ had an AUC significantly different from the null-hypothesis; the $p$ values for the AUCs for hS-CRP and SAA were 0.141 and 0.074 , respectively. In group Ia, the AUC for sll $-2 R$ did not differ significantly from the AUC for $A C E(p=0.111)$. 

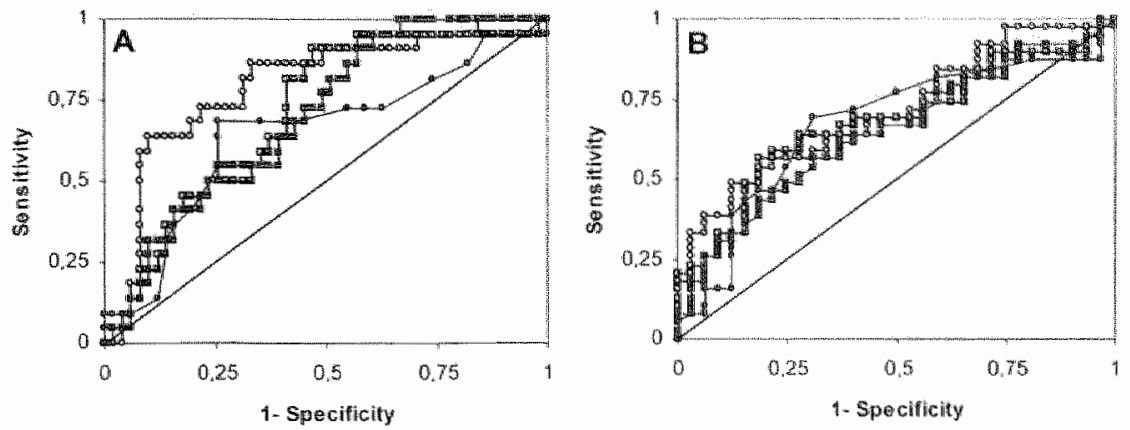

Figure 5.2. ROC curves for the inflammatory markers to determine RFI in untreated (A) and treated $(B)$ patients.

Closed circles indicate ACE, open circles siL-2R, closed squares SAA, and open squares indicate hs-CRP. The diagonal line indicates an AUC of 0.5 (no discrimination between the two states). RFI was defined as present if DLCO was $<80 \%$, FEV1 was $<80 \%$, or FCV was $<80 \%$ of the predicted value and as absent if DLCO was $\geq 80 \%$. FEV1 was $280 \%$, or FVC was $\geq 80 \%$ of the predicted value. (A). For Group I (all untreated patients), the AUCS (95\% confidence intervals) were $0.799(0.686-0.913)$ for sIL-2R, $0.650(0.504-0.795)$ for ACE, 0.708 $(0.583-0.832)$ for hs-CRP, and 0.701 $(0.580-0.821)$ for SAA. (B). For Group II (all treated patients), the AUCs (95\% confidence intervals) were $0.711(0.592-0.829)$ for silt-2R, $0671(0.541-0.801)$ for ACE, $0.681(0.556-0.806)$ for $h \mathrm{hs} \sim \mathrm{CRP}$, and $0.645(0.518-0.773)$ for SAA.

In group Ib (chronic group, $\mathrm{n}=31$ ), the AUCs for sIL-2R ( $p=0.043$ ), hs-CRP $(p=0.019)$, and SAA $(p=0.035)$ all were significantly different from the AUC of 0.5 $(\mathrm{p}<0.05)$, in contrast to $\mathrm{ACE}(\mathrm{p}=0.536)$. The data for group lb are presented in Figure $5.3 \mathrm{~B}$.

The linear prediction score based on a combination of all four markers yielded AUCs (SE) of $0.886(0.056)$ for group Ia and $0.773(0.084)$ for group Ib. The combinations of sLL-2R and hs-CRP, sIL-2R and SAA, and sll-2R and ACE yielded AUCs (SE) of $0.812(0.067), 0.889(0.055)$, and $0.880(0.058)$, respectively, for group la and 0.777 $(0.083), 0.723(0.093)$, and $0.723(0.043)$ for group lb. However, they also were not significantly different from the AUCs for SIL-2R alone $10.891(0.054)$ for group la and $0.723(0.043)$ for group Ib).

For untreated group of patients, the optimal cut-off points were defined, as were their sensitivity/specificity pairs and predictive values. The combined results are presented in Table 5.3. Somewhat overlapping sensitivity and specificity conficlence intervals were observed, but sIL-2R had the highest combination of positive and negative predictive values among the markers: $70 \%$ and $85 \%$ respectively, for group $1,82 \%$ and $94 \%$ for group la, and $67 \%$ and $84 \%$ for group $\mathrm{Ib}$. In group $\mathrm{Ib}$, however, he negative predictive values for both SAA and hs-CRP was $85 \%$ and the positive predictive value was only $50 \%$ for the chosen cut-ofts. 

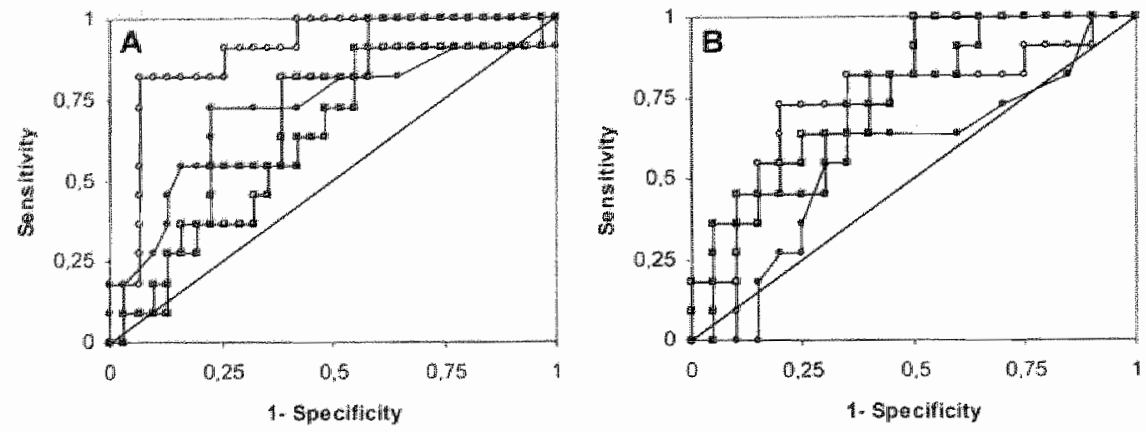

Figure 5.3. ROC curves of the inflammatory markers in untreatted subgroups of patients. Closed circles indicate ACE, open circles SIL-2R, closed squares SAA, and open squares indicate hs-CRP. The diagonal line indicates an AUC of 0.5 (no discrimination between the two states). RFI was defined as present if DLCO was $<80 \%$, FEV1 was $<80 \%$, or FCV was $<80 \%$ of the predicted value and as absent if DLCO was $\geq 80 \%$, FEV1 was $\geq 80 \%$, or FVC was $\geq 80 \%$ of the predicted value. (A). Group la (nonchronic group). AUCs (95\% confidence intervals) were $0.891(0.786-0.997)$ for siL-2R, 0.720 $(0.523-0.917)$ for ACE, $0.651(0.466-0.836)$ for hs-CRP, and $0.683(0.518-0.848)$ for SAA. (B). Group It (chronic group). ALCs (95\% confidence intervals) were 0.723 $(0.521-0.924)$ for $\$ 1 L-2 R, 0.568(0.351-0.786)$ for ACE, $0.759(0.591-0.927)$ for hsCRP, and $0.732(0.552-0.912)$ for SAA.

\section{Prognostic value of sIL-2R for untreated group of patients}

Although this study was not designed to be a prognostic study, we looked how many patients of the non-chronic untreated group, which is the most interesting for the prediction of the future outcome, were finally treated with respect to the sIL-2R values. Only 7 out of 31 patients with low sIL-2R $(\leq 1300 \mathrm{kU} / \mathrm{L})$ values, as compared to 8 out of I I patients with high sIL-2R values (>1300 kU/L) needed treatment. This indicates that $73 \%$ of the cases with high values had a less favorabie outcome companed to $23 \%$ with low sL $-2 R$ levels. 
Table 5.3. ROC curve analysis results for the inflammatory markers in retation to RFI in the untreated (sub)groups".

\begin{tabular}{|c|c|c|c|c|c|}
\hline & Selected cutoff & $\begin{array}{c}\text { Sensitivity } \\
(95 \% \mathrm{Cl}) \%\end{array}$ & $\begin{array}{c}\text { Specificity } \\
(95 \% \mathrm{Cl}) \%\end{array}$ & PPV. \% & NPW \\
\hline \multicolumn{6}{|c|}{ Group $1, n=73$} \\
\hline$A C E$ & $21 \mathrm{U} / \mathrm{L}$ & $68(45-36)$ & $75(60-86)$ & 54 & 84 \\
\hline siL-2R & $1200 \mathrm{kUNL}$ & $64(41-83)$ & $88(76-96)$ & 70 & 85 \\
\hline hs-CRP & $3.0 \mathrm{mg} / \mathrm{L}$. & $91\left(7^{1}-99\right)$ & $53(39-67)$ & 46 & 93 \\
\hline SAA & $2.5 \mathrm{mgh}$ & $96(77-99)$ & $37(24-52)$ & 40 & 95 \\
\hline \multicolumn{6}{|c|}{ Group la, $n=42$} \\
\hline $\mathrm{ACE}$ & $21 U / L$ & $73(39-94)$ & $77(59-80)$ & 53 & 89 \\
\hline slL2R & $1300 \mathrm{kU} / \mathrm{L}$ & $82(48-98)$ & $94(79-99)$ & 82 & 94 \\
\hline hns CRP & $3.5 \mathrm{mg} / \mathrm{L}^{\mathrm{f}}$ & $82(48-98)$ & $58(39-76)$ & 41 & 90 \\
\hline SAA & $8.0 \mathrm{mg} / \mathrm{L}^{\mathrm{c}}$ & $55(23-83)$ & $77(59-90)$ & 46 & 83 \\
\hline \multicolumn{6}{|c|}{ Growp $1 b, n=31$} \\
\hline$A C E$ & $21 \mathrm{mg} / \mathrm{L}^{\circ}$ & $64(30-89)$ & $70(46-88)$ & 54 & 78 \\
\hline$s \| L-2 R$ & $750 \mathrm{kU} / \mathrm{L}$ & $73(39-94)$ & $80(57-94)$ & 67 & 84 \\
\hline hs-CRP & $3.5 \mathrm{mg} / \mathrm{L}$ & $82(48-98)$ & $55(32-77)$ & 50 & 85 \\
\hline SAA & $4.0 \mathrm{mg} / \mathrm{L}$ & $82(48-98)$ & $55(32-77)$ & 50 & 85 \\
\hline
\end{tabular}

a Group I, all untreated patients; Group la, nonchronic untreated patients (time since diagnosis $\leq 2$ years); Group $\mathrm{Ib}_{\text {i }}$ chronic untreated patients (time since diagnosis $>2$ years).

b $\mathrm{Cl}$, confidence interval; PPV, positive predictive value; NPV, negative predictive value

c The AUCs of the ROC curves had wide confidence intervals (see legends of Figures 5.2 and 5.3.) and were inot significantly different from 0.5 .

\section{Discussion}

\section{Diagnostic performance of the evaluated markers}

This study evaluated the diagnostic accuracy of inflammatory markers to predict respiratory severity (RFI) in sarcoidosis. The present study provided a clear definition of the reference standard and used ROC-curves in the assessment of the test performance as proposed by Zweig er at. ${ }^{25}$. The respiratory severity was assessed by lung function test results. In the whole untreated sarcoidosis patient group as well as in the subgroups of untreated group divided according to time since diagnosis (group la, the non-chronic group, and group Ib, the chronic group), ROC curves and logistic regression analysis indicated that $\mathrm{SIL}-2 \mathrm{R}$ had the highest ability to determine pulmonary severity. Comparable ROC-curves for ACE, SAA, and hs-CRP were found in both untreated groups, independent of time since diagnosis. In the treated group (group II), all markers showed the same, weak ability to predict severity in sarcoidosis. Furthermore, their lines were far from the ideal ROC shape, giving several possible (sub)optimal cut-off points. Logistic regression analysis yielded linear predictor scores based on different combinations of markers, which were used to construct the ROC curves in the various groups, but the ROC curves of the obtained models were comparable to the sIL-2R ROC curve.

Although the sensitivity confidence intervals for $A C E$ and slL-2R were largely overlapping, positive predictive values were higher for sIL-2R than for $A C E$. In addition, the specificity confidence intervals for sLL-2R and ACE only partly 
overlapped (Table 5.2). Because these markers were correlated with each other, the Delong method (non-parametric method) was used to avoid overemphasizing the differences between the AUCs ${ }^{24}$. It could definitely be confirmed that SIL-2R was the strongest predictor of RFI in both untreated groups by means of logistic regression analysis (parametric method). These results are in agreement with results reported for previous clinical studies with comparable numbers of patients ${ }^{16.17}$. The study of Grutters et al. also suggested that extrapulmonary manifestations are accompanied by increased SIL-2R values ${ }^{7}$. Although extrapulmonary manifestations of sarcoidosis were beyond the scope of this study, this underlines the importance of $\$ I L-2 R$ in sarcoidosis.

In line with results reported by others, this study demonstrated that $\mathrm{ACE}$ concentrations have poor predictive value in sarcoidos is $16,26 \cdot 28$. The reason for its poorer performance compared with sIL-2R might, at least for a part, be explained by the fact that $A C E$ concentrations can be influenced by an $\mathrm{ACE}$ polymorphism (I/D polymorphism in intron 16 of the $\mathrm{ACE}$ gene) $)^{20,30}$. Therefore, adjustment of the reference values for the $A C E$ polymorphism has been suggested ${ }^{30,3 !}$. Nevertheless, with respect to the $A C E$ polymorphism and susceptibility to disease progression, inconclusive data have been reported ${ }^{32,33}$.

In the present study, the usefulness of hs-CRP and SAA to predict RFI in sarcoidosis was evaluated. The confidence intervals for hs-CRP and SAA sensitivity and specificity were broad and only partly overlapped with the confidence interval for sIL-2R. In addition, their positive predictive values were much lower than those of sIL-2R. These results are in agreement with a previous study, which found that the mean CRP concentrations of patients with stable or progressing disease (indicating severe disease) did not differ significantly from those in controls, in contrast to sIL-2R $\mathrm{R}^{16}$. It appears that acute-phase response, reflected througlincreased CRP and SAA concentrations, can be expected only in patients with active disease, including Löfgren syndrome ${ }^{8,10,16}$.

SAA has been shown to be less sensitive to immunosuppressive drugs (i.e., corticosteroids) and has been recommended for monitoring of patients to whom such drugs have been administered ${ }^{6}$. However, this could not be confirmed by our study. Indeed, in treated patients, all four markers had comparable, rather low, AUCs. Because corticosteroids might affect the concentrations of the markers differently, we selected only those patients who had been on treatment for at least several months. Presumably this is the only way to gather information about the usefulness of the evaluated markers to reflect RFI in patients with sarcoidosis under treatment in general. To date, ACE has not appeared to be useful in the follow-up of sarcoidosis patients during corticosteroid treatment ${ }^{4}$. Similar results were demonstrated for $51 L-2 R$, CRP, and SAA in the present study.

\section{Definition of severity}

The recommendations of the STARD group for the evaluation of diagnostic accuracy studies were followed as far as possibie in the present study ${ }^{35}$. Pulmonary disease severity is usually evaluated by lung function tests and chest radiography ${ }^{1.18}$, but there is no gold standard. In addition, there is only a weak correlation between lung function tests and chest radiographic stage ${ }^{136}$. The most common indicators of RFI are DLCO and FVC, which give information on actual state of the lungs. Both indicate mutually 
restrictive and/or obstructive pumonary function abnomalities in sareoidosis. Abnormal FVC, DLCO, and FEVI values are traditionally used as indicators for treatment in case of pulmonary involvement ${ }^{36}$.

\section{Conclusion}

In conclusion, to initiate treatment it is crucial to know whether sarcoidosis is severe, rather than actiwe. Hence, in this study, we examined whether the evaluated markers were able to predict sarcoidosis severity. Sarcoidosis severity was defined through RFI. In the untreated group of patients, $s I L-2 R$ appeared to be the best marker for predicting disease severity, whereas the traditionally used ACE appeared comparable to hs-CRP and SAA. We therefore recommend the measurement of $\mathrm{SIL}-2 \mathrm{R}$, in addition to the standard measurement of $\mathrm{ACE}$, to monitor disease severity and follow-up in sarcoidosis. 


\section{References}

1. Huminghake GW, Costakel U, Ando M, Baghman RP, Cordier JF, Du Bois RM. Eklund A, Kitaichi M, Lynch J, Rizzato $G$, Rose C. Selroos O, Semenzato G, Sharma OP. ATS ERSWWASOG statement on Sarcoidosis. American Thoracic Society/European Respiratory Society/World Association of Sarcoidosis and other Granulorwatous Disorders. Sarcoidosix Yase Diffuse Lung Dis 1999;16:149-73.

2. Baughman RP. Lower EE. Du Bois RM. Sarcoidosis. Lancet 2003;361 11111-8.

3. Shama OP, Alam S. Diagrosis, pathogenesis, and treatment of sarcoidosis. Curr Opm Pulm Med $1995,1392-400$

4. Authier FJ, Mhiri C, Chazaud B, Christow C, Cherin P, Barlovatz-Meimon G, Gherardi RK. Interleuk in-1 expression in inflammatory myopathies: evidence of marked inmunoreactivity in sarcoid grantulomas and muscle fibres showing ischaemic and regencrative changes. Neuropal hol Appl Neurobiol 1997,23:1 32-40.

5. Zheng L, Teschler H, Guzman I, Hubner K, Striz I, Costabel U. Alwcolar macrophage TNF-alpha release and BAL cell phenotypes in sarcoidosis. An J Respin Crit Care Med 1995;152:1061-6.

6. Yamada T. Serum amyloid A (SAA): a concise review of biology, assay methods and clinical usefulness. Clin Chem Lab Med 1990,37:381-8.

7. Peasson TA, Mensah GA, Alexander RW, Anderson UL, Camon RO, Criqui M, Fad YY, Fortmann SP, Hong Y, Myers GL, Rifai N, Smith SC Jr, Taubert K, Tracy RP, Vinicor F; Centers for Disease Control and Prevention; American Heart Association. Markers of inflammation and cardiovascular disease: application to clinical and public health praclice: A siatement for healtheare professionals from the Centers for Disease Control and Prevention and the American Heart Association. Circulation $2003 ; 107: 499-511$.

8. Drent M, Wirnsherger RM, De Vries ¿, van Dieijen-Visser MP, Wouters EFM, Schols AMWJ. Assocination of ratigue with an acute phase response in sarcoidosis. Eur Respir $J$ 1999:13:718-22.

9. Rothkrantz-Kos S, Schmilz MP, Bekers O, Menheere PPCH, van Dieijen-Visser MP. High-sensitivity Creactive protein methods examined. Clin Chem 2002;48:359-62.

10. Salazar A, Mana J, Fiol C, Huriado I, Argimon JM, Pujol R, Pinto X. Influence of senum amyloid A on the decrease of high density lipoprotein-eholesterol in active sarcoidosis. Asherosclerosis $2000 ; 152: 497$. 502.

11. Wink A, Uyttenhove C, Wauters $P$, Van Snick J. Accessory factors involved in murine $T$ cell activation. Distinct roles of interleukin 6, interlenkin 1 and tumor necrosis factor. Eur d hmmowol 1990:20:1 -6.

12. Kunar A, Moreau JL, Gibert M, Theze 1. Internalization of interleukin 2 (IL.2) by high affinity IL-2 receptors is required for the growth of JL-2-dependent $T$ cell lines. I Imomunot 1987:139:3680-4.

13. Agosini C, Trentin L, Facco M, Sancetta $R$, Cenuti A, Tassinari C, Cimarosto L, Adami F, Cipriani A, Zumbelo R. Semenzato C. Role of $1 \mathrm{~L}-15,11-2$ and their receptors in the development of I" cell alveollitis in pulnonary sarcoidosis. I Immunol 1996:157:910-8.

14. Huminghake $\mathrm{GW}$, Bedell $\mathrm{ON}$, zavala DC, Monick M. Brady $M$. Role of interteukin 2 release by lung Tcells in attive pulnonary sarcoidosis. Am Rev Respir Dis 1983;128:634.8.

15. Millew Quernheim I. Serum markers for the staging of disease activity of sarcoidosis and other interstitial

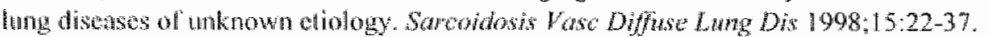

16. Ziegenhagen MW. Rothe ME, Schllatk M, Muller-Quernheim J. Bronchoalveolar and serological parameters reflecting the severity of sarooidosis. Ene Respir $J 2003: 21: 407-413$.

17. Oruters JC, Fellath J-M. Mulder L, Jathsen R, van den Boseh JMM, wan Velzen-Blad H. Senum slL2R measuremen in sarcoidosis patients: a clinical exaluation. Chest 2003:124:186-95.

18. Sath H, Gruters JC. Puntelidis P. Mizzon AN, Alomad T, Van Houte AJ, Lammers JW, van den Bosch IMM, Welsh KI. Du Bois RM. HLA-DOBi 1*0201: A Marker for Good Prognosis in British and Dutch Fratients with Sarouidosis. Am , Respir Cell Mal Biol 2002;27:406-12.

19. Drent M, Jacols JA, Cobben NAM, Costabel U. Wouters EFM, Mulder PGH. Computer program supporting the diagnostic accuracy of cellular BALF analysis: a new release. Respir Med 2001,95:781786.

20. Banglunan RP. Lower EE. The variability of sareoidosis: can we predict it? Ches 2003;123:1329-32.

21. Rothkrantz-Kos S. Bekers. O. Gubbels A, Drent M. Schmitz MPJ, van Dieijen-Visser MP. Evaluation of wo new highusensitivity CRP methods. Am Clin Biochem 2003:40:398-405. 
22. DeRemee RA. The roentgenographic staging of sarcoidosis. Historic and contemporiary perspotives. Chest 1983:83:128-33.

23. Quanjer PH, Tammeling GJ, Cotes JE, Pedersen OF, Peslin R. Yernault IC. Lung volunes and forced ventilatory flows. Report Working Pary Standardization of Lung Function Tests, European Community for Steel and Coal. Official Statement of the European Respiratory Society. Eur Respir I Suppl $1993 ; 16.5-40$.

24. DeLong ER, Delong DM, Clarke-Pearson DL. Conparing the areas under wo or more correlated receiver operating characteristic curves: a nonparametric approach. Brometric 1988:44:837-45

25. Zweig MH, Campbell G. Receiveroperating characteristic (ROC) plots: a fundamental evaluation fool in clinical medicine Clin Chem 1993:39:561-77.

26. Ziegenhagen MW, Benner UK, Zissel G, Zabel P, Schlatk M, Müler-Quemheim d. Sarcoidosis: INFalpha release from alveolar macrophages and serum lewel of $\$ 1 L-2 R$ atre prognostic makers. An J Respir Crit Core Med 1997; 156:1586-92.

27. Prior C, Barbee RA, Evans PM, Townsend PJ, Primet ZS, Fyhrquist F, Grondayen-Riska C, Haslan PL. Lavage versus serum measurements of lysozyme, angiotensin converting enzyme and other infarmatory markers in pulmonary sarcoidosis. Eur Respir J 1990;3:1146-54.

28. Ainslie GM, Poulter LW. Du Bois RM. Relation between immunocy yological features of bronchoalveolar lavage fluid and clinical indices in sarcoidosis. Thorax 1989;44:501-9.

29. Sharma $P_{n}$ Smith 1, Maguire G, Stewart S, Shneerson J, Brown MJ Clinical value of ACE genotyping in diagnosis of sarcoidosis. Lancet 1997;349:1602-3.

30. Tomita H, Ina Y, Sugiura Y, Sato S, Kawaguchi H, Morishita M, Yamamoto M. Ueda R. Polymorphism in the angiotensin-converting enzyme (ACE) gene and sarcoidosis. Am I Rexpir Crif Care Med $1997 ; 156: 255-9$.

31. Stokes GS, Monaghan JC, Schrader AP. Glenn CL, Ryan M, Morrs BI. Inlluence of angiotensin converting enzyme (ACE) genotype on interpretation of diagnostic tests for serum $A C E$ aclivity, Aust $N Z$ J Med 1999:29:315-8.

32. Pietinalho $A$, Fumya $K$, Yamaguchi $E$, Kawakami $Y$, Selroos $O$. The angiotensin-converting enzyne DD gene is associated with poor prognosis in Finnish sarcoidosis patients. Eur Respir $J 1999 ; 13: 723-6$.

33. Maliarik MJ, Rybicki BA. Malvitz E, Sheffer RG, Major M, Popovich J, Lannuzzi MC Angiotensinconverting enzyme gene polymorphism and risk of sarcoidosis. Am d Respir Crit Care Med $1998 ; 158: 1566-70$.

34. Baughman RP, Ploysongsang Y, Roberts RD, Swwastava L. Elfects of sarcoid and steroints on angiotensin-converting enzyme. Am Rev Respir Dis 1983;128:631-3.

35. Bossuyt PM, Reitsma JB, Bruns DE, Gaisonis CA, Glasziou PP, Irwig LM, Mloher D. Rernie D, de Vet HC, Lijmer JG. The STARD Statement for Reporting Studies of Diagnostic Accuracy: Explanation and Elaboration. Chin Chem 2003;49:7-18

36. Costabel U. Consensus conference adivity of sarcoidosis. Third WASOG meeting, Los Angeles, USA. September 8-11, 1993. Eur Respir 1 1994:7:624-7. 


\section{Chapter 6}

\section{The relationship between fatigue and clinical parameters in acute pulmonary sarcoidosis}

Jolanda De Vries, Snježana Rothkrantz-Kos, Marja P. van Dieijen-Visser, Marjolein Drent 


\section{Abstract}

\section{Barkiground}

Studies on the relationship between fatigue and clinical parameters are sparse. In the present study this relationshp was examined in a systematic way.

\section{Methods}

Patients with time since diagnosis $\leq 2$ years, visiting the outpatient clinic of the University Hospital Maastricht ( $\mathrm{n}=60 ; 34$ untreated, 26 treated) were clinically evaluated and completed the Fatigue Assessment Scale (FAS). A representative sample of the Dutch population $(n=1893)$ also completed the FAS. Pulmonary disease severity was estimated from lung function test results and measures of metabolic derangement. Acute phase response markers high-sensitivity C-reactwe protein (hs-CRP), serum amyloid A (SAA) and sarcoidosis activity parameters, soluble interleukin-2-receptor (sIL-2R), and angiotensin-converting enzyme (ACE) were also measured.

\section{Results}

Only $27 \%$ of the sareoidosis patients were diagnosed as non-fatigued (FAS score $<22$ ), compared to $80^{\circ} \%$ in the control population $(n=1893)$. In the sarcoidosis patients no sex differences and no differences in fatigue scores between the treated and the untreated groups were found. Patients with fatigue (FAS-score $\geq 22$ ) had lower DLCO values $(p<0.05)$. However, none of the tested clinical or serological parameters appeared to be a significant predictor of fatigue.

\section{Conclusion}

In the present study, it was confrrmed that fatigue is a major problem in sarcoidosis. The extent of fatigue could not be explained by clinical parameters. Thus, up to now, no clinical or physiological variable seems useful in predicting which patients are fatigued. In this light, the Fatigue Assessment Soale might be considered as a supplementary tool in sarcoidosis. 


\section{Introduction}

Sarcoidosis is a disorder of unknown origin most frequently occurring in the lung. Although sarcoidosis occurs worldwide, the prevalence and the course of the disease vary across countries and ethnic group. In the Netherlands the prevalence is estimated to be $40-50 / 100000^{2}$.

Clinical manifestations of sarcoidosis depend on the intensity of the inllammation and organ systems affected. Pulmonary sarcoidosis may present itself in a variety of ways with symptoms related directly to the chest such as coughing, dyspnea on exertion, retro-sternal chest pain, chest discomfort, and wheezing ${ }^{3,4}$. Furthermore, fatigue, arthralgia, and erythema nodosum are common features of sarcoidosis, which vary however, across countries ${ }^{4-7}$. Fatigue appeared to be a major problem in 30 to 90 per cent of the patients ${ }^{3,3,-15}$. This fatigue can be substantial and persistent ${ }^{3-5,9,10,12,14,15}$. Fatigue is disabling for the patient, causes an impaired quality of life (QOL), and may become chronic ${ }^{16}$. In a study among 64 sarcoidosis patients, even patients who did not suffer from fatigue had an impaired QOL compared to healthy persons. However, patients who reported fatigue had the most impaired quality of life $\mathrm{e}^{\mathrm{is}}$. In addition, fatigue is a predictor of depressive symptoms ${ }^{17.18}$ as well as of pain? ${ }^{7}$. Because of the capacity of fatigue to cause impaired QOL, it is important to measure and study fatigue.

An acute phase response evidenced by moderate increase of the C-reactive protein (CRP) level was found in sarcoidosis patients who suffered from fatigue and other related symptoms ${ }^{12}$. Besides, in the same study, a presence of metabolic derangement was shown to be related to fatigue and to the CRP concentrations. In line with this, a relation between elevated CRP concentrations and fatigue was demonstrated in rheumatoid arthritis, Crohn's disease, and ulcerative colitis patients ${ }^{19}$.

Nowadays more sensitive parameters have been introduced to monitor inflammation such as high-sensitivity C-reactive protein (hs-CRP) and serum amyloid A (SAA). Besides, a new questionnaire has been developed, allowing to measure fatigue in sarcoidosis patients more in-depth ${ }^{20,21}$, as compared to the single item fatigue question and the facet Energy and Fatigue of the WHOQOL-100 questionnair", used previously ${ }^{15}$. Therefore, the aim of this study is to examine whether the more sensitive measures used to monitor inflammation can be used to explain fatigue in patients with acute manifestations of pulmonary sarcoidosis.

\section{Materials and Methods}

\section{Participants}

From January 2000 to October 2002,60 (34 untreated and 26 treated) patients who visited the outpatient clinic of the University Hospital Maastricht, a referral center for sarcoidosis, with a time since diagnosis of $\leq$ two years ("acute" sarcoidosis patients) were included in this study. Patients were diagnosed with sarcoidosis based on consistent clinical features and bronchoalveolar lavage (BAL) fluid analysis results, according to the WASOG guidelines. Comorbidity was defined as any medical problem 
not related to satcoidosis. Disorders or conditions considered as comorbidity included cardiovascular disease, thyroid disease, diabetes, anemia, cancer, muscle weakness and immobility due to musculo-skeletal disorders. Extrapulmonary localisations of sarcoidosis were not considered as comorbidity but as sarcoidosis related. None of the patients had any significant medical history or co-morbidity.

Informed consent was obtained from all participating patients. A control group of persons also completed the fatigue questionnaire. This group, comprising of 1893 persons, was a representative sample of the Dutch population ${ }^{20}$. They completed a computer-administered questionnaire. The respondents of the latter sample were all inwolved in an internet-based panel. Every week this panel received a questionnaire directly on their personal computer. With regard to the demographics of the reference sample, there were 1128 males and 765 females and the mean age of the reference sample was $44.7(\mathrm{SD}=15.3$; range $16-87$ ). This sample was not analyzed as part of this study but was used as a reference group.

\section{Lung function testing}

Lung function measurements, including forced expiratory volume in one second (FEV1) and forced vital capacity (FVC), were measured with a pneumotachograph. The diffusing capacity for carbon monoxide (DLCO) was measured by the single-breath method (both Masterlab, Jaeger, Wirzburg, Germany). Values were expressed as a percentage of those predicted ${ }^{22}$.

\section{Chest radiographs}

Chest radiographs were graded according to the radiographic staging of DeRemee (0 to III), adding stage IV, the end stage of lung fibros $1 \mathrm{~S}^{3,23}$. A radiologist, blinded to the patient's history, performed all interpretations.

\section{Serum markers}

Simultaneously with lung function tests and fatigue assessment, blood samples were taken and serum was stored at $-20^{\circ} \mathrm{C}$ until actual measurement of inflammatory markers. Serum IL2 receptor (sIL-2R) was determined on the IMMULITE Automated Analyser, by means of a two-site chemiluminescent enzyme immunonetric assay, with a detection limit of $50 \mathrm{kU} / \mathrm{L}$, and a measuring range $50-7500 \mathrm{kU} / \mathrm{L}$ (Diagnostic Product Corporition, Los Angeles, CA, cat no LKIPI). The imprecision of the assay (both within- and between run) appeared to be below $7.20 \%$. The reference range for sIL-2R was $241-846 \mathrm{kU} / \mathrm{L}$.

Hs CRP and SAA were determined by particle-entranced immunonephelometry, on the BN Prospec from Dade Behring. The detection limit for hs-CRP was $0.175 \mathrm{mg} / \mathrm{L}$ and the measuring range was $0.175-1100 \mathrm{mg} / \mathrm{L}$, depending on the dilution (Dade Behring, Liederbach Germany N Hs CRP, cat no OQIY 13; supplement reagent OUMU).

The detection limit of SAA was $3 \mathrm{mg} / \mathrm{L}$, with a measuring range of $3-1000 \mathrm{mg} / \mathrm{L}$, depending on the dilution (Dade Behring, Liederbach Germany, N SAA reagent, cat no OQMP 11). 
The imprecision of the SAA BN ProSpec method appeared to be below 10.7\%. The reference values were $0.90-10.22 \mathrm{mg} / \mathrm{L}$.

Evaluation of the hs-CRP assay on the BN ProSpec was reported prewously. Reference values were $0.26-7.24 \mathrm{mg} / \mathrm{L}^{24}$.

Serum ACE (ACE) was measured by a colorimetric method (Fujirebio Ino. Tokyon Japan, cat. nr. FU 116). ACE acts on a substrate p-hydroxybenzoyl-glycyl-L-hystidyl-Lleucine and separates p-hydroxybenzoyl-glycine, which is converted in two subsequent reactions in quinoneimine dye. To evaluate the $\mathrm{ACE}$ activity, the absorbance of quinoneimine dye is measured at $505 \mathrm{~mm}$. The imprecision of the $\mathrm{ACE}$ assay appeared to be bellow $5.6 \%$. Reference values of $\mathrm{ACE}$ were $9-25 \mathrm{U} / \mathrm{L}$.

\section{Metabolic measures}

Body composition was measured by single frequency bioelectrical impedance analysis (RJL systems, Detroit, USA) in the supine position on the riglt side. Fat-free mass (FFM) was calculated from [(height $)^{2} /$ resistance] and body weight using the Lukaski formula. Resting energy expenditure (REE) was measured after an overnight fast under standardized conditions ${ }^{25}$ by indirect calorimetry using a ventilated hood (Oxycon beta, Mijnhardt, Bunnik, The Nederlands). REE was adjusted for FFM and gender, by analysis of covariance ${ }^{26}$.

\section{Questionnaire}

The Fatigue Assessment Scale (FAS) ${ }^{20,21}$ was used to measure latigue (Appendix). This questionnaire consists of ten questions. The response scale is a 5 -point scalle (1 never to 5 always). Scores on the FAS can range from 10 to 50 . The psychometric properties are good also in sarcoidosis. Moreover, the FAS appeared to be unidimensional in a large sarcoidosis population ${ }^{20,21}$.

Table 6.1. Demographics data of the evaluated sarcoidosis patients.

\begin{tabular}{|c|c|c|c|}
\hline Variables & Total group & Untreated patients & Treated patients \\
\hline Number of cases & 60 & 34 & 26 \\
\hline Sex: malelfemalle & $31 / 29$ & $15 / 19$ & $16 / 10$ \\
\hline Age $^{*}$, years & $\begin{array}{c}40.8 \pm 10.4 \\
(19-66)\end{array}$ & $\begin{array}{c}40.3 \pm 10.5 \\
(23-66)\end{array}$ & $\begin{array}{c}41.5 \pm 10.5 \\
(19-58)\end{array}$ \\
\hline $\begin{array}{l}\text { Time since diagnosis }{ }^{a} \text {, } \\
\text { months. }\end{array}$ & $\begin{array}{r}10.2 \pm 9.6 \\
(0-24)\end{array}$ & $\begin{array}{r}8.9 \pm 9.0 \\
(0-24)\end{array}$ & $\begin{array}{c}12.0 \pm 10.2 \\
(0-24)\end{array}$ \\
\hline Smoking: nolyes ${ }^{b}$ & $53 / 7$ & $27 / 7$ & 26.10 \\
\hline
\end{tabular}

a The data are presented as mean \pm standard deviation with range in parentheses.

${ }^{b}$ Significant difference $(p<0.01)$ between the treated and untreated patients.

The cut-off score of the FAS (22) was derived from two large representative samples of 1) the Dutch working population and 2) the general population. In both samples, $80 \%$ of the participants had a FAS score below $22^{27}$. In addition, this result was compared with other fatigue measures such as the emotional exhaustion subscale of the Dutch Maslach Bumout Inventory (UBOS) ${ }^{28}$ to verify the appropriateness of the found FAS cut-off score. 
In a large study among 1046 sarcoidosis patients, the FAS appeared to be a unidmensional scale. The content validity (factor analysis and mokken scale analysis), construct validity (factor analysis comparing with the Beck Depression Inventory), and internal consistency (Cronbach's alpha) of the FAS were good. The test-retest reliability was $0.89^{20,21}$. A change in score of 5 or more is considered clinically significant (minimal clinical difference for score to be significant).

Patients also conpleted the Bath Breathlessness Scale (BBS) ${ }^{29}$. This is a 35-item adjective subjective breathlessness (dyspnea) scale measuring four aspects of breathlessness. In addition, patients can be asked to indicate on an 8-point response scale (range 0 to 7 ) how breathless they felt during the last two weeks. In the present study, only the question about perceived severity of breathlessness was used.

\section{Statistical Analysis}

For all of the selected patients non-missing and interpretable results were obtained for the laboratory tests, lung function tests, metabolic derangement measures and the FAS. The comparison between the sarcoidosis group and the reference sample, was performed by means of one sample t-tests. The distributions of the explanatory variables CRP, SAA, ACE and SIL-2R were positively skewed. Therefore, the data are presented as median with interquartile range. Patients were divided into two groups: non-fatigued (FAS score $<22$ ) and fatigued (FAS score $\geq 22$ ). Differences between the fatigued and non-fatigued groups wete tested by means of Student t-tests or Mann-Whitney $U$ test, depending on the distribution (normal or skewed) of the tested (explanatory) variables, i.e. serum markers, metabolic derangement measures and lung function test results.

A $\log$ transformation ( $\ln$ ) was applied to normalize the data prior to further analyses. First, the relationship between fatigue (as continuous variable) and the laboratory parameters was examined by means of Pearson correlations. Second, univariate logistic regression was used to test the discriminatory effect of each explanatory variable with regard to being fatigued or non-fatigued. Finally, multivariate logistic regression was used to assess simultaneously the effect of the three clinical parameters with the lowest $p$-values from the univariate analyses. The lung function test results were firstly treated as continuous wariables and thereafter the values were dichotomized (the abnomal values were considered those with the \%predicted of $<80 \%$ ). The metabolic derangement measures were treated as continuous variables. The hs-CRP, CRP, SAA, $\$ I L-2 R$ and $A C E$ levels were not treated as continuous variables in the logistic regression analyses, but were dichotomized. The reason was that the distribution of the data was highly skewed and all levels below the lower detection limit of these assays were recorded the lower detection limit value. As the upper reference limit can be influenced by the presence of some subclinical inflammation and, therefore gives outliers, the values of the $90^{\text {th }}$ percentile of the reference values were used to dichotomize the laboratory parameters. The likelihood ratio tests (-2 LL) were used. All $p$-values were wo-tailed and $p<0.05$ was considered statistically significant. Statistical analyses were performed using the SPSS10.0 for Windows (SPSS, Chicago, IL, USA). 


\section{Results}

\section{General and clinical characteristics of sarcoidosis patients}

General characteristics of sarcoidosis patients $(n=60)$ are presented in Table 6.1. In the group of untreated patients $(n=34)$ there were 7 smokers $(20.6 \%)$, while all patients of the treated group $(n=26)$ were non-smokers.

Clinical characteristics of the patients are presented in Table 6.2. With respect to lung function data, the FEVI $(p<0.01)$ and FVC $(p<0.05)$ values appeared lower in the treated group as compared to the untreated group. No differences in radiographic staging or the DLCO between the two groups were found. Also, with regard to serological data and the metabolic derangement measures, no differences were observed between the treated and untreated group.

The perceived severity of dyspnea was also assessed. During the previous two weeks prior to the study, the sarcoidosis patients had a mean score of $3.28(\mathrm{SD}=1.71)$ on a possible range of 0 to 7 . This score represents a moderate level of dyspnea. Compared with a group of idiopathic pulmonary fibrosis patients from a previous study (mean $=3.80, \mathrm{SD}=2.0)^{30}$ the sarcoidosis group scored significantly but not extremely lower.

Table 6.2. Clinical characteristics of the sarcoidosis patients.

\begin{tabular}{|c|c|c|c|}
\hline Variables & $\begin{array}{l}\text { Total group } \\
(n=60)\end{array}$ & $\begin{array}{l}\text { Untreated patients } \\
\qquad(n=34)\end{array}$ & $\begin{array}{l}\text { Treated patients } \\
\qquad(n=26)\end{array}$ \\
\hline \multicolumn{4}{|l|}{ Lung function tests ${ }^{c}$} \\
\hline DLCO & $87.6 \pm 17.3$ & $90.1 \pm 13.4$ & $84.2 \pm 21.4$ \\
\hline FEV $\|^{\text {b }}$ & $90.1 \pm 22.6$ & $94.2 \pm 18.4$ & $84.8 \pm 26.5$ \\
\hline $\mathrm{FVC}^{\mathrm{a}}$ & $99.0 \pm 20.2$ & $102.3 \pm 16.14$ & $946 \pm 24.3$ \\
\hline \multicolumn{4}{|l|}{ Radiographic stages } \\
\hline $0 / / / 1 / 1 / 1 / 1 / \mathrm{V}$ & $14 / 15 / 11 / 18 / 2$ & $6 / 11 / 8 / 9 / 0$ & $B / 4 / 3 / 9 / 2$ \\
\hline \multicolumn{4}{|l|}{ Serological parameters ${ }^{\text {d }}$} \\
\hline$A C E(U / L)$ & $21.0(17.0-30.0)$ & $21.0(17.0-31.0)$ & $22.0(18.0-31.0)$ \\
\hline $\mathrm{CRP}$ (mg/L) & $9.0(5.0-15.0)$ & $3.7(1.4-12.7)$ & $3.8(1.3-8.5)$ \\
\hline hs-CRP (mg/L) & $3.5(1.3-10.5)$ & $7.0(2.0-15.3)$ & $10(6.0-15.5)$ \\
\hline SiAA (mg/L) & $6.3(3.3-11.7)$ & $5.9(2.6-11.1)$ & $6.9(4.0-11.8)$ \\
\hline sll $-2 R(k \cup / L)$ & $711(405-1066)$ & $737(427-1269)$ & $697(454-865)$ \\
\hline \multicolumn{4}{|c|}{ Metabolic derangement measures } \\
\hline REE (kcal/24h) & $95.9 \pm 10.1$ & $94.7 \pm 11.7$ & $97.5 \pm 7.5$ \\
\hline REE/FFM (kcal/kg FFM) & $31.0 \pm 4.5$ & $30.8 \pm 4.9$ & $31.3 \pm 4.1$ \\
\hline \multicolumn{4}{|l|}{ Fatigue measure } \\
\hline \multirow[t]{2}{*}{ FAS score } & $27.5 \pm 8.6$ & $25,7 \pm 9,0$ & $29.7 \pm 7.7$ \\
\hline & $(10-48)$ & $(10-45)$ & $(13-48)$ \\
\hline
\end{tabular}




\section{Evaluation of the FAS (fatigue) score}

The whole patien group $(\mathrm{n}=60)$ had a mean FAS score of $27.5(\mathrm{SD}=8.6)$, whereas the reference group $(\mathrm{n}=1893)$ had a mean score of $18.0(\mathrm{SD}=5.7)(\mathrm{t}=-8.51, \mathrm{p}<0.001)$. Only $27 \%$ of sarcoidosis patients had a FAS score $<22$ (mean $\pm \mathrm{SD}: 17.1 \pm 3.6$ ), compared to $80 \%$ in the control population.

Table 6.3. shows that the difference between both groups on the total FAS score reflects substantial differences for each individual item. In each instance, the sarcoidosis patients are more fatigued than the reference group. The onlly exception is question 10 ("When I am doing something I can concentrate quite well"). As this question is not recoded, a high score on this question indicates a low score for fatigue. In other words the reference group has more problems with staying concentrated.

In sarcoidosis patients, no sex differences were found with respect to the FAS score. In contrast, in the control group females had higher fatigue scores as compared to males. $(t=-6.1, p<0.001)$. No differences in fatigue scores between the treated and the untreatted groups were found (Table 6.2).

Table 6.3. A comparison between the sarcoidosis group and the reference group at the FAS item level.

\begin{tabular}{lccc}
\hline Question/ltem & Sarcoidosis patients $^{\mathrm{a}}$ & Reference group $^{\mathrm{a}}$ & t-value $^{\mathrm{b}}$ \\
\hline 1 & $3.53 \pm 1.19$ & $2.13 \pm 0.88$ & 9.17 \\
2 & $3.47 \pm 1.21$ & $1.90 \pm 0.94$ & 10.0 \\
3 & $2.75 \pm 1.20$ & $1.78 \pm 0.87$ & 6.25 \\
$4^{\circ}$ & $2.62 \pm 1.19$ & $3.74 \pm 1.14$ & -7.28 \\
5 & $2.92 \pm 1.12$ & $1.72 \pm 0.79$ & 8.24 \\
6 & $2.43 \pm 1.13$ & $1.79 \pm 0.81$ & 4.43 \\
7 & $2.10 \pm 1.07$ & $1.47 \pm 0.67$ & 4.57 \\
8 & $2.40 \pm 1.11$ & $1.77 \pm 0.72$ & 4.41 \\
9 & $2.15 \pm 0.99$ & $1.48 \pm 0.71$ & 5.25 \\
$10^{\circ}$ & $3.67 \pm 1.13$ & $1.72 \pm 0.79$ & 13.34 \\
\hline
\end{tabular}

"The data are presented as mean \pm standard deviation.

"p $<0.001$ for each of the then items, between the sarcodosis group and reference group.

These questions are not recoded, meaning that a high score reflects low score for fatigue.

\section{FAS score in relation to clinical data}

Since with regard to the laboratory parameters, metabolic derangement measures, radiographic staging and lung function data (except for FVC and FEVI) no differences were observed between the treated and untreated groups (Table 6.2), grouping of the data was allowed. Figure 6.1 shows the distribution of the clinical data in fatigued and non-fatigued groups in respectively untreated and treated groups of patients. 

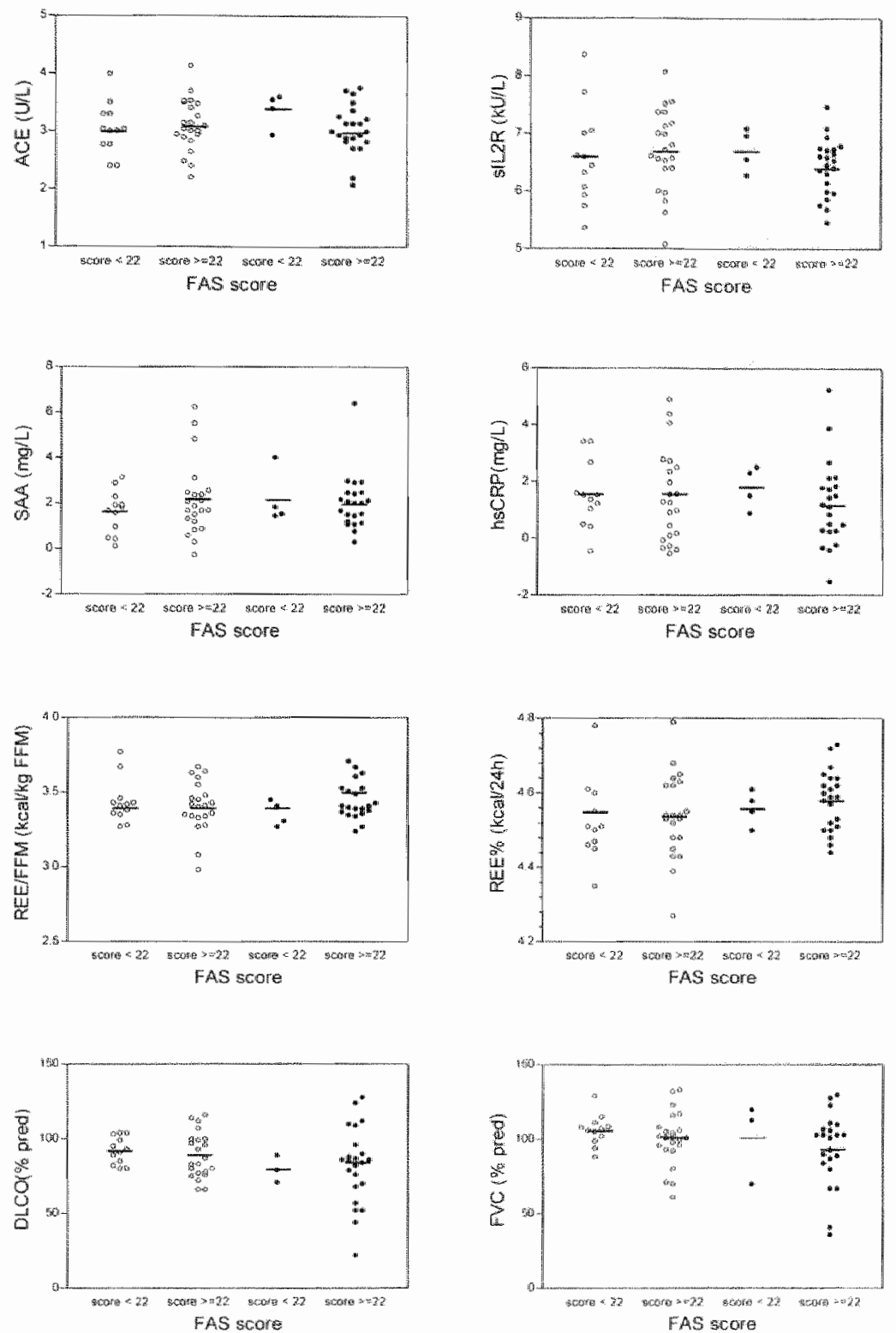

Figure 6.1. Scatter of serological parameters and metabolic derangement measures.

Patients were divided into two groups with respect to their FAS score. The group with fatigue had a FAS score $\geq 22$, whereas group without fatigue had a FAS score $<22$. The horizontal line represents the mean values of the (logarithmic transformed, except for the DLCO, FEV1 and FVC) data, divided according to treatment.

Open circles indicate untreated patienis, whereas closed circles indicate with prednison treated patients. For the DLCO and FVC there was one missing case in treated non. fatigued group 
These results further suggest that prednisone treament at the moment of "sampling" probably had no influence on the results of clinical or serological tests (Figure 6.1). Therefore, for the further evaluation of the FAS score with respect to clinical data, patients were divided into two groups: the group without fatigue (total FAS-score <22) and the group with fatigue (total FAS score $\geq 22$ ).

Patients with fatigue (FAS-\$core $\geq 22$ ) had lower DLCO values $(\mathrm{p}<0.05$ ). However, with regard to FEV, FVC and the radiographic staging no differences between the fatigued and non-fatigued groups were observed. Also regarding laboratory parameters and metabolic derangement measures no significant differences between fatigued and non-fatigued groups were present.

Among the laboratory markers, only sIL-2R and SAA correllated with the metabolic derangement measures $(\mathrm{p}<0.05)$. The sIL-2R correlated with $R E E \%(r=0.30$, $p=0.023)$, whereas SAA correlated with REE/VVM $(r=0.31, p<0.02)$. sIL-2R and SAA correlated also with each other $(r=0.39, p<0.01)$. sIL-2R appeared to correlate with $A C E$ to a large extent $(r=0.60, p<0.0001)$.

\section{Prediction of fatigue (FAS-score $\geq 22$ ) using clinical data}

First., a serie of univariate logistic regression anallyses was completed. Table 6.4. showis the odds ratios with their corresponding confidence intervals. As can be seen from the Table 6.4, no statistically significant predictors were found. For each single variable the analyses were repeated correcting for prednisone use (data not shown).

Table 6.4. Prediction of fatigue assessed by Fatigue Assessment Scale (FAS) by clinical data in patients with acute pulmonary sarcoidosis.

\begin{tabular}{|c|c|c|c|c|}
\hline Variables & $\begin{array}{l}\text { Univariate } \\
\text { OR }(95 \% \mathrm{Cl})\end{array}$ & p-value & $\begin{array}{l}\text { Multivariate } \\
\text { OR }(95 \% \mathrm{Cl})\end{array}$ & $p$-value ${ }^{\circ}$ \\
\hline \multicolumn{5}{|l|}{ Prednison use } \\
\hline Yes & $3.0(0.8-10.8)$ & 0.078 & $2.7(0.7-10.0)$ & \\
\hline \multicolumn{5}{|l|}{ Severity of disease ${ }^{a}$} \\
\hline RFI Present & $2.4(0.6-7.5)$ & 0.249 & $1.3(0.3-5.4)$ & \\
\hline \multicolumn{5}{|c|}{ Presence of hypermetabolism } \\
\hline REE & $1.0(1.0-1.1)$ & 0.852 & & \\
\hline REE/FFM & $1.0(0.9-1.2)$ & 0.827 & & \\
\hline \multicolumn{5}{|l|}{ Serum markers ${ }^{b}$} \\
\hline ACE $>24.4 \mathrm{U} / \mathrm{L}$ & $0.7(0.2-2.1)$ & 0.495 & & \\
\hline SILL-2R $>685 \mathrm{kU} / \mathrm{L}$ & $1.0(0.3-3.2)$ & 0.969 & & \\
\hline$S A A>6.9 \mathrm{mg} / \mathrm{L}$ & $3.0(0.8-10.8)$ & 0.078 & $26(0.6-10.0)$ & \\
\hline $\mathrm{hs} \mathrm{CRP}>5 \mathrm{mgh}$ & $0.9(0.2-3.3)$ & 0.860 & & \\
\hline $\mathrm{CRP}>5 \mathrm{mg} / \mathrm{L}$ & $1.3(0.4-4.3)$ & 0.712 & & \\
\hline
\end{tabular}

"Severity of disease. RFI Present, if DLCO $<80 \%$ or FEV $1<80 \%$ or FVC $<80 \%$. RFI absent if all of these parameters $\geq 80$.

18 The serum markers were dichotomised according to the goth percentile of the reference values.

c The pwalue in the multivariate analysis is for the prediction of fatigue by the SAA, corrected for prednisone use and the presence of respiratory functional impairment.

The p-values correspond to the -2LL test in the respectively univariate or multivariatie analysis. 
However, no significant results were obtained. The three variables with the lowest $p$ values from the univariate analysis: prednisone use $(\mathrm{p}=0.078)$, presence of respiritory functional impairment $(p=0.249)$ and the SAA values $(p=0.078)$ were used in the multivariate logistic regression analysis. However, no signilicant model conld be obtained $(\mathrm{p}=0.163)$.

\section{Discussion}

The present study clearly showed that fatigue is a major problem in sarcoidosis. Seventy-three percent of the sarcoidosis patients were fatigued. compared with $20 \%$ in the control population. No differences were found in fatigue scores between the treated and the untreated group and between male and female patients. The prednisone treatment at the moment of 'sampling' appeared not to have influence on the results of clinical or serological tests, which allowed for the grouping of the patients. Subsequently, patients were divided with respect to the FAS score in the fatigued and non-fatigued groups. The fatigued patients tended to have decreased lumg function test results, although only the DLCO $(\mathrm{p}<0.05)$ appeared to be significantly decreased. With regard to radiographic staging no differences between the groups conceming fatigue were observed. With respect to serological data and netabolic derangement measures patients with fatigue tended to have increased values, albeit not significantly. The serological parameters SAA and sIL-2R correlated well with metabolic derangement measures, whereas ACE, CRP, and hs-CRP showed no relationship with metabolic derangement measures. Among the clinical parameters, none of the explanatory variables were able to predict whether patients were fatigued or not and no combined model could be found.

\section{Fatigue}

Compared with a representative sample, the sarcoidosis patients had much higher fatigue scores. The finding that fatigue is a major problem in sarcoidosis is in accordance with previous studies ${ }^{3-58-15}$. However, besides the fact that the faligue was assessed by means of a more appropriate questionnaire, this was the first time that fatigue scores in sarcoidosis patients were compared with a healthy population. Another study that used the FAS, examined a large group of Dutch persons working at least 20 hours per week $(n=765)^{2 i}$. In the latter study about $80 \%$ of the persons from the working population sample thad a FAS score of $<22$, comparable to the control sample used in the present study. This emphasizes the large difference with the sarcoidosis. population and provides a further underpinning of the severity of fatigue in satcoidosis. The present study differs from the previous studies in the way the fatigue was assessed. In this study, a fatigue questionnaire (FAS) was used. In the other studies, fatigue was measured with a single dichotomous (yes/no response) fatigue question. The FAS provides information on the severity of fatigue instead of merely presence or absence of fatigue. Furthermore, it is known that single items as used in previous studies are less reliable ${ }^{3 !}$. 


\section{Fatigue in relation to clínical data}

In disorders like COPD it was appreciated that, at least in part, in hypermetabolic patients the resting energy expenditure (REE) was attributed to the level of the systemic inflammation ${ }^{2532}$. The study of Drent $e$ al. indicated that an acute phase response (reflected through increased CRP values), in combination with metabolic derangement (reflected through increased REE) might provide some insight into fatigue in sarcoidosis $^{12}$. Even those cases without signs of pulmonary involvement appeared to have increased REE values"? Therefore, assessment and inclusion of REE (corrected or not for the fat-free mass, FFM) was considered to have an additional value in the management and follow-up of sarcoidosis patients. For that reason, clinical data indicating lung function and metabolic derangement together with serological data were used to see whether a combined model could be found that was able to predict fatigue.

Among all the tested markers, SAA was the strongest $(p=0.078$ (Table 6.4.), if corrected for prednison use, $\mathrm{p}=0.108$ ) but non-significant positive univariate predictor of fatigue. The lack of significance at 0.05 level might be due to the fact that the present sample size was too small. Therefore, a careful interpretation of this result is needed. In fatigue, the concentration of brain 5-hydroxytyptamine (5-HT or serotonine) was shown to be increased ${ }^{33,3}$. Interestingly, in a murine model it was shown that an increase of 5HT upon stimulation of interleukin-6 was accompanied by the increase of $\mathrm{SAA}{ }^{34}$. Nevertheless, larger studies are needed to validate the results of this study and confirm whether the SAA can indeed be used to monitor fatigue.

With respect to corticosteroid treatment, some trend between corticosteroid use and fatigue appeared to exist, although the result of logistic regression analysis seemed not significant. As the sample size is rather small, careful interpretation of this result is needed. In a logistic regression analysis we corrected for the effect of prednisone, as we indeed considered the OR for prednisone of 3 , with a p-value of 0.078 rather high. In a larger sample, this p value might become significant (the same holds for the SAA). However, no differences in fatigue scores and most of the clinical parameters (Table 6.2 ) between the treated and the untreated groups were found. Therefore, it might be assumed that in our sample the influence of corticosteroid therapy is limited.

Neither the CRP nor hs-CRP were able to predict fatigue. Overall, the CRP values were higher as compared to hs-CRP values. This only emphasizes the discrepancies between the two methods as shown earlier ${ }^{24}$. Moreover, activity markers such as ACE and SII.2R also showed no relation to fatigue. Besides, in contrast with previous findings " in the present study no relationship with the measures of metabolic derangement and the CRP or hs-CRP could be found. Despite the discrepancies between the methods (CRP and hsCRP), the lack of relationship of the CRP or hs-CRP with the measures of metabolic derangement is difficult to explain. It is probably population related. Moreower, the SAA and s[L-2R appeared to correlate with metabolic derangement measures, nevertheless confiming the relationship of the acute phase response with metabolic derangement in sarcoidosis, at least party, in agreement with a previous study ${ }^{\prime 2}$.

As mentioned before, one of the limitations of this study is the small sample size. Since we expected low correlations, a large sample size would be needed to make firm statements. However, large populations of sarcoidosis patients are difficult to recruit for any study since the disease is not extremely common. In comparison to our previous 
study ${ }^{2}$, a different type of statistical analysis was now used with the ain to predict fatigue (logistic regression analysis). Although both, the previous as the present study show some overlap in clinical parameters (REE, CRP), in the present study we added additional clinical (presence of respiratory functional impaiment) and laboratory parameters ( $\mathrm{SL}-2 \mathrm{R}, \mathrm{SAA}$ and $\mathrm{ACE}$ ). In the multivariate analysis we combine all these parameters. Furthermore, the CRP concentrations reported in the previous study were measured with a less sensitive CRP method, which appeared to be very sensitive to sample turbidity and might give unreliable results ${ }^{24}$. It was to be expected that the CRP concentrations would only slightly be increased in sarcoidosis patients ${ }^{12,35}$. To measure these minor increases from the upper reference level, the more sensitive CRP method is needed. Therefore, in this study we used the so-called high-sensitivity CRP method to accurately measure the CRP concentrations.

Although it was beyond the scope of this study, it might have been important to compare the exercise test and its relationship with the FAS. Changes in gasmexchange with exercise were previously demonstrated to be the most sensitive physiologic measurement to assess the extent of pulmonary disease in early radiographic stages of sarcoidosis ${ }^{3,33}$. Accordingly, a significant maximall exercise limitation in sarcoidosis patients without significant pulmonary impairment was shown by Delobbe et al. $^{34}$. In line with this, a recent study, further confirmed the value of exercise testing. Namely, HRCT findings appeared to be much more sensitive in depicting respiratory disability, especially abnornal gas exchange, as compared to radiographic staging ${ }^{35}$. Currently, a prospective study is conducted to evaluate the possible relationshup of impaired gas exchange with fatigue and dyspnoea more carefully. Preliminary results showed only a moderate relationship with the FAS score between the subscore mental fatigue and desaturation during exercise $(r=-0.23, p<0.05)^{33}$.

The results of this study emphasize the difficulties that clinicians face when irying to objectify fatigue. Fatigue, as an integral part of the clinical picture of sarcoidosis, is disabling for the patient and causes an impaired quality of life ${ }^{3,4,12}$. The course of the disease is mainly monitored by assessing clinical features and using auxiliary diagnostic procedures. However, an objective system for the assessment of disease activity and fatigue is still lacking. Moreover, the non-specific symptoms including fatigue are often hard to objectify, as confirmed by this study. Up to now, no clinical or physiological variable seems useful in predicting which patients are fatigued. The feeling of fatigue is a subjective experience that is associated with many diseases and states. However, the large ostensibly healthy population was screened by means of the FAS for the presence of fatigue and the cutoff of 22 was carefully chosen ${ }^{2 !}$. Besides, the FAS was constructed in a way to minimize the intersubjective agreement, the well-known source of error and bias in human judgement ${ }^{36}$.

\section{Conclusion}

The present study confirmed that fatigue is a major problem in sarcoidosis. None of the tested variables such as lung function data, metabolic derangement measures and laboratory parameters of inflammation. $T$ cell activation or granuloma formation seemed useful in predicting which patients are fatigued. In this light, the Fatigue Assessment Scale can be considered as a supplementary tool in sarcoidosis to assess fatigue. 


\section{Appendix}

\section{The Fatigue Assessment Scale (FAS)}

1. I am bothered by fatigue

2. I get tired very quickly

3. I donit do much during the day

4. I have enough energy for eweryday life

5. Physically, I feel exhausted

6. I have problems to start things

7. I have problems to think clearly

8. Heel no desire to do anything

9. Mentally, I feel exhausted

10. When I am doing something, I can concentrate quile well ${ }^{c}$

$\begin{array}{ccccc}\text { Never } & \text { Sometimes } & \text { Regularly } & \text { Often } & \text { Always } \\ 1 & 2 & 3 & 4 & 5 \\ 1 & 2 & 3 & 4 & 5 \\ 1 & 2 & 3 & 4 & 5 \\ 1 & 2 & 3 & 4 & 5 \\ 1 & 2 & 3 & 4 & 5 \\ 1 & 2 & 3 & 4 & 5 \\ 1 & 2 & 3 & 4 & 5 \\ 1 & 2 & 3 & 4 & 5 \\ 1 & 2 & 3 & 4 & 5 \\ 1 & 2 & 3 & 4 & 5\end{array}$

${ }^{2}$ The following ten statements refer to how well the person usually feels. Per statement one out of five answer categories can be chosen, warying from Never to Always. $1=\mathbb{N}$ ever, 2 = Sometimes; $3=$ Regularly: $4=$ Often; $5=$ Always.

"Based on large representative samples of the Dutch population, the cut-off score of the FAS is 21 , $i \theta_{1}$ scores of $\geq 22$ are considered to represent substantial fatigue. A change in the FAS score of 5 points is considered to be clinically relevant.

- Scores on questions 4 and 10 should be recoded $(1=5,2=4,3=3,4=2,5=1)$. Subsequently, the total FAS score can be calculated by surmming the scores on all questions (the recoded scores for questions 4 and 10) 


\section{References}

1 Thomas PD, Hunninghake GW: Current concepts of the pathogenesis of sarcoidosis. Ain Rew Respir Dir $1987 ; 135: 747-60$.

2 James DG: Epidemiology of sarcoidosis. Sarcoidosis 1992;979-87.

3 Hunninghake $G W$, Costabel U, Ando $M$, Batughman $R$, Cordier IF, du Bois R. Eklund A, Kitaichi $M$ Lynch J, Rizzato G, Rose C. Seloos O. Semenzato G, Shama OP: ATSAERSWASOG statement on sarcoidosis. American Thoracic Society/European Respiratory Society/World Association of Sintovidosis and other Granulomatous Disorders. Sarcoidosis Warc Diffuse Lung Dis 1999:16:149-73.

4 Wirnsberger RM. De Vries J, Wouters EFM. Drent M: Clinical presentation of sarcoudosis in The Netherlands an epidemiological study. Neth J Med 1998;53:53-60.

5 Pietinallho $A$, Ohmichi $M$. Hiraga $Y$, Lotroos $A B$, Selroos $O$ : The mode of presentation of sarcoidosis in Fintand and Hokkaido, Japan. A comparative analysis of 571 Firmish and 686 dapancse patients. Sarcoidosis Wasc Diffuse Lung Dis 1996;13:159-66.

6 Fite $\mathbb{E}$, Alsina $J M$, Mana I. Pujol $R$, Ruiz J, Morera J: Epidemiology of sarcoidosis in Catalonia: 1979. 1989. Sarcoidosis Vase Difuse Ling Dis 1996:13:153-8.

7 Hoitsma E, DeVries J, van Santer-Hoeuff M, Faber $\mathrm{CG}$, Drent M: Impact of pain in a Duch sacoidosis patient population. Sarcoidosis Fasc Diffuse Lung Dis 2003;20:33-39.

8 De Vries 1, Drent M, Van Heck GL. Wouters EFM: Quality of life in sarcoidosis: a comparison between members of a patient organisation and a random sample. Sarcotdosis Vasc Diffuse Lung Dis 1998;15:1838.

9 Thomeer MJ, Costabel U, Rizzalo G, Poletti $V$. Demedts M: Disease pereeption in members of a Sarcoidosis patient association: a survey.? Sarcoidosis Vase Diffuse Lang Dir 2001;18 (Suppl 1):60-61.

10 Demedis M. Wells AU, Anto JM, Costabel U, Hubbard R, Cullinan P, Slabbynck H, Rizzato G, Polati V, Verbeken EK, Thomeer MJ, Kokkarinen J, Dalphin JC, Taylor AN: Interstitial lung disewses: an epidemiological overview. Eur Respir J Supp/ 2001;32:2s-16s.

11 Drent M, Bomans PH, Van Suylen RJ, Lamers RJS, Bast A, Wouters EFM: Association of man-made mineral fibre exposure and sarcoidlike granulomas. Respir Med 2000;94:815-20.

12 Drent M, Wimsberger RM, De Vries $\mathrm{J}$, van Diejien-Visser MP, Woulers EFM. Schols AMWI: Association of fatigue with an acute phase response in sarcoidosis. Ear Respir. 1 1999;13:718-22.

13 James DG: Complications of sarcoidosis. Chronic fatigue syndrone. Sarcoidos is $1993 ; 10: 1-3$.

14 Sharma OP: Fatigue and sarcoidosis. Eur Respir $J 1999 ; 13: 713-4$.

15 Wirnsberger RM, De Vijes J, Breteler MHM, van Heck GL, Wouters EFM, Drenl M: Evaluation of quality of he in sarcoidosis patients. Rexper Med 1998:92:750-6.

16 De Vries I. Michielsen $H$, Van Heck GL, Drent $M$ : Measuring datigue in sarcoidosis: the labigne Assessment Scatc (PAS). Br J Heald Psychof, in pressis 2004.

17 Drent M. Wimsberger RM, Breteler MHM. Kock LM, De Vries I, Wouters VFM: Quadity of lite atnd

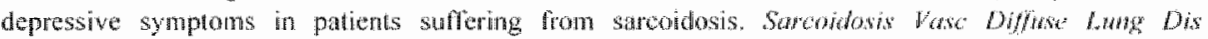
$1998: 15.59-66$.

18. DeRemee RA: Dysphoria and sarcoidosis. Sarcoidosis Vas Diffruse Lunge D\& $1998 ; 1521$.

19 Fagan IEA, Dyck RJ, Maton PN, Hodgson HJ, Chadwick VS. Petrie A. Pepys MB: Serunn Levds of C. reactive protein in Crolm's disease and ulcerative colitis. Eur I Clin Inwes 1982:12:351-9.

20 Michielsen HJ, De Vries J. Van Heck GL, Varr de Vijver FJR, Sijtsmi K, Examination of the dimensionaliry of fatigue: The construction of the fatigue Assessment Seale (FAS). Eur J Psyol Asw in press. 2003.

21 Michelsen HJ, De Vries J, Van Heck GL: Psychometric qualities of a briel self-ratted fatigue measure: The Fatigue Assessment Scale (FASj. J Psychosom Mes 2003;54:345-52.

22 Quarjer PH, Tammeling GJ, Cotes JE, Pedersen OF, Pestin R, Yernauli JC: Lung wolumes and forced ventilatory flows. Report Working Party Standardization of Lung Function Tesis. Buropean Comununity for Steel and Coal. Official Statement of the Ruropean Respiratory Socicty. Fat Respir I Suppl $1993 ; 16: 5-40$.

23 DeRemee RA: The roengenographic staging of sarcoidosis. Historic and contemporary perspectives. Ches 1983;83:128-33. 


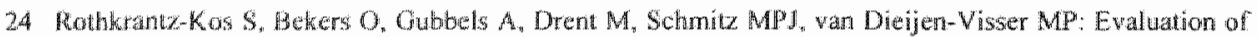

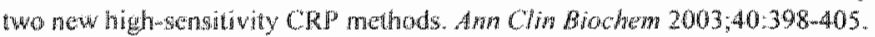

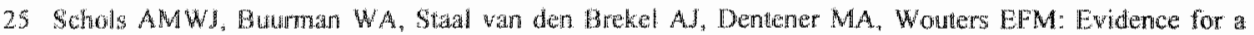
fathon between metabolic derangenents and increased levels of inflammatory mediators in abgroup of putents with chonic obstructive pulinonary diserse. Thorax 1996,51:819-24.

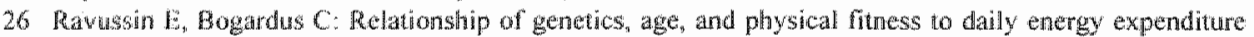
and fuel utitization. Am J Clim Nur 1989-49.968-75.

27 Michusen H: Working out fatigue: Conceptualization, assessment and theory, Dochoral thes is 2002 . Tiburg Uniwersity.

28 Maskch C. Jaekson SE: The Masach burnout Inwentory manual (2nd adtion) 1986; Sage, Paolo Alto, Califormia.

29 Skevington SM, Pilat M, Routh D, Macleod RD: On the language of breathlessness. Psychol Heall $1997 ; 12: 677-89$.

30 De Vries $\pi$, Kessels BLJ, Drent M: Qually of life of idtopathic pumomary fibrosis patients. Enu Respir $J$ $2001 ; 17: 954-61$.

31 Sadter IJ, Jacobsen PB, Booth-Jones M, Belanger H. Weitzmen MA, Fields KK. Prelininary evaltation of a clincal syndrome approach to assiessing cancer-related fatigtue. I Pain Symporm Manaze 2002;23:40616.

32 Medinger Al: Khour S, Rohatgi PK: Sarcoidosis: the value of exercise testing. Chest 2001; 120:93-101.

33 Luters M. Maassen van den Brink KI, Rothkrantz-Kos S, Wouters EFM, van Dieijer-Visser MP, Drent M: Abnomal gas exchange in chronic sarcoidosis. Sarcordowis 2001;18 (Suppl.1).49.

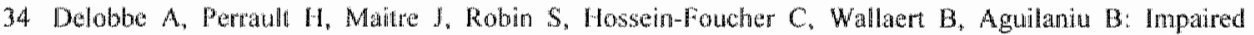
exercist response in sarcoid patients with nomal pumonary functio. Sorcoidosis Vasc Diffuse Lurg Dis $2002 ; 19: 148-53$

35 Drent M, De Vries J, Lenters M, Lamers RJS, Rothknan-Kos S, Wouters EFM, Van Diejien-Visser MP. Verschakelen $\mathbb{A}$ : Sarcoidosis: assessment of disease sewenity using HRCT. Eur Radiol 2003;13:2462-71.

36 Schols AMWJ. Soeters PB, Dingemans AM, Mostert R, Frantzen PJ, Wouters EFM: Prevalence and characteristics of nutritional depletion in pettents with stable COPD eligible for pulmonary nehabiluation. Am Rev Respir Dis 1993;147:1151-6.

37 Newsholme EA, Blomstrand E: Tryptophan, 5-luydroxytryptamine and a possible explanation for cental fatigue. Adh Exp Med Biol 1995;384;315i-20.

38 Wang $J$, Dunn AJ: Mouse interleukin-6 stimulates the HPA axis and increases bran tryptophan and serotonin mabolism. Neurochem /nt 1998;33:143.54.

39 Peros-Golubicic T: Serum C-reactive protein measurement in the detection of intercurrent infection in patients with sarcoidosis. Acta Med Crodtica 1995;49:1-3.

40 Annet J: Subjectiva rating scales: science or art? Engorowies 2002,45:966-87. 
Chapter 7

\section{Decreased redox state in red blood cells from patients with sarcoidosis}

Snježana Rothkrantz Kos, Marjolein Drent, Herma Vuil, Martin De Boer, Aalt Bast, Emiel F.M. Wouters, Dirk Roos, Marja P. van Dieijen-Visser 


\section{Abstract}

\section{Background}

The gluathione system has a key role in the defense against oxidative stress. To function properly, this system needs NADPH to maintain glutathione (GSH) in its reduced form. We hypothesized that the clinical problems associated with sarcoidosis might be related to a decreased anti-oxidant defense and we therefore measured the activity of the NADPH-generating enzyme glucose-6-phosphate dehydrogenase (G6PD), the GSH-regenerating enzyme glutathione reductase (GR) and indirectly the level of NADPH in red blood cells from patients with sarcoidosis.

\section{Methods}

In a population of sarcoidosis $(n=88)$ patients, G6PD, GR and GR activity after incubation with chromate (GR-Cr) were measured in erythrocytes. A decreased concentration of NADPH was revealed by an increased $\mathrm{GR}-\mathrm{Cr}(>0.6 \mathrm{IU} / \mathrm{g} \mathrm{Hb})$. To exclude a mutation in the G6PD gene, sequencing was performed in cases with an abnormal GR-Cr. Sarcoidosis pulmonary disease severity was evaluated by means of laboratory data, radiographic staging, HRCT scoring, pulmonary function- and exercise capacity testing.

\section{Results}

Fourteen (29.2\%) females and one male (2.5\%) demonstrated an increased GR-Cr test, indicative of a clecreased NADPH level. Patients with an abnormal test result demonstrated also significantly increased $A C E$ and $G R$ values $(p<0.05$ ). Only one female case (of 6 tested) appeared to have a mutation in the G6PD gene.

\section{Conclusion}

In a considerable percentage of female patients with sarcoidosis, a decreased level of NADPH in the erythrocytes was found. 


\section{Introduction}

Sarcoidosis, a disease predominantly affecting young adults, is the commonest difuse lung disease, with a population prevalence ranging from 1.4 to 64 per 100,000 population. The disease etiology remains undetermined, although genetic predisposition is likely to play an important role ${ }^{1,2}$. Environmental factors, which are mostly unknown, may determine the disease course. A consequence of environmental factors is often oxidative stress, inducing the production of free radicalsi.

During oxidative stress, either intracellular in origin or initiated by drugs or envirommental chemicals, reduced glutathione (GSH) is eritical for protection of the cells ${ }^{4.5}$. GSH is involved in the detoxification of reactive oxygen species through its donation of reducing equiwalents. Furthermore, GSH reduces oxidized protein thiol groups back to reduced thiol groups $(-\mathrm{SH})^{5,6}$. The enzyme glutathione reductase (GR) maintains high intracellular concentrations of GSH by reducing the oxidized form of glutathione (GSSG) back to GSH. For this reaction, the reducing equivalents are derived from reduced nicotinamide adenine dinucleotide phosphate (NADPH) (GSSG th NADPH $\left.+\mathrm{H}^{+} \leftrightarrow 2 \mathrm{GSH}+\mathrm{NADP}\right)^{6-9}$. The only pathway to generate NADPH in erythrocytes is the hexose monophosphate shunt (HMS). In this pathway, glucose-6phosphate dehydrogenase (G6PD) is the first and rate-limiting enzyme ${ }^{5 / 10}$.

There is clearly lack of international data about the relation of cellular redox state and sarcoidosis. We hypothesized that the malfunctioning of this protective system might be involved in sarcoidosis, and recognition of this phenomenon might be of clinical importance. Avoiding certain drugs and other causes of oxidative stress might then limit the extent of the inflammatory response in sarcoidosis.

Therefore, the erythrocyte capacity to naintain NADPH concentrations was evaluated in a population of sarcoidosis patients by means of the chromate inhibition test ${ }^{11.12}$.

\section{Materials and Methods}

\section{Study population}

Eighty-eight mainly Caucasian sarcoidosis patients were included in this study. These patients visited the Sarcoidosis Management Center of the University Hospital Maastricht, a Dutch referral center for sarcoidosis, between January 2000 and January 2001. The patients' diagnosis was based on consistent clinical features and bronchoalveolar lavage fluid analysis", according to the ATS/ERS/WASOG guidelines. The diagnosis was histologically confirmed in $91 \%$ of the cases. Informed consent was obtained from all participating subjects. Patient characteristics are summarized in Table 7.1.

\section{Erythrocyte redox-state evaluation}

The activities of G6PD and GR, as well as the chromate inhibition test (GR-Cr) were measured spectrophotometrically in hemolysates of washed erythrocytes according too 
the method of Zurcher et al." with minor modifications as described by Jonges et al ${ }^{12}$. G6PD activity was measured to screen for possible G6PD deficiency and GR for its capacity to regenerate $\mathrm{GSH}$, both by means of a direct spectrophotometric method ${ }^{11,12}$. To screen for levells of NADPH in the erythrocytes, the chromate inhibition test was used. This test is based on the inhibition by chromate $\left(\mathrm{Cr}^{6+}\right)$ of GR activity in erythrocytes with a normal level of NADPH, but not in erythrocytes with decreased levels of NADPH. Chromate inactivates GR with reduced, catalytically active (-SH) thiol groups (this reduction is dependent on WADPH concentration) in the active center of the enzyme, but not GR with oxidized ( $-S-S-$ ) thiol groups. The remaining glutathione reductise activity, will be thus higher in NADPH-deficient cells than in normal cells, and is thus a reflection of the intracellular redox state.

Table 7.1. General characteristics of the studied sarcoidosis patient population.

\begin{tabular}{lccc} 
& Female & Male & Total \\
\hline Number of casesi & 48 & 40 & 88 \\
Age at diagnosis $(y r)^{3}$ & $36.1 \pm 13.0$ & $36.8 \pm 8.3$ & $36.4 \pm 11.1$ \\
& $(12-68)$ & $(25-55)$ & $(12-68)$ \\
Smoking (no/ yes) & $42 / 6$ & $38 / 2$ & $80 / 8$ \\
Use of prednison (no/ yes) & $41 / 7$ & $22 / 18$ & $63 / 25$ \\
Race (caucasian / negroid) & $41 / 7$ & $37 / 3$ & $78 / 10$ \\
\hline
\end{tabular}

"Data are mean \pm SD with range in parenthesis

\section{Molecular genetic studies}

Nucleotide sequence analysis of the G6PD gene was performed in 6 cases with an increased GR-Cr $(>0.6 \mathrm{IU} / \mathrm{g} \mathrm{Hb})$. Genomic DNA was isolated from $5 \mathrm{ml}$ of $\mathrm{K}_{3}-\mathrm{EDTA}$ anti-coagulated whole blood (buffy coat) with the High Pure PCR Template Preparation Kit, cat no. 1796828 (Roche, Mijdrecht, The Netherlands). The whole G6PD coding sequence was amplified from genomic DNA by polymerase chain reaction (PCR) with primers complementary to the intron regions, to ensure analysis of all exon and intron splicing regions of the G6PD gene (Table 7.2). Aliquots of $50-200$ ng genomic DNA were amplified in the Air Thermo-cycler 1605 (ldaho Technology, Inc., Idaho Falls, ID, USA). The protocol used was as follows: denaturation at $95^{\circ} \mathrm{C}$ for 5 minutes, followed by $40-50$ cycles of annealing at $60^{\circ} \mathrm{C}$ for 30 seconds and extension at $72{ }^{\circ} \mathrm{C}$ for 15 seconds. For nucleotide sequencing, the dideoxynucleotide chain termination method was used, with an ABI PRISM Big Dye Terminator Cycle sequencing kit on the ABI PRISM 377 DNA Sequencer (Perkin-EIner, Norwalk, CT, USA).

\section{Evaluating Sarcoidosis Pulmonary Disease Severity}

Serum ACE was measured with a colorinetric method (Fujirebio Inc., Tokyo, Japan, cat. nr. FU 1 16). ACE hydrolyzes p-hydroxybenzoyl-glycyl-L-hystidyl-L-leucine and generates p-hydroxybenzoyl-glycine, which is converted in two subsequent reactions in quinoneimine dye. The absorbance of the quinoneimine dye is measured at $505 \mathrm{~nm}$ to evaluate the $\mathrm{ACE}$ activity. 
Serum calcium concentration was messured by indirect potentiometry on a synchron $\mathrm{LX}^{2} 20$ with a detection limit of $0.5 \mathrm{mmol} \mathrm{L}$ and a measuring range of 0.5 to $5.0 \mathrm{mmol} / \mathrm{L}$ (Beckman Coulter, Inc. Fullerton, CA. US; electrolyte buffer reagent (P/N $467915)$ and electrolyte reference reagent ( $\mathrm{P} / \mathrm{N} 467935)$ ).

Table 7.2. Primers used for the sequencing of the G6PD gene.

\begin{tabular}{|c|c|c|c|}
\hline \multicolumn{2}{|c|}{$\begin{array}{l}\text { Pither sequences } \\
\left.\text { (5' to } 3^{\prime}\right)\end{array}$} & \multirow{3}{*}{$\begin{array}{l}\text { Amplifed tragnent } \\
\text { bp } \\
\text { from ... - }-10 \ldots \text { (size) } \\
2015-2443(428)\end{array}$} & \multirow{3}{*}{$\begin{array}{l}\text { G6PO protein part } \\
\text { Promotor region }\end{array}$} \\
\hline PRS & OTCTGCAGGCCCGCGGAAGCTCGGT & & \\
\hline PRAS & CCGCTGCCGCTGCTCTGCATCCOC A & & \\
\hline 13 & CGGCGATGGGGATGCGGGAGCACTA & $2364-2773(409)$ & Exon l: ho coding sequence \\
\hline MAS & GCGCAGCGCGGGACAGTACGCTICCT & & \\
\hline 25 & AGGAACTCTCAAGAAAGGGGCTAAC & $3264-3533(269)$ & Exon II: Met1 - Ser 39 \\
\hline $2 A S$ & AAAAGCTGAGGCATGGAGCAGGCAC & & \\
\hline $3 S$ & AAGGGTGGAGGATGATGTATGTAGG & $13253-13623(370)$ & $\begin{array}{l}\text { Exon III Gy44-Tpp53 } \\
\text { Exon IV: L.eu54-Lys80 }\end{array}$ \\
\hline $4 A S$ & TGGGGGCTGGTAGAGAGGGGAGAAC & & \\
\hline $5 s$ & CTGGGGCAGAACACACACGGACTCA & $14042-14403(361)$ & Exon V: Áa89-- He162 \\
\hline SAS & ATAGAGTGGTGGGAGCACTGCCTGG & & \\
\hline 65 & TGGGAGGGCGTCTGAATGATGCAGC & $14820-15227(307)$ & Exory VI: Gily163-Arg215 \\
\hline GAS & GGCCAGGTGAGGCTGGTGAGTACCA & & \\
\hline $7 \mathrm{~S}$ & GGGTGACCCCTCACATGTGGCCCCT & $15268-15517(249)$ & Exon Vul: Phe 216 - Arg257 \\
\hline TAS & GOCTCTGCCACCCTGTGCCAGCCT & & \\
\hline $8 S$ & GTTTGGGGTCCCCATGCCGTTGAAC & $15756-15979(223)$ & Exon VIII: Asp258 - Lys288 \\
\hline BAS & CAGATGGGCGTGCGACAGGGCATGC & & \\
\hline $9 \mathrm{~S}$ & TGCACATCTGTGGCCACAGTCATCO & $16294-16619(325)$ & Exon IX: Val239 - Asp350 \\
\hline $9 A S$ & TGCCCGCACACAGGGCATGOCCAGT & & \\
\hline $10 \mathrm{~s}$ & GCTCCCACTGAGACACTGACGCACT & $16624-16982(358)$ & Exan X: Gly.351-Lys429 \\
\hline TOAS & GGCGCAGGCCGCCCACCCTCCACA & & \\
\hline $11 S$ & CTGGGGCCCGGGGGACTCCACATGGT & $16975-17162(187)$ & Exon XI: $A \sin 430-\operatorname{Ser} 455$ \\
\hline $11 \mathrm{AS}$ & ACCCCATAGCCCACAGGTATGCAG & & \\
\hline $12 S$ & GGGGTGGCCTTTGCCCTCOCTCC & $17157-17388(231)$ & Exon XII: Asp456 - Ser486 \\
\hline $12 \mathrm{AS}$ & GGCATGAGOTAGCTCCACCOTCAC & & \\
\hline 135 & AGGAAAGGGTGGGGGCTGGGGACAGA & $17318-17590(272)$ & Exon Xlll: Arg $487-$ Leus15 \\
\hline $13 \mathrm{AS}$ & GTCAPTGGTCCCGGAGTCCTCCCGA & & \\
\hline
\end{tabular}

* Primers were designed based on the Genbank sequence with accession number $\times 55448$. (Homo sapiens gene for G6PD, glucose-6-phosphate dehydrogenase) and the nulmbering of amino acids was deduced from the cDNA accession number $\times 03674$.

Soluble IL2 receptor (SIL-2R) was measured on the IMMULITE automated analyzer, which is a two-site chemiluminescent enzyme immunometric assay with a detection. limit of $50 \mathrm{kU} / \mathrm{L}$ and a measuring range of $50-7500 \mathrm{kU} / \mathrm{L}$. (Diagnostic Product Corporation, Los Angeles, CA, cat no LKIPI).

Chest radiographs were graded according to the radiographic staging of DeRemee (0 to III), adding stage [V, i.e. the end stage of lung fibrosis ${ }^{1.4}$.

By means of high-resolution computer tomography (HRCT), thin-section scans with 1 mm collimation were obtained at 10 -mm intervals through the chest. The scanning parameters included $137 \mathrm{kVp}, 255 \mathrm{~mA}$, and 1 -second scaming time. Both mediastinal 
(width, $400 \mathrm{HU}$ level, $40 \mathrm{HU}$ ) and lung (widh, 1,600 HU; level, $-800 \mathrm{HU}$ ) window images were obtained. The semiquantitive HRCT scoring system was used as described previously ${ }^{15}$. This HRCT score measures parenchymal, as well as lymphatic, and pleural involvement and grades each of these pathological features (six in total) into four categories. The total $\mathrm{HRCT}$ score was obtained by counting the six individual scores together, obtanning a maxinal score of 18 .

Lung function parameters, including the forced expiratory volume in 1 second (FEV I) and forced vital capacity (FVC), were measured with a pneumotachograph. The diffusing capacity for carbon monoxide (DLCO) was neasured by the single-breath method (both Masterlab, Jaeger, Würburg, Germany). Values were expressed as a percentage of those predicted ${ }^{10}$.

Patients perfomed a symptom-limited incremental exercise test as described previousty. Breath-by-breath gas exchange was measured by a ventilated hood system (Oxyconbeta; Jaeger, Bunnik, The Netherlands). In rest and during maximall exercise, arterial blood samples were taken for blood gas analyses. The alveolar-arterial oxygen differences at rest $\left(\mathrm{PO}_{2}\right.$ rest) and at maximal exercise ( $\mathrm{AaPO}_{2}$ max) were calculated.

\section{Statistics}

All analyses were performed with the Statistical Package for Social Science (SPSS) for Windows (SPSS version 10.0, Chicago, $\mathbb{L}$, USA). Group comparisons were performed by means of parametric tests (Independent Samples t-test) for continuous data and by means of non-parametric tests (Mann-Whitney $U$ test) for categorical data. A two-sided. p-value of less than 0.05 was considered to be statistically significant.

\section{Results}

Table 7.3. shows clinical and laboratory data of the studied sarcoidosis population. Male patients appeared to have a worse clinical picture than female patients with respect to radiographic staging, total HRCT score, FEVI and FVC. They also appeared to have significantly lower GR activities in their erythrocytes than female patients.

To assess whether normal levels of NADPH were present in the erythrocytes, the chromate inhibition test was performed. Abnormal GR-Cr values were found in $17.1 \%$ of sarcoidosis patients, 14 of 48 females $(29 \%)$ and 1 of 40 male patients $(2.5 \%)$, indicating decreased levels of NADPH.

In Table 7.4 the clinical data of the female patients have been divided into two groups, one with GR-Cr test results lower than or equal to $0.6 \mathrm{IU} / \mathrm{g} \mathrm{Hb}$ (normal) and another with a GR-Cr test result higher than $0.6 \mathrm{IU} / \mathrm{g} \mathrm{Hb}$ (abnormal). Among clinical parameters, only GR and ACE appeared to be significantly higher $(p<0.05)$ in the group with the abnomal GR-Cr test results, even after correction for the use of prednison. 
Table 7.3. Clinical and laboratory findings of the studied sarcoldosis population ${ }^{2}$

\begin{tabular}{|c|c|c|c|}
\hline Parameter (normal range) & $\begin{array}{l}\text { Female } \\
(n=48)\end{array}$ & $\begin{array}{c}\text { Male } \\
(n=40)\end{array}$ & $\begin{array}{c}\text { Tolal } \\
(n=88)\end{array}$ \\
\hline ACE $(9-25 \cup / L)$ & $22.8 \pm 9.6$ & $20.1 \pm 8.4$ & $21.6 \pm 9.4$ \\
\hline SIL-2R $(24 \|-846 k U R)$ & $\begin{array}{c}(88-60) \\
861 \pm 561 \\
(2168-2271)\end{array}$ & $\begin{array}{c}(38-41) \\
735 \pm 432 \\
(2368-2243)\end{array}$ & $\begin{array}{c}(38-60) \\
804 \pm 507 \\
(2168-2271)\end{array}$ \\
\hline Totallia ${ }^{2+}(2.1-2.6 \mathrm{mmol} / \mathrm{L})$ & $\begin{array}{c}2.4 \pm 0.1 \\
(2.38-2.6)\end{array}$ & $\begin{array}{c}2.5 \pm 0.1 \\
(2.38-2.7)\end{array}$ & $\begin{array}{l}2.4 \pm 0.1 \\
(2.3-2.7)\end{array}$ \\
\hline $\begin{array}{l}\text { GR-Cr }(\leq 0.6) />0.6) \\
\operatorname{GSPD}(4.8-7.2 \mathrm{U} / \mathrm{g} \mathrm{Hb})\end{array}$ & $\begin{array}{c}34 / 14 \\
5.1 \pm 1.0 \\
(1.58-8.6)\end{array}$ & $\begin{array}{c}39 / 1 \\
4.8 \pm 0.4 \\
(3.98-5.7)\end{array}$ & $\begin{array}{c}73 / 15 \\
5.0 \pm 0.8 \\
(1.58-8.6)\end{array}$ \\
\hline $\mathrm{GR}^{b}(2.4-4.8 \mathrm{U} / \mathrm{g} \mathrm{Hb})$ & $\begin{array}{c}4.5 \pm 1.1 \\
(2.78-7.1)\end{array}$ & $\begin{array}{c}3.9 \pm 0.7 \\
(2.58-5.4)\end{array}$ & $\begin{array}{l}4.2 \pm 1.0 \\
(2.58-7.1)\end{array}$ \\
\hline FEV1, \% pred & $\begin{array}{l}91.2 \pm 19.9 \\
(298-135)\end{array}$ & $\begin{array}{l}77.4 \pm 20.9 \\
(268-108)\end{array}$ & $\begin{array}{l}85.2=21.3 \\
(268-135)\end{array}$ \\
\hline FVC, \% pred ${ }^{\circ}$ & $\begin{array}{l}99.3 \pm 19.2 \\
(498-152)\end{array}$ & $\begin{array}{l}86.7 \pm 15.3 \\
(498-110)\end{array}$ & $\begin{array}{l}93.9 \pm 18.6 \\
(498-152)\end{array}$ \\
\hline DLCO, \% pred & $\begin{array}{l}81.9 \pm 15.7 \\
(378-112)\end{array}$ & $\begin{array}{l}84.7 \pm 20.7 \\
(398-124)\end{array}$ & $\begin{array}{l}83.2 \pm 18.0 \\
(378-124)\end{array}$ \\
\hline DNA $\%$ pred & $\begin{array}{l}76.5 \pm 13.3 \\
(468-105)\end{array}$ & $\begin{array}{l}81.8 \pm 13.8 \\
(538-107)\end{array}$ & $\begin{array}{l}78.9 \pm 13.7 \\
(468-107)\end{array}$ \\
\hline $\mathrm{PO}_{2}$ rest,$(8.7-13.1 \mathrm{kPa})$ & $\begin{array}{l}11.6 \pm 1.7 \\
(7.8-15.0)\end{array}$ & $\begin{array}{c}11.3 \pm 1.6 \\
(6.48-15.6)\end{array}$ & $\begin{array}{c}11.4 \pm 1.6 \\
(6.48-15.6)\end{array}$ \\
\hline $\mathrm{AaPO}_{2} \max (0-4.7 \mathrm{kPa})$ & $\begin{array}{l}4.1 \pm 1.8 \\
(0.8-8.7)\end{array}$ & $\begin{array}{c}4.4 \pm 1.6 \\
(0.98-7.5)\end{array}$ & $\begin{array}{c}4.2 \pm 1.7 \\
(0.88-8.7)\end{array}$ \\
\hline $\begin{array}{l}\text { Radiographic stages }{ }^{5}, 0 / \mathrm{W} / \mathrm{I} / \mathrm{I} / \mathrm{IV} \\
\text { HRCT tot }(0-18)\end{array}$ & $\begin{array}{c}10 / 7 / 18 / 6 / 3 \\
4.6 \pm 3.4 \\
(0-12)\end{array}$ & $\begin{array}{c}3 / 4 / 14 / 9 / 5 \\
6.7 \pm 3.6 \\
(8-13)\end{array}$ & $\begin{array}{c}13 / 11 / 32 / 15 / 8 \\
5.5 \pm 3.6 \\
(8-13)\end{array}$ \\
\hline
\end{tabular}

"Data are mean $\pm S D$ with range in parenthesis, except for $\mathrm{GR}-\mathrm{Cr}$ and radiographic stages.

${ }^{10} p<0.05$ (males vs. females).

$p<0.01$ (males vs. females).

Table 7.4. Clinical parameters in female sarcoidosis patients with abnormal chromateinhibition test as compared to those with normal test result ${ }^{\text {at }}$

\begin{tabular}{|c|c|c|}
\hline Parameter (normal range) & $\begin{array}{r}\mathrm{GR}-\mathrm{Cr}<0 \\
(\mathrm{~m}=\end{array}$ & $\begin{array}{l}6 \mathrm{ll} / \mathrm{g} \mathrm{Hb} \\
34)\end{array}$ \\
\hline$A C E(9-25 \cup / L)$ & $20.4 \pm 8.2$ & $(8-47)$ \\
\hline slL-2R $(241-846 \mathrm{kU} / \mathrm{L})$ & $843 \pm 571$ & $(216-2271)$ \\
\hline Total $\mathrm{Ca}^{2+}(2.1-2.6 \mathrm{mmol} / \mathrm{L})$ & $2.4 \pm 0.1$ & $(2.3-2.6)$ \\
\hline $\operatorname{G6PD}(4.8-7.2 \| \mathrm{U} / \mathrm{g} \mathrm{Hb})$ & $5.2 \pm 0.9$ & $(4.0-8.6)$ \\
\hline $\mathrm{GR}^{\mathrm{b}}(2.4-4.8 \mathrm{u} \mathrm{u} \mathrm{H} \mathrm{Hb})$ & $4.1 \pm 1.0$ & $(2.7-6.7)$ \\
\hline FEV $1, \%$ pred & $93.9 \pm 14.6$ & $(58-128)$ \\
\hline FVC \% pred & $101.1 \pm 13.8$ & $(63-128)$ \\
\hline DLCO $\%$ pred & $83.4 \geq 13.3$ & $(58-112)$ \\
\hline DNA, \% pred & $76.6 \pm 12.9$ & $(57-105)$ \\
\hline $\mathrm{PO}_{2}$ rest, $\mathrm{kPa}(8.7-13.1 \mathrm{kPa})$ & $11.8 \pm 1.7$ & $(7.8-15.0)$ \\
\hline $\mathrm{AaPO}_{2} \max , \mathrm{kPa}(\mathrm{O}-4.7 \mathrm{kPa})$ & $4.2 \pm 1.8$ & $(2.3-8.7)$ \\
\hline Radiographic stages ${ }^{\circ}$ o////IIII//V & $6 / 7 / 1$ & $1 / 3 / 1$ \\
\hline HRCT tot $(0-18)$ & $4.4 \pm 311$ & $(0-12)$ \\
\hline
\end{tabular}

$$
\begin{aligned}
& \mathrm{GR} \cdot \mathrm{Cr}>0.6 \mathrm{UU} / \mathrm{g} \mathrm{Hb} \\
& (\mathrm{n}=14)
\end{aligned}
$$

$\begin{array}{cl}28.4 \pm 10.6 & (17-60) \\ 902 \pm 553 & (373-1891) \\ 2.4 \pm 0.1 & (2.3-2.5) \\ 5.2 \pm 1.3 & (1.5-6.7) \\ 5.3 \pm 1.0 & (4.1-7.1) \\ 84.8 \pm 28.5 & (29-135) \\ 95.3 \pm 28.2 & (49-152) \\ 78.6 \pm 19.6 & (37-104) \\ 76.4 \pm 14.6 & (46-100) \\ 11.0 \pm 1.4 & (9.4-13.6) \\ 3.8 \pm 1.9 & (0.8-6.1) \\ 4 / 0 / 4 / 3 / 2\end{array}$

$5.0 \pm 4.1 \quad(0-12)$

Data are mean $\pm \mathrm{SO}$ with range in parenthesis.

ip $p<0.05$ (normal vs. abnormal GR-Cr test group).

" $p<0.01$ (normal ws. abnormall GR-Cr test group). 
Since an abnomal GR-Cr test result is usually caused by G6PD deficiency (leading to decreased levels of NADPH), we also measured the G6PD activity in the patients" erythrocytes. In only one patient a strongly reduced G6PD activity and highly abnormal GR-Cr tesit result was found, with $1.5 \mathrm{IU} / \mathrm{g} \mathrm{Hb}$ for G6PD and 5. IU/ $\mathrm{g} \mathrm{Hb}$ for GR-Cr. To investigate due to which genetic defects in the G6PD gene the abnormal chromate inhibition test results were obtained, DNA was sequenced in 6 of 14 randomly chosen female patients with an abnormal GR-Cr test result (42.8\% of cases), as shown in Figure 7.1 .

Of the 14 females, two were negroid, whereas all other females with an abnomal GRCr test result were Caucasian and from Dutch origin. Only in one negroid female (patient with G6PD activity of $1.5 \mathrm{IU} / \mathrm{g} \mathrm{Hb}$ for $\mathrm{G} 6 \mathrm{PD}$ and $\mathrm{GR}-\mathrm{Cr}$ result of $5.1 \mathrm{IU} / \mathrm{g} \mathrm{Hb}$ ) a mutation in the $\mathrm{G} 6 \mathrm{PD}$ gene was found. This was a combination of $202 \mathrm{G} \rightarrow \mathrm{A}$ (Met68 to $\mathrm{Val})$ and $376 \mathrm{~A} \rightarrow \mathrm{O}$ (Asp126 to Asn) called G6PD A-, the most common G6PD mutation in the negroid race. The male patient with an abnormal GR-Cr result was Caucasian.

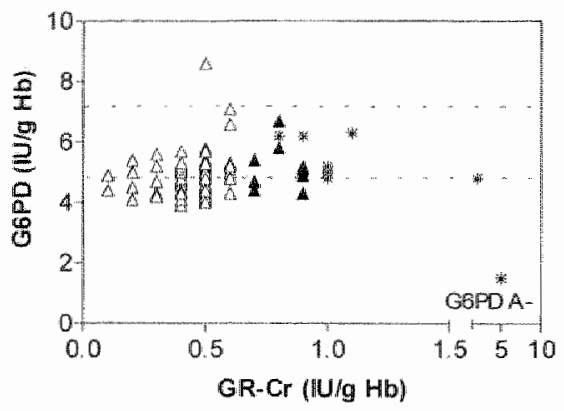

Figure 7.1. G6PD in relation to GR-Cr test and patients selected for sequencingl.

Open triangles present patients with normal GR-Cr test values $(\leq 0.6 \mathrm{lU} / \mathrm{g} \mathrm{Hb})$, whereas closed triangles present patients with abnormal GR-Cr test values $(>0.6 \mathrm{IU} / \mathrm{g} \mathrm{Hb})$. Remaining patients were those with abnormal GR-Cr test values, which were sequenced (star symbol). Only one patient of 6 sequenced with $\mathrm{GR}-\mathrm{Cr}=5.1 \mathrm{IU} / \mathrm{g} \mathrm{Hb}$ appeared to be a carrier of a G6PD A-.

\section{Discussion}

The lung, through its large contact surface with the environment, is one of the most oxygen-exposed organs. Therefore, a causal role for oxidative stress in the inflammatory process involved in various pulmonary disorders, including sarcoidosis, has been considered ${ }^{17.18}$. Pulmonary antioxidant defenses are widely distributed and include both enzymatic and non-enzymatic systems. "The major enzymatic antioxidants are superoxide-dismutase, catalase and GSH peroxidase. However, the GSH peroxidase activity is dependent on GR for the genetation of GSH, a reaction for which NADPH is required. The only pathway to generate NADPH in erythrocytes is the hexose monophosphate shunt (HMS). In this pathway, glucose-6-phosphate dehydrogenase (G6PD) is the first and rate-limiting enzyme $\mathrm{s}^{5.10}$.

Prompted by earlier observations, it was hypothesized that decreased levels of NADPH might be involved in the pathogenesis of sarcoidosis ${ }^{19.20}$. This was indirectly established 
by means of the chromate inhibition test (GR-Cr), which gave abnormal results in $29 \%$ of female sarcoidosis patients, whereas only one male patient $(2.5 \%)$ appeared to have an abnormal test result. Although most studies suggest a slightly higher disease rate for women', it is hard to find the explanation for this large sex difference.

The chromate inhibition test is considered to be a sensitive biochenical assay that indirectly indicates cellular NADPH concentrations, and is used for the detection of G6PD deficiency in female carriers of this disease ${ }^{11.12}$. In the West-European, Caucasian population, G6PD deficiency is found with a prevalence of less than $0.1 \% \%^{21}$, and the GR-Cr test yields an abnomal value in a similar percentage of this population (unpublished data). Thus, our finding of 15 abnomal $\mathrm{GR}-\mathrm{Cr}$ tests in 73 sarcoidosis patients $(17 \%)$, i.e. in 13 of 68 Caucasians $(19 \%)$, is very deviant from the values, which are to be expected. One possible reason for the abnomal GR-Cr test could be G6PD deficiency. However, these results could not be explained by genetic mutations in the G6PD genes of the sarcoidosis patients. Only one patient of negroud origin appeared to be a carrier of G6PD A-. G6PD A-represents a mild form of G6PD deficiency, found largely in the African population, but also in other parts of the world ${ }^{22,23}$.

Among clinical parameters, only GR and ACE appeared to be significantly higher $(p<0.05)$ in the group with the abnomal GR-Cr test results. Metabolic stress can lead to increased riboflavin uptake by erythrocytes ${ }^{24}$. In modified form (as FAD), riboflavin is incorporated into $\mathrm{GR}^{24}$. Slightly decreased NADPH might possibly also cause this phenomenon and lead as compensation to increased GR concentrations, as observed in G6PD deficiency ${ }^{24,27}$. Also ACE appeared to be significantly higher $(p<0.05)$ in the group with the abnormal GR-Cr test results, which might indicate an increased granuloma burden in this patient subgroup ${ }^{28}$.

Increased NADPH consumption in erythrocytes of sarcoidosis patients could be a reflection of oxidative stress, which develops during pulnonary damage. NADPH might indirectly be used for instance in protection of hemoglobin from oxidation. Methemoglobin reductase (NADH diaphorase) catalyzes methemoglobin reduction ${ }^{20}$. Through the reduction of methemoglobin the cellular level of NADH decreases. There is an exchange of reducing equivalents between NADH and NADPH (catalyzed by NAD:NADP transhydrogenase), which could subsequently lead to a decrease "in NADPH concentration. Decreased NADPH will lead to abnormal chromate-inhibition test results.

\section{Conclusion}

A substantial, unexpectedly high number of patients suffering from sarcoidosis appeared to have an abnormal chromate inhibition test, indicating decreased NADPH concentrations in their erythrocytes. Possibly, an increased consumption of reduced NADPH is involved in the inflammatory process triggered by oxidative stress in sarcoidosis. 


\section{References}

1. Hunninghake GW, Costabel U, Ando M, Baughman R, Cordier JF, Du Bois RM, Eklund A, Kitaichi M, L.ynch $J$, Hixzato $G$, Rose $C$. Selroos $O$, Semenzato $G$, Sharma OP. ATS/ERS/WASOG statement on sarcoidosis. American Thoracic Soejety/European Respiratory Society/World Association of Sarcoidosis and other Granulomiatous Disorders. Sarcoidosis Vasc Diffuse Lurg Dis 1999;16:149-73.

2. Newman LS, Rose CS, Maier LA. Sarcoidosis. N Engl J Med 1997;336:1224-34.

3. Drem $M$, van den Berg $R$, Henenen GRMM, van den Berg $H$, Wouters EFM, Bast $A$. NF- $k B$ activation in

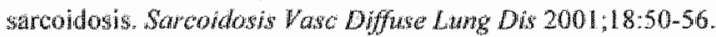

4. Bossi $\mathrm{D}_{\mathrm{t}}$ Giardina B. Red cell physiology. Mol Aspects Med 1996,17:117-28.

5. Nicol CJ, Zielenshi I, Tsui LC, Wells PG. An embryoprotective role for glucose-6-phosphate dehydrogenase in developmental oxidative stress and chemical teratogenesis. Faseb $12000 ; 14: 111-27$.

6. Bolme CC, Arscott LD, Becker $K$, Schimer RH, Williams CH. Kinetic characterization of glutathione reductase flom the malarial parasite Plasmodum falciparum. Comparison with the human enzyme. $J$ Biol Che:m 2000;275:37317-23.

7. Kirkman HN, Rolfo M, Ferraris AM, Gaetani GF. Mechanisms of protection of catalase by NADPH. Kinetios and stoichumery. J Biol Chem 1999:274:13908-14.

8. Arscot $L D$. Velne DM, Williams CH. Mixed disulfide with glutathione as an internediate in the reaction catalyzed by glutathione reductase from yeast and as a major form of the enzyme in the cell. Brochemistry $2000 ; 39: 4711-21$.

9. Schirner R, Krath-Siegel $R$, Schulz G. Glutathione reductase, In: Dolphin D, Poulson R, Avramovic O, eds. Ghutathrone, Chemical, Biochemical and Medical Aspects. 1989; New York, John Wiley \& Sons Ine. $1989.553-598$.

10. Beutler E. GGPD deficiency. Blond 1994;84:3613-36.

11. Zürcher C, Kuijlman FF, Sass Ft, Zürcher T, Loos JA, Prins HK Glucose-6-phosphate dehydrogenase deficiency in females, diagnosed by partial inhibition of glutathone reductase activity in the erythrocytes atter incubation with chromate. Clim Chin Acha $1969 ; 25: 139-46$.

12. Jonges $G N$, Hagen $H_{x}$ van Noordetn $C$, Weening RS, Roos D. Comparison between the chromate inhibition test and a cytochemical method for the determination of glucose-6-phosphate detydrogenase deficiency in erythrocytes. Clin Chin Acta 1989;181:135-41.

13. Drent $M$, Jacobs $\ A$, Cobben NAM, Costabel $U$, Wouters EFM, Mulder PGH. Computer program supporting the diagnostic accuracy of cellular BALF analysis: a new release. Respir Med 2001;95:781. 786.

14. DeRemee RA. The roentgenographic staging of sareoidosis. Historic and comemporary perspectives. Chase 1983,83:128-33.

15. Obersten $A$, von Zitzewite $H_{n}$ schweden $F$, Müller-Quernheim I. Non inwasive exaluation of the inllammatory activity in sarcoidosis with hugh-resalution compuned tomography. Sarcoidosis Vasc Diffus: Lung Dis 1997:14:65-72.

16. Quanjer PH, Tammeling G. Coles JE, Pedersen OF, Peslin R, Yernall JC. Lung volumes and forced ventilatory flows. Report Working Party Standardization of Lung Function Tests, European Comnunity for Steed and Coal. Onicial Statement of the European Respiratory Society. Eur Respir I Suppl $1993 ; 165-40$.

17. Lonz AG, Costabel U. Maier KL.. Oxidtzed BAL fluid proteins in patients with interstitial lung diseases. Eum Respin J $1996 ; 9 ; 307-\sharp 2$.

18. Boethme DS, Maples KR. Henderson RIF. Glutahione release by pumonary atweolar macrophages in response to particles in witro. Toxice Led lif $1992,60,53-60$.

19. Drent M. Dung-indheed pneumonia alssociated with hemizygote glucose-6-phosphate- dehydrogenase deliciency: En I Hersmutiol 1998;61:218-20.

20. Drent M. Assaciation of heterozygote glucose-6-phosphate-dehydrogenase deficiency with more andvanced disease in sarcoidosis. Sareondesis Hasc Diffuse Lung Dis 1999;16:108-9.

21. Ruwende C. Hill A. Gihcose-6h-phosphate dehydrogenase deficiency and malaria. I Mol Mod $1998,76: 581-8$ 


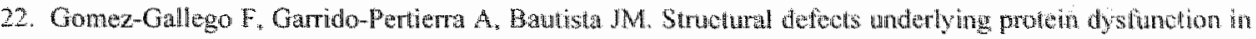

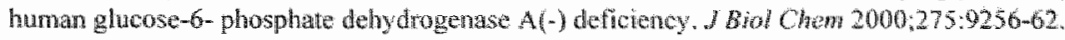

23. Bewter E. Glwcose-6-phosphate dehydrogenase deficiency. N Engl / Med 1991:324:169-74.

24. Vawata $Y$, Tanaka KR. ERect of metabolic stress on actwation of glutathone reduotase by taD human red cells. Experiantia 1971:27:1214-5.

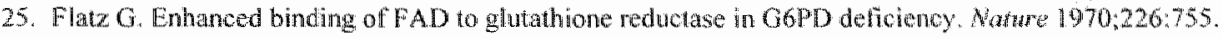

26. Yawata $Y$, Tanaka KR. Regulatory mechanism of glutathone reductase achivity human red colls. Bhod $1974 ; 43: 99-109$

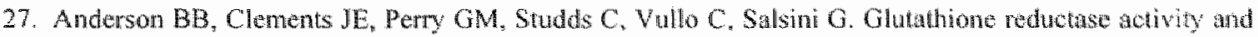

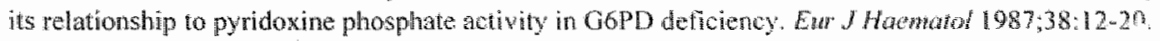

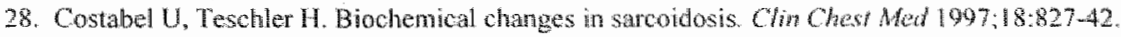

29. Bieutler E. Energy metabolism and maintenance of erythroytes. In: Bewler E, Coller BS, Lichman MA.

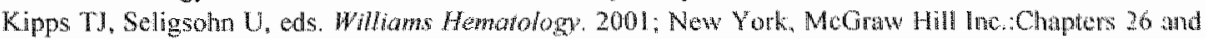
45. 


\section{Chapter 8}

\section{Relationship of myeloperoxidase promotor polymorphism and disease severity in sarcoidosis?}

Snježana Rothkrantz-Kos, Marjolein Drent, Abraham Rulgers, Peter Heeringa, Jolanda De Vries, Marja P. van Dieijen-Visser, Jan-Willem Cohen Tervaert 


\section{Abstract}

\section{Background}

Previously, we demonstrated that the number of polymorphonuclear neutrophils (PMNs) in the bronchoalveolar lavage fluid (BALF) is usefull in distinguishing sarcoidosis patients with a more favourable outcome from those having a more severe course of disease. Neutrophils contain the oxidant generating enzyme, myeloperoxidase (MPO). Cellular levels of MPO can be influenced by functional promotor polymorphisms, $-463 \mathrm{G} / \mathrm{A}$ and $-129 \mathrm{G} / \mathrm{A}$, which might modulate disease severity.

\section{Methods}

In the present sudy, we investigated nwo MPO promotor polymorphisms in 110 sarcoidosis patients and in 191 ethnically matched controls. Pulmonary disease severity was evaluated by means of radiographic staging, HRCT scoring, lumg function- and exercise capacity testing.

Results

No significant differences were found between sarcoidosis patients and healthy controls, with regard to either polymorphism. Furthermore, no association was observed between $-463 \mathrm{G} / \mathrm{A}$ and $-129 \mathrm{G} / \mathrm{A}$ polymorphism, and the severity of sarcoidosis.

\section{Conclusion}

Funciional MPO promotor polymorphisms, $-463 \mathrm{G} / \mathrm{A}$ and $-129 \mathrm{G} / \mathrm{A}$, did not explain for disease severity in the studied sarcoidosis population. Future studies are needed to identify predictive features useful in guiding therapeutic strategies and to determine difficult to treat cases. 


\section{Introduction}

Sarcoidosis, a disease predominantly affecting young adults, is the mast common diffuse lung disease with a population prevalence of around $40: 100.000^{1.2}$. Sarcoidosis is an immune mediated inflammatory disease with unknown etiology, although genetic predisposition is likely to be important ${ }^{2,3}$. The main pathologic feature of the disease is a chronic inflammation resulting in non-caseating granuloma formation. The prognosis of sarcoidosis is rather variable. A great deal of uncertainty exists on how to predict the natural course of the (untreated) disease, and identify those individual cases who should be treated immediately. More important, as it is still not possible to identify the cause of sarcoidosis, therapy is directed at controlling the inflammatory reaction".

Bronchoalveolar lavage fluid (BALF) analysis appears to reflect the severity of sarcoidosis ${ }^{5-9}$. Notably, the number of polymorphonuclear neutrophils (PMNs) is increased in advanced, chronic sarcoidosis ${ }^{5-7.9}$. In line with these findings, interleukin 8 (IL-8), a potent chemoattractant and activator of neutrophils, in BALF appears to be highly elevated in sarcoidosis patients who showed progressive disease ${ }^{8.10}$. Myeloperoxidase (MPO) is an abundant protein in PMNs and monocytes, stored in the azurophilic granules of neutrophils and released during phagocytosis ${ }^{11.12}$. MPO in BALF originates from lung PMNs and can be used to estimate the presence and/or activation of PMNs ${ }^{13}$. Indeed, a strong correlation between the MPO level and the PMNs count in BALF has been demonstrated in patients with Wegener's granulomatosis ${ }^{14}$. The MPO concentrations appear to be assaciated with two described functional promotor polymorphisms, namely the $-463 \mathrm{G} / \mathrm{A} \mathrm{MPO}$ promotor polymorphism ${ }^{15.16}$ and the recently described $-129 \mathrm{G} / \mathrm{A}$ promotor polymorphism ${ }^{17}$. Several diseases were reported to be associated with $-463 \mathrm{G} / \mathrm{A}$ promotor polymorphism $^{16,18-22}$, whereas no association studies of $-129 \mathrm{G} / \mathrm{A}$ have yet been reported.

MPO appears to be involved in tissue damage through production of potent oxidlant $\mathrm{HOCl}$, which is able to oxidize many cellular compounds such as thiols and NADPH and lead to chlorination of DNA bases and tyrosine residues in proteins ${ }^{11,12,23-25}$. Therefore, it can be assumed that decreased availability of MPO related to functional MPO promotor polymorphisms, has a protective effect by decreasing the chance of tissue damage.

It was hypothesized that MPO polymorphism might contribute, at least in part, to disease severity in sarcoidosis and make it possible to determine those cases who might benefit from agents controlling the inflammatory reaction at an early stage. Hence, the incidence of two MPO promotor polymorphisms $(-463 \mathrm{G} / \mathrm{A}$ and $-129 \mathrm{G} / \mathrm{A}$ ) was analyzed in a Dutch Caucasian sarcoidosis population as well as a possible relationship with disease severity. 


\section{Materials and Methods}

\section{Study population}

Caucasian sarcoidosis patients $(n=110)$, who visited the Sarcoidosis Management Center of the University Hospital Maastricht, a Dutch referral center for sarcoidosis between January 2000 and April 2001, were included in this study. Patients were diagnosed based on consistent clinical features and BALF fluid analysis, according to the ATS/ERS/WASOO guidelines ${ }^{2,26}$. The diagnosis was histologically confirmed in $85 \%$ of the cases. The control population consisted of 191 healthy individuals. Informed consent was obtained from all participating subjects. Patient characteristics are summarized in Table 8.1.

Table 8.1. Characteristics of the Dutch Caucasian sarcoidiosis patients and controls genotyped for -463 G/A and -129 G/A myeloperoxidase (MPO) promotor polymorphism.

\begin{tabular}{lcc} 
& Sarcoidosis patients $(n=110)$ & Control subjects $(n=191)$ \\
\hline Male / female, $n$ & $55 / 55$ & $100 / 91$ \\
Age" years & $40.7 \pm 11.0(17-70)$ & $36.4 \pm 14.4(18-82)$ \\
Time since diagnosis ${ }^{2}$, years & $4.25 \pm 5.67(0-37)$ & - \\
Smoking (no/ yes), $n$ & $101 / 9$ & - \\
Prednison (no/ yes), $n$ & $78 . / 32$ & -
\end{tabular}

${ }^{a}$ Data are expressed as mean $\pm S D$ with range in parentheses.

\section{Evaluating Sarcoidosis Pulmonary Disease Severity}

Chest radiographs were graded according to the radiographic staging of DeRemee ( 0 to III), adding stage IV, the end stage of lung fibrosis ${ }^{2.27}$. With high-resolution computer tomography (HRCT), thin-section scans with 1 -mm collimation were obtained at 10$\mathrm{mm}$ intervals through the chest. The scanning parameters included $137 \mathrm{kVp}, 255 \mathrm{~mA}$, and 1 -second scanning time.

Both mediastinal (width, $400 \mathrm{HU}$; level, $40 \mathrm{HU}$ ) and lung (width, $1600 \mathrm{HU}$; lewel, $-800 \mathrm{HU}$ ) window images were obtained. The semiquantitive HRCT scoring system was used as described previously ${ }^{25}$.

Lung function parameters, including the forced expiratory volume in $1 \mathrm{~s}$ (FEVI) and forced vital capacity (FVC), were measured with a pneumotachograph. The diffusing capacity for carbon monoxide (DLCO) was measured by the single-breath method (both Masterlab, Jaeger, Würburg, Germany). Values were expressed as a percentage of those predicted ${ }^{29}$.

Serum ACE (SACE) was measured by colorimetric method (Fujirebio Inc., Tokyo, Japan, cat. nr. FU 1 16). ACE acts on a substrate p-hydroxybenzoyl-glycyl-L-hystidyl-Lleucine and separates p-hydroxybenzoyl-glycine, which is converted in two consequent reactions in quinoneimine dye. The absorbance of quinoneimine dye is measured at 505 nm to evaluate the ACE activity. 
Soluble Interleukin-2 receptor (sLL-2R) was measured on the IMMULITE Automated Analyzer, which is a two-site chemiluminescent enzyme ummumometric assay with a detection limit of $50 \mathrm{kU} / \mathrm{L}$ and a measuring range of $50-7500 \mathrm{kU} / \mathrm{L}$ (Diagnostic Product Corporation, Los Angeles, CA, cat no LKIP1).

\section{Molecular studies}

The $-463 \mathrm{G} / \mathrm{A}$ polymorphism was determined as previously described ${ }^{16,18,10}$. The - $129 \mathrm{G} / \mathrm{A}$ polymorphism was determined as described by Hoy at al. ${ }^{\text {? }}$. The most important features are presented in Table 8.2. When screening for $-129 \mathrm{G} / \mathrm{A}$ polymorphism, we identified a $1.29 \mathrm{G}$ to $\mathrm{A}$ specific Apal restriction site within the $278 \mathrm{bp}$ PCR product. PCR products were digested with 20 units of Apal (Roche, Mijdrecht, The Netherlands) for two hours or overnight at $30^{\circ} \mathrm{C}$, separated on a $2 \%$ agarose gell and stained with ethidium-bromide.

Table 8.2. Sequences of primers and digestion fragments length used for myeloperoxidase (MPO) genotyping.

\begin{tabular}{llcl}
$\begin{array}{l}\text { MPO } \\
\text { Promotor }\end{array}$ & Primers & $\begin{array}{l}\text { Digestion of } \\
\text { PCR product }\end{array}$ & $\begin{array}{l}\text { Genotype (characterized } \\
\text { by fragments in bp) }\end{array}$ \\
\hline -463 G/A & 5'CGGTATAGGCACACAATGGTGAG & Acil & GG $(168,121,61)$ \\
& 5'R-GCAATGGTTCAAGCGATTCTTC & & $G A(289,168,121,61)$ \\
-129G/A & 5'-CCTCCACAGCTCACCTGATAT & Apa I & GG $(289,61)$ \\
& 5'R-CGCTTGACCATTGCACATCA & & GA (154)
\end{tabular}

\section{Statistics}

All analysis were perfomed using the SPSS10.0 for Windows (SPSS, Chicago, IL, USA). Agreement with Hardy-Weinberg-equilibrium and differences in allele and genotype frequencies between groups were examined using chi-square tests. Because multiple comparisons were performed, a probability value divided by number of comparisons was considered statistically significant (Bonferroni"s correction). Univariate logistic regression analysis was used to calculate odds ratios with $95 \%$ confidence intervals. Group comparisons were performed by means of Independent Samples t-test or Mann-Whitney U test.

\section{Results}

The two functional MPO polymorphisms fulfilled Hardy-Weinberg expectations in both sarcoidosis and control subjects. Genotype distributions associated with the $-463 \mathrm{G} / \mathrm{A}$ or $-\rrbracket 29$ G/A polymorphism did not differ significantly between patients with sarcoidosis and healthy controls (Table 8.3). Furthermore, for both polymorphisms sex-specific analysis showed no differences of allele or genotype frequencies (data not shown). Base-line clinical data of the patients with sarcoidosis are presented in Table 8.4. 
Additionally, it was tested whether any association could be found with MPO polymorphisms. For this purpose, for $-463 \mathrm{G} / \mathrm{A}$ polymorphism, the GA and $\mathrm{AA}$ genotypes were grouped together and compared to the GG genotype. No relation with age at diagnosis was found. Furthermore, severity of the disease was evaluated in relation to genotype. The results of this analysis are presented in Table 8.5 . As can be seen no significant differences in the severity as presented by clinical data could be found, the finding which remained also after correction for prednison use. The same analysis as shown in Table 8.5 was repeated with respect to $-129 \mathrm{G} / \mathrm{A}$ polymorphism and no relation to clinical data was found (data not shown).

Table 8.3. Genotype frequencies of the myeloperoxidase (MPO) promotor polymorphisms in the Dutch Caucasian sarcoidosis and control population.

\begin{tabular}{|c|c|c|c|c|c|}
\hline Polymorphism & & $\begin{array}{c}\text { Sarcoidosis } \\
\text { Patients } \\
(n=110)\end{array}$ & $\begin{array}{l}\text { Control } \\
\text { Subjects } \\
(n=191)\end{array}$ & $\operatorname{OR}(95 \% \mathrm{Cl})$ & p-value \\
\hline \multicolumn{6}{|l|}{$-463 \mathrm{G} / \mathrm{A}$} \\
\hline Genotype & $\begin{array}{l}Q G \\
\mathrm{CA}^{\mathrm{C}} \\
\mathrm{AA}^{\mathrm{C}}\end{array}$ & $\begin{array}{c}67(60.9 \%) \\
37(33.6 \%) \\
6(5.5 \%)\end{array}$ & $\begin{array}{c}113(59.2 \%) \\
68(35.6 \%) \\
10(5.2 \%)\end{array}$ & $\begin{array}{l}1.0 \\
1.01(0.35-2.91) \\
0.91(0.56-1.52)\end{array}$ & 0.942 \\
\hline Allele & $\mathrm{A}^{\mathrm{C}}$ & $\begin{array}{r}171(77.7 \%) \\
49(22.3 \%)\end{array}$ & $\begin{array}{c}294(77.0 \%) \\
88(23 \%)\end{array}$ & $\begin{array}{l}1.0 \\
0.95(0.64-1.42)\end{array}$ & 0.829 \\
\hline \multicolumn{6}{|l|}{$-129 G i A^{d}$} \\
\hline Genotype & $\begin{array}{l}\mathrm{GG} \\
\mathrm{GA}^{\circ}\end{array}$ & $\begin{array}{l}97(88.2 \%) \\
13(11.8 \%)\end{array}$ & $\begin{array}{r}167(87.4 \%) \\
24(12.6 \%)\end{array}$ & $\begin{array}{l}1.0 \\
0.93(0.45-1.91)\end{array}$ & 0.849 \\
\hline Allele & $\begin{array}{l}G \\
\mathbb{A}^{C}\end{array}$ & $\begin{array}{c}207(94.1 \%) \\
13(5.9 \%)\end{array}$ & $\begin{array}{c}358(93.7 \%) \\
24(6.3 \%)\end{array}$ & $\begin{array}{l}1.0 \\
0.93(0.46-1.88)\end{array}$ & 0.854 \\
\hline
\end{tabular}

Data are expressed as absolute numbers with percentages in parentheses.

" p-values are for overall comparison between cases and control subjects (Chi-square analysis).

Odds ratios (OR) for genotypes/alleles were calculated by logistic-regression analysis.

"GG genotype or G allele is the reference group.

"AA genotype was absent from both sarcoidosis and control group.

Table 8.4. Evaluation of severity in Dutch Caucasian sarcoidosis patient population ${ }^{2}$

\begin{tabular}{|c|c|c|c|}
\hline & Fermale $(n=55)$ & Male $(n=55)$ & Total $(n=110)$ \\
\hline$A C E(9-25 \cup / L)$ & $20(17-26)$ & $20(15-28)$ & $20(16-27)$ \\
\hline sll-2R $(241-846 \mathrm{kU} / L)$ & $550(404-937)$ & $767(409-1180)$ & $667(408-1085)$ \\
\hline FEV $1, \%$ pred & $97.0(84-106)$ & $87.0(63-99)$ & $92.0(69.8-103)$ \\
\hline FVC, \% pred & $105(94.2-115)$ & $91.0(77.5-102)$ & $98.5(84.5-410)$ \\
\hline DLCO, $\%$ pred & $89(78-96)$ & $85.5(72.5-97.5)$ & $87.0(76.5-96.5)$ \\
\hline Rediographic stages $0 / \| / 1 / / 11 / 1 \mathrm{~W}^{b}$ & $17 / 8 / 14 / 14 / 2$ & $4 / 8 / 14 / 20 / 9$ & $2 \| / 16 / 28 / 34 / 11$ \\
\hline HRCTtot $(0-18)^{\circ}$ & $4.0(1-6)$ & $6.0(3-9)$ & $5.0(3-8)$ \\
\hline
\end{tabular}

"Data are median with interquartile range (25th -75 th percentile) in parenthesis, except for radiographic staging.

$p<0.01$ comparing males and females. 
Table 8.5. Rellationship of the 463 G/A myloperoxidase (MPO) promotor polymorphism and disease severity in a Dutch Caucasian sarcoidosis population $(n=110)^{\text {is }}$

\begin{tabular}{|c|c|c|c|c|}
\hline \multirow[t]{2}{*}{ Diagnostic parameter } & \multicolumn{2}{|c|}{ Female } & \multicolumn{2}{|c|}{ Male } \\
\hline & $\begin{array}{c}G G \\
(n=32)\end{array}$ & $\begin{array}{l}\text { GA/AA } \\
(n=23)\end{array}$ & $\begin{array}{c}G G \\
(n=35)\end{array}$ & $\begin{array}{l}\text { GA/AA } \\
(n=20)\end{array}$ \\
\hline $\operatorname{SACE}(9-25 \cup / L)$ & $20(18-26)$ & $20(16-27)$ & $23(15-27)$ & $18.5(15.3-32.8)$ \\
\hline sIL-2R (241-846 kU/L) & $511(397-806)$ & $732(414-1581)$ & $801(409-1180)$ & $664(409-1181)$ \\
\hline FEV $1 \%$ pred & $99(88-107)$ & $92(71-106)$ & $79(61-100)$ & $90(73-96)$ \\
\hline$F W C_{n} \%$ pred & $105(96-115)$ & $105(88-114)$ & $89(75-105)$ & $95(86-100)$ \\
\hline DLCO, \% pred & $89(81-95)$ & $87(72-99)$ & $83(69-96)$ & $92(80-102)$ \\
\hline $\begin{array}{l}\text { Radiographic stages } \\
\text { O//1/III/IV }\end{array}$ & $11 / 8 / 6 / 7 / 0$ & $6 / 0 / 8 / 7 / 2$ & $3 / 5 / 7 / 13 / 7$ & $1 / 3 / 7 / 7 / 2$ \\
\hline HRCT tot $(0-18)$ & $3(1-5)$ & $6(2-7)$ & $7(4-9)$ & $6(3-9)$ \\
\hline
\end{tabular}

- Data are median with interquartile range (25th -75 th percentile) in parenthesis, except for radiographic staging

\section{Discussion}

This study showed that distribution of two functional myeloperoxidase (MPO) promotor polymorphisms ( $-463 \mathrm{G} / \mathrm{A}$ and $-129 \mathrm{G} / \mathrm{A}$ ) was similar in sarcoidosis patients as compared to controls. Furthermore, no relation was found between these polymorphisms and disease severity. To exclude a possible bias due to corticosteroid use, treated and untreated sarcoidosis patients were also considered separately. The results in both subgroups appeared to be similar to those in the total population, i.e. no relation with MPO genotype (also after stratification for sex and age) was found.

Among the cells present in bronchoalveolar lavage fluid (BALF), polymorphonuclear neutrophils (PMNs) are considered to be a key mediator indicative of severity of the disease. In cases with more extensive long term radiographic features, impaired lung function parameters, having a worse prognosis and sometimes corticosteroid resistant chronic disease, PMNs were found to be increased in BALF ${ }^{5-7,9}$. Moreover, a strong correlation exists between the myeloperoxidase level and the PMN count in BALF ${ }^{\text {id }}$.

Some could argue that the neutrophils might just be an epiphenomenon, coming in when disease is extensive and fibrotic. However, it was recently demonstrated that the number of neutrophils in BALF even at first presentation is indicative of prognosis and disease outcome $e^{5.9}$.

GG genotype of $-463 \mathrm{G} / \mathrm{A}$ polymorphism was previously found to correlate with higher levels of MPO mRNA and higher protein levels, as shown by Western blotting, than the GA or AA genotype ${ }^{15}$. In contrast, when circulating levels of MPO were measured in serum by means of enzyme immunoassay, no such correlation was found with $-4.63 \mathrm{G} / \mathrm{A}$ polymorphism, but only with $-129 \mathrm{G} / \mathrm{A}$ polymorphism ${ }^{17}$.

It was recently demonstrated that $-463 \mathrm{G} / \mathrm{A}$ MPO promotor polymorphism influences diseases severity and expression in chronic granulomatous disease $\mathrm{e}^{22}$ and Wegener's granulomatosis ${ }^{20}$, both granulomatous diseases different from sarcoidosis. In the present study, however, no association of MPO promotor polymorphisms with sarcoidosis were found. One possible explanation could be, that disease expression in chronic granulomatous disease and Wegener's granulomatosis is modulated by infections with 
extensive PMN involvenent. Indeed, co-trimoxazol (antibacterial drug) positively influences the course of disease in both chronic gramulomatous disease $\mathrm{s}^{30}$ and Wegener"s granulomatosis ${ }^{31.32}$, whereas this has never been shown in sarcoidosis.

Granulona formation in sarcoidosis appears to be a strictly $T$ cell dependent process ${ }^{3}$. Since MPO was shown to inhibit T cell proliferation ${ }^{34,35}$, one can postulate that MPO promotor polymorphisms might also inflwence the $T$ cell dependent disease process in sarcoidosis. Therefore, the role of MPO and its polymorphisms seem very complex and not completely defmed in the different diseases that are characterized by granulomatous inflammation.

In conclusion, the PMN count in BALF appears to be useful in determining chronic and difficult to treat sarcoidosis patients. MPO plays a key role in the immunopathogenesis of several granulomatous disorders and MPO release appears to be related to MPO polymorphism(s). However, in the Dutch Caucasian sarcoidosis population studied, similar frequencies of functional MPO promotor polymorphisms $(-463 \mathrm{G} / \mathrm{A}$ and $-129 \mathrm{G} / \mathrm{A}$ ) were found as compared to control subjects. Furthermore, no association between $-463 \mathrm{G} / \mathrm{A}$ and $-129 \mathrm{G} / \mathrm{A}$ MPO promotor polymorphisms, and the severity of sarcoidosis, including radiographic features, impaired lung function, time since diagnosis and corticosteroid use was found in our study population. Given the inability to identify the cause of sarcoidosis, therapy is directed to control the inflammatory reaction. Furure studies are needed to determine those cases with a more advanced chronic course of the disease who might benefit from early treatment of the inflammatory reaction. 


\section{References}

1. Foley PJ, Mullighan CG, MoGrath DS, Pantelidis P, Marshall S. Lympany PA, Welsh KI, Da Bois RM. Mannose-binding lectin pronoter and structural gene warians in sarcoldosis. End / Cho Ifwest 2000; $30: 549-52$.

2. Hunninghake GW, Costabel U. Ando M, Baughnan R, Cordier JE, Du Bois RM, Eklund A, Kitaichi M. Lynch I, Rizzato $G$, Rose $C$, Selroos O, Semenzato G. Sharna OP. ATSRERS/WASOG statement on sarcoidosis. American Thoracic Society/European Respiratory Soctery/World Asscociation of Sarcoidosis and other Giranulomatous Disorders. Sarcotidosis Vasc Diffure Lung Dis 1999:16:149-73.

3. Newman LS, Rose CS, Maier LA. Sarcoidosis. N Eng? J Med 1997;336:1224-34.

4. Baughman R.P. Can persistant tumor mecrosis factor release lead to refractory satcoidosis? Sancoidosis Vase Diffuse Lung Dis 2002;19:164-6.

5. Drent M, Jacobs JA, De Vries J, Lamers RUS, Liem IH, Wouters EFM. Does the cellutar bronchoatveolar lavage fluid profile reflect the severity of sarcoidosis? Ear Respir J 1999:13:1338 -44.

6. Roth C, Huchon GJ, Arnoux A, Stanislas-Leguern G. Marsac JH, Chretien J. Bronchoalveolar cells in advanced pulmonary sarcoidosis. Am Rey Respir Dis 1981;124:9-12.

7. Lin YH, Hasian PL, Turner-Warwick M. Chronic pulnondy sarcoidosis: retaionship between inng. lavage cell counts, chest radiograph, and results of standard lung function tests. Thora 1985:40:501-7.

8. Car BD, Meloni F, Luisetti M, Semenzato G, Gialdroni-Grassi $\mathrm{G}$. Walz A. Elevaled IL -8 and MCP-1 in the bronchoalveolar lavage fluid of patients with idiopathic pulmonary fibrosis and pulnonary sarcoidosis. Am d" Respir Crit Care Med 1994:149:655-9.

9. Ziegenhagen HW, Rothe ME, Schlaak M, Müller-Quernheim J. Bronchoniveolar and serological parameters reflecting the severity of sarcoidosis. Ear Respir $/ 2003: 21: 407-13$.

10. Takizawa H, Satoh M, Okaraki H, Matsuzaki G, Suruki N, Ishii A. Suko M, Okudaira H. Morita $Y_{\text {, Ito }}$ K. Increased $1 L-6$ and IL.8 in bronchoalweolar lavage fluids (BALAF) from paticnts with sarcoidosis: correlation with the clinical parameters. Clin Exp Immanol 1997;107:175-81.

11. Winterbourn CC, Vissers MC, Kettle A. Myeloperoxidase. Cur Opin Hemato/ 2000:753-8.

12. Klebanoff SJ. Myeloperoxidase. Proc Assoc Am Phyxicians 1999;111383.9.

13. Schmekel B, Karlsson SE, Linden M, Sundstrom C, Tegner Hi, Venge P. Myeloperox idase in human lung lavage. 1. A marker of local neutrophil activity. Inflammation $1990 ; 144: 447-54$.

14. Setinabel A, Csemok E, Braun J, Gross WL. Activation of neutrophils, cosinophils, and lynuphocytes in the lower respiratory tract in Wegener's granulomatosis. Am I Respir Crit Care Med 2000; 161;399-405.

15. Piedrafita FJ, Molander RB, Vansant G, Orlova EA. Pfahl M, Reynolds WF. An Alu element in the mycloperoxidase promoter contains a composite SP1 whyrod bormone-retinoic acid response element. I Brol Chem 1996;271:14412-20.

16. Reyrolds WF. Chang E, Doner D, Ball EO, Kanda $V$. An allelic association inplicates myeloperoxiduse in the etiology of acute promyelocytic leukemia. Blowd 1997;90:2730/7.

17. Hoy Aregonet D, Leininger-Muller $B$, Poirier $O$, Mauriee $M$. Sass $C$, Siest G, Tiret $L$, Visvikis $S$. Serum myeloperoxidase concentration in a healtry population: biological variations, familial resemblance and new genetic polymorphisms. Eur J Hum Gener 2001:9780-6.

18. Cascorbi I, Henning S. Brockmötler J, Gephart J, Meisel C. Müller JM. Loddenkenper R, Roots I. Substantially reduced risk of cancer of the aerodigestive tract in subjects with variant $463 \mathrm{~A}$ of the myeloperoxidase gene Cancer Res 2000:60:644*9.

19. London SI, Lehman TA. Taylor JA. Myeloperoxidase genetic polymorphism and lung cancer risk. Concer Res 1997:57:5001-3.

20. Reynolds WF, Stegeman CA, Cohen Tervaert JW. 463 G/A Myeloperoxidase Promoter Pollymorphism Is Associated with Clinical Marifestations and the Course of Disease in MPO ANCA Associated Vagculisis. Clin Immunol 2002; 103:154-60.

21. Reynolds WF. Hiftunen $M_{\text {, }}$ Pirskanen M, Mannermaa A, Helisalmi S, Lehtowirta M, Alafuzoff L. Soininen H. MPO and APOEepsilon4 polymorphisms interact to increase risk for AD in Finnish inales. Newrology $2000 \div 55: 1284-90$. 


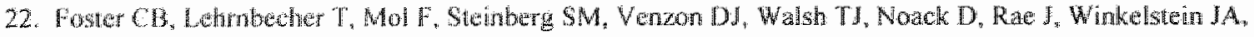

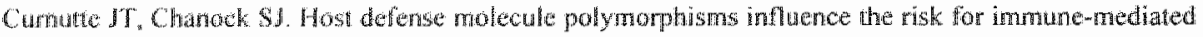

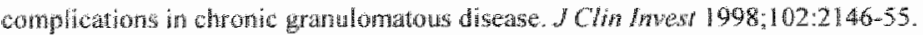

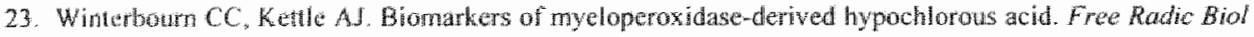
Mcd $2000,29 \cdot 403-9$

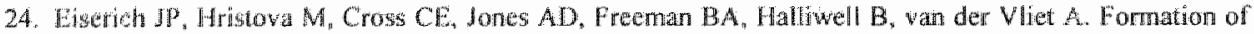

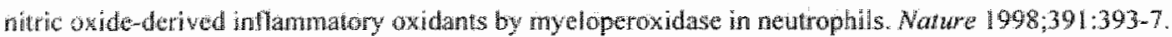

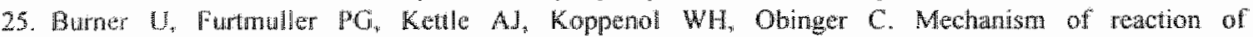
myeloperoxidase with nilrite if Biol Chem 2000,27520597-601.

26. Drent M, Jacobs M, Cobben NAM, Costabel U, Wouters EFM, Mulder PGH. Computer program supporting the diagrostic accuacy of celluar BALF analysis: a new release. Respin Wed 2001,95: 781.786.

27. Dekemee RA. The roentgenographic staging of sarcoidosis. Historic and contwmporary perspectives. Ches $1983,53: 128-33$.

28. Obusten $A$, von Zlzewitz H, Schweden F" Maller-Quemhem J. Non inwasive evaluation of the inflammatory activity in sarcoldosis with high-resolution computed tonography. Sarcoidowis Vasc Diffuse Luagg Dis $1997 ; 14: 65-72$.

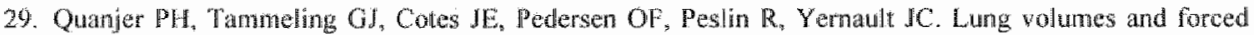
ventilatory flows. Report Working Party Stundardization of Lung Function Tests, European Community for Sted and Codil. Oplicial Statement of the European Respiratory Society. Eu Respir J Suppl 1993; $16: 54-40$.

30. Cak CM, Jones AM, Goldblan D. Follow up of paticnts whth chronic grantomatous disease diagnosed

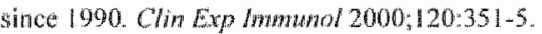

31. Stegenan CA, Cohen Tervaen JW, de Jong PE, Kallenberg CG. Trimethoprim-sulfamethonazole (co-

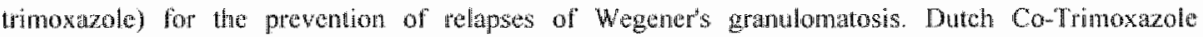
Wegener Study Group. N Engl I Med 1996;335:16-20.

32. DeRernes RA. The treatment of Wegener's granulomatosis with trimethoprim/sulfamethoxazole: illusion or vision? Arthitis Rheum 1988:31:1068-74.

33. Agostini C, Basso U, Semenzato G. Cells and molecules involyed in the development of sarcoid grantuloma. IClin Inwnthof 1998; $18: 184,92$.

34. el-Hag A, Clatk RA. Immunosuppression by activated humar neutrophils. Dependenee on the myeloperoxidase system. al Immant 1987; $39: 2406-13$.

35. van der Veen RC, Dietlin TA, Hoiman FM, Pen L, Segal BH, Holland SM. Superoxide prevents nitric oxide-mediated supprassion of helper "T" lymphocytes" decreased autoimmune ancephalomyelitis in

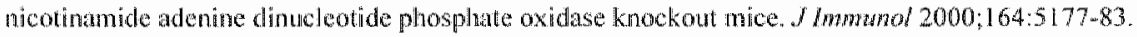


Chapter 9

\section{General discussion}




\section{General discussion}

Sarcoidosis is characterized by an abundant immunological response, which in most cases spontaneously resolves. Nevertheless, in some cases the disease has a more or less severe course. Finally, it may lead to end-stage lung fibrosis with signs of respiratory functional impairment. One of the most important issues to deal with for clinicians is to identify those cases that will deteriorate and eventually develop fibrosis. Those cases should be monitored more closely and receive appropriate and timely treatment in order to prevent fibrosis development.

In general, the state of a disease can be classified either by activity or severity. Unlike other disorders, activity in sarcoidosis does not necessarily indicate a progressive course, a fatal prognosis, or the need for medical treatment ${ }^{1}$. Many markers have been searched to reflect the disease activity. Unfortunately, the term "activity" has in the past been used unsystematically, resulting in the fact that no good marker of activity could be found ${ }^{2}$. Previously, the term activity in pulmonary sarcoidosis has been related to the presence of $\mathrm{T}$ cell activation (alveolitis in case of pulmonary sarcoidosis), whereas until now no good consensus on activity exists (CHAPTER 1). Angiotensin converting enzyme (ACE) is still recommended by World Association of Sarcoidosis and Other Granulomatous Disorders (WASOG) as a marker of activity in sarcoidosis, despite of its shortcomings ${ }^{3-5}$.

So far little attention has been paid to the appropriateness of markers to detect severity. From a clinical point of view, it is more important to depict whether the disease is severe, i.e. will have a more or less chronic course and will end-up with functional impairment wather than the initial activity. No proper marker of severity in sarcoidosis exists, which enables to predict deterioration. Moreover, this is complicated by the fact that an appropriate and sufficient definition of activity and severity is still lacking.

There is a lot of discussion going on about the definitions of both terms, as it is difficult to make a clear distinction between these two entities. Besides, there is overlap between the two. Activity is a sign of inflammation. Severity, reflected through respiratory functional impairment, might be accompanied by inflammation (so activity may be present) as well. However, finally an end-stage situation without signs of an active inflammation can be found.

For each appropriate evaluation in the form of a diagnostic accuracy study for any marker a clear definition of the condition such as activity or severity is needed. In this thesis we introduce the definition of respiratory functional impairment to define pulmonary severity. We suggest the usage of this term, as it is as such of more interest to pulmonary physicians. Furthermore, we feel that severity, indicating functional impairment is of more clinical relevance.

Accordingly, one of the aims of this thesis was to search for new markers, which would enable to reflect disease severity in sarcoidosis. Respiratory functional impairment was used to depict the severity of the disease.

Four markers which have been claimed or suggested to be good markers of disease activity were evaluated for their ability to reflect disease severity: $\mathrm{C}$-reactive protein 
(CRP), serum amyloid A (SAA), soluble interleukin-2-receptor (sIL-2R) and angiotensin-converting enzyme (ACE).

These markers were also related to one of the most common and bothering symptoms, i.e. fatigue.

Prior to clinical evaluation of different biomarkers, the methods used to measure these markers were evaluated.

A previous study showed that CRP was associxted with metabolic derangement and fatigue in sarcoidosis, using our routine CRP method ${ }^{6}$. CRP is also used as a marker of prediction of risk of future arteriosiclerosis. From that aspect, several papers indicated that the routine CRP measurement as used among many laboratories could not be used in the low range because of the poor performance and too high detection limit (mostly between 2 and $5 \mathrm{mg} / \mathrm{L}$ ). Moreover, in case of sarcoidosis, CRP changes were for a considerable part confined to the lower range ${ }^{6}$.

Our routine CRP method (detection limit $5 \mathrm{mg} / \mathrm{L}$ ) indeed appeared to suffer from serious shortcomings in the low range. Moreover, the method appeared to be extremely sensitve to sample turbidity, making the results obtained in such samples unreliable. This underlined further the need for a more appropriate method for the CRP measurement. The methods able to measure consistently very low CRP concentrations are called high-sensitivity CRP (hs-CRP) methods. Several hs-CRP methods were evaluated for their performance together with their sensitivity to turbidity of a sample. Based on the extensive evaluation of hs-CRP and CRP methods in CHAPTER 2 and 3 , we decided to use BN ProSpec hs-CRP method for further evaluation of sarcoidosis patients.

Based on several previous studies it was assumed that SAA and SLL-2R might potentially be usefull in sarcoidosis ${ }^{7-9}$. We evaluated these two new assays for analytical performance and determined the reference values as shown in CHAPTER 4. Evaluation of the sIL-2R method on the IMMULITE and the SAA method on the BN ProSpec yielded good imprecision results and satisfying linearity. The reference values for sIL$2 \mathrm{R}$ appeared to be sex and age independent. The reference values for SAA on BN Prospec were sex dependent and showed a relationship with age.

The am of the study presented in CHAPTER 5 was to evaluate the clinical usefulness of serological markers, of which the analytical performance was evaluated across the previous chapters. Thus, the diagnostic accuracies of hs-CRP, SAA and SIL-2R were established in sarcoidosis patients and they were compared to the traditionally used ACE in monitoring disease severity. Hundred forty-four non-smoking, 73 untreated (Group I) and 71 treated (Group II) patients were selected. The subgroups of the untreated patients, Group la (non-chronic group with time since diagnosis $\leq 2$ years) and Group Ib (chronic group with time since diagnosis $>2$ years) were evaluated separately. ROC-curves and logistic regression analyses were used to compare the diagnostic accuracy of different markers to assess disease severity. Respiratory functional impaiment i.e. pulmonary disease severity was defined by means of lung function test results. The major finding of this chapter was that among the evaluated matkers, in untreated patients, s[L-2R appeared to be the best marker to monitor 
respiratory functional impaiment and thus puimonary severity. Furthemore, it appeared to be the most suitable marker for the follow-up. In line with others, $\$ L-2 R$ was clearly shown to be superior to usually used ACE to monitor not only the activity but also pulmonary severity ${ }^{8-10}$. However, the difference between the approach used in this chapter and other studies is that we performed an appropriate diagnostic accuracy study. For relationship between the markers, a fact that is often overlooked, was statistically corrected. Moreover, the value of the four markers was examined in an extensive way in non-treated as well as treated sarcoidosis patients. Finally, an attempt was made to give a reproducible and clear definition of criteria used to define pulmonary severity based on lung function test results as follows: DLCO $<80$ or FVC $<80$ or FEV $1<80$. We suggest that the criteria as defined in this chapter could be used more broadly; at least as long as there is a lack of official definition of severity criteria.

Patients with sarcoidosis most often suffer from symptoms related to the lungs, but may also suffer from a wide spectrum of other symptoms. One of the most often reported general symptoms is fatigue. As studies on the relationship between fatigue and laboratory and clinical parameters are sparse, in CHAPTER 6 this relationship was examined.

Previously it was shown that CRP appeared to be associated with metabolic derangement and fatigue in sarcoidosis, by means of less sensitive routine CRP measurement ". Our evaluation in CHAPTERS 2 and. 3 clearly showed that this routine method has serious shontcomings. Therefore, new hs-CRP method on the BN Prospec, the SAA and SIL-2R were measured among the serum markers in addition to traditionally used ACE. As factors that might predict fatigue also lung function test results reflecting respiratory functional impairment and the measures of metabolic derangement were included.

Patients with a time since diagnosis $\leq 2$ years, $(n=60 ; 34$ untreated, 26 treated $)$ were clinically evaluated and completed the Fatigue Assessment Scale (FAS)" It was confirmed that fatigue is a major problem in sarcoidosis. A representative sample of the Dutch control population $(\mathrm{n}=1893$ ) also completed the FAS. Only $27 \%$ of the sarcoidosis patients were classified as not being bothered by fatigue (FAS score <22), compared to $80 \%$ in the control population. Moreover, in the sarcoidosis patients no sex differences and no differences in fatigue scores between the treated and the untreated. groups were found.

The extent of fatigue was neither related to the new tested markers nor to $A C E$, metabolic derangement measures or lung function data. As long as there is lack of 'measurable' clinical parameters to objectively assess fatigue, the AS is useful and recommended as a supplementary tool to characterize the extent of fatigue in sarcoidosis.

The first part of this thesis was used to evaluate inflammatory markers and their ability to define respiratory functional impairment and fatigue in sarcoidosis. In the second part attention was paid to the systems, directly and/or indirectly involved in oxidative stress and microbial killing. 
Prompted by earlier observations, it was hypothesized that oxidative stress probably plays an important role also in sarcoidosis and can eventually modify severity of the disease. Therefore, enzymatic systems, which take care of normall cellular redox-state glucose-6-phosphate dehydrogenase, G6PD and of continuous production of reduced glutathione (GSH) such as glutathione reductase (GR), were assessed in CHAPTER 7. The possibility was raised that some subclinical G6PD-deficiency might be present in patients with sarcoidosis that may modify disease severity. As the G6PD-gen lies on the $X$-chromosome, $\mathrm{C} 6 \mathrm{PD}$-deficency will be clearly visible in males through the measurement of $\mathrm{G} 6 \mathrm{PD}$ activity, but it will be masked in heterozygous females. Consequently, in females the degree of G6PD deficiency might vary enormously. Therefore, the chromate inhibition test (GR-Cr) as a more reliable test was used to assess the G6PD-deficiency. In the Netherlands, the GR-Cr test is the standard test used to establish the G6PD deficiency. This test is based on the inhibition of GR activity by chromate in erythrocytes with a normal level of reduced nicotinamide adenine dinuclleotide phosphate (NADPH), but not in erythrocytes with decreased levels of NADPH, which might be a consequence of G6PD inactivity.

Decreased levels of NADPH, indicating G6PD deficiency, were found in $29 \%$ of the female sarcoidosis patients and in one male patient $(2.5 \%)$. No explanation for this sex difference could be given. Six patients with abnormal chromate-inhibition test were chosen and their G6PD gene was completely sequenced, including non-coding and promotor region of the gene. The selection of patients for sequencing was random, although representing as well extremely abnormal as nearly nomal GR-Cr values. Only one female of Negroid origin appeared to have a mutation in the G6PD gene. This same patient also had enormously decreased G6PD activity, so that even based on solely G6PD activity the diagnosis of G6PD deficiency could be considered. In the remaining patients no mutation in the G6PD gene was found.

Taken together, the GR-Cr test appeared inappropriate to reflect G6PD-deficiency in patients with sarcoidosis, due to its high-degree of false-positivity. One explanation for these findings is that an increased consumption of reduced NADPH is involved in the inflammatory process triggered by oxidative stress in sarcoidosis.

However, the false-positivity of the test might also be caused by the increased GR activity on its own, so that the inhibition is less efficient. The GR appears to be present in two foms, the active form, which is associated with flavine adenine dinucleotide (FAD) and the inactive form, not associated with FAD. GR is almost completely saturated with FAD in red cells in patients with severe metabolic disorders or G6PD deficiency. In line with that, increased GR activity with a high degree of saturation with FAD can be found in red cells of severe uremia, cirthosis of liver and G6PD deficiency ${ }^{12,3}$. In the young red cells (reticulocytes) GR activity can also be increased and is sometimes used to correct for the presence of young cells, which in general have the activities of the nost enzymes increased.

The major problem associated with G6PD deficiency is hemolytic anemia. Hemolytic anemia is the decreased ability of red blood cells to transport oxygen throughout the body, which can have rather serious consequences. Many (oxidative) drugs, infections, or fava beans can cause this. When any one of these agents enters the red blood cell, 
hemoglobin becomes denatured, thus destroying its function as the principle oxygencarrying molecule.

Usually, G6PD deficiency is accompanied with rather large restrictions in drugs and nutrients, which may be taken to avoid hemolytic crisis due to G6PD deficiency. Therefore, it is very important to have a reliable test to establish the G6PD deficiency. As shown in CHAPTER 7, the GR-Cr test cannot be used to establish G6PD deficiency in sarcoidosis patients. The question, which arises, is whether the same test can be used in other "comparable" inflammatory conditions. Anyhow, a careful revision of the test is needed.

In CHAPTER 8, the role of another enzyme involved in non-specific immunity, related to oxidative stress, has been examined. It was previously demonstrated that the number of polymorphonuclear neutrophils (PMNs) in the bronchoalveolar lavage (BAL) fluid is useful to distinguish patients with a more favorable outcome from those having a more severe course of disease in sarcoidosis ${ }^{14}$. The major content of neutrophils is the oxidant-generating enzyme, myeloperoxidase (MPO). Cellular levels of MPO can be influenced by functional promotor polymorphisms, $-463 \mathrm{G} / \mathrm{A}$ and $-129 \mathrm{G} / \mathrm{A}$ that might modulate disease severity. These two MPO promotor polymorphisms were investigated in 110 sarcoidosis patients and in 191 ethnically matched controls. For both polymorphisms no significant differences were found between sarcoidosis patients and healthy controls. Furthermore, no association was observed between both polymorphism, and the severity of sarcoidosis. 


\section{Directions for future research}

The study presented in CHAPTER 8 showed that two functional polymorphisms, which were previously shown to be related to diseases with comparable clinical presentation, were not associated with sarcoidosis. Also other studies looked at many different polymorphisms. However, although some of them found an association ${ }^{15-19}$, many showed a lack of any association with sarcoidosis ${ }^{3.20}$. Therefore, the search for a combination of polymorphisms, which might predict the course and progression of the disease (severity) is warranted.

Recently, a new unrecognized neurological complication of sarcoidosis, small-fiber neuropathy has been demonstrated ${ }^{2 !}$. For some disorders the link between decreased redox-state and cellular changes has already been established, such as neurons or cardiomyocytes ${ }^{22-25}$. Sarcoidosis has been suggested to trigger an oxidative stress response as also indicated by an increased activation of nuclear regulatory factorkappaB $(\mathrm{NF}-\mathrm{kB})^{26,27}$.

The possibility exists that the decreased redox-state in patients with inflammatory disorders including sarcoidosis might contribute to nerve-cell changes, which in turn can lead to small-fiber neuropathy. This is an interesting area with great clinical implications, which should be further explored.

As shown in CHAPTER 6, although helpful, a questionnaire is always at least partly a subjective measure to evaluate fatigue. Therefore, other markers able to objectify fatigue should be explored. Sarcoidosis manifests mostly in active young adults of age $20-40$. The possibility exists that a stressful life accompanied with prolonged cortisol production can somehow evoke the sarcoidosis appearance. Possibly some hormonal dysbalance can also be a potentially useful measure of fatigue in sarcoidosis and should further be explored.

In sarcoidosis, there appears to be extra-renal production (by granuloma) of active form of vitamin $\mathrm{D}$. As the active form of vitamin $\mathrm{D}$ has influence on calcium metabolism, the calcium metabolism can largely be deregulated in patients with sarcoidosis ${ }^{28}$. The mechanisms behind this deregulation as well as the clinical impact are largely unknown and need further to be explored.

Finally, one of most interesting areas to be explored and of interest in sarcoidosis is proteomics, which offers the possibility to look at the whole spectrum of serum or BAL fluid proteins at the same time. The first step has been set by group of Grinewald et $a l^{29}$. The proteomics might offer the possibility to find markers that will be able to distinguish acute from chronic patients and possibly to predict patients which will deteriorate due to fibrotic changes from those who will not end up with fibrosis. This new approach might give answers to many questions, which the clinicians are facing for a very long time. This underlines once more the importance of cooperation between clinicians and laboratories to explore the insight in this whimsical disorder sarcoidosis. 


\section{References}

1. Sharma OP, Alam S. Diagnosis, pathogenesis, and trament of sarcoidosis. Cum Opin Pudm Med 1995;1:392-400。

2. Stirling RG, Cullinan P, Du Bois RM. Sarcoidosis. In: Schwarz M, King T, eds. Interstitial Lwog Diweawe 1998; Pliladelphia, BC Decker Inc:279-323.

3. Hunningliake GW, Costabel U, Ando M, Baughman RP, Cordier JF, Du Bois RM, EKhound A, Kitaichi M,

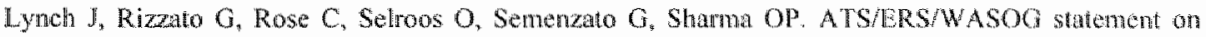
sarcoidosis. American Thoracic Society/European Respiratory Society/World Association of Sarcoidosis and other Granulomatous Disorders. Sarcoidoxis Vase Diffuse Lumg Dis 1999;16:149-73.

4. Bunting PS, Szalai IP, Katic M. Diagnostic aspects of angiotensin converting enzyme in pulmonary sarcoidosis. Clin Biochem 1987;20:213-219.

5. Cohen RD, Bunting PS, Meindok HO, Chamberlain DW, Rebuck AS. Does serum angiotensin conkenting enzynne reflect intensity of alveolitis in sarcoidosis? Thorax 1985;40:497-500.

6. Drent M, Wimsberger RM. De Vries J, wan Dieijen-Visser MP, Wouters EFM, Schols AMWI. Association of fatigue with ath acute phase response in sarcoidosis. Eur Respir J1999-13:718-22.

7. Salazar A, Mana I, Fiol C, Hurlado I, Argimon JM, Pujol R. Pinto X. Influence of serum amyloid A on the decrease of high density lipoprotein-cholesterol in active sarcoidosis. Apherosclerosis 2000:152: 497-502.

8. Ziegenhagen MW, Rothe ME, Schlaak M, Muller-Quemhein I. Bronchoalveolar and serological parameters reflecting the severity of sarcoidosis. Eur Respir $J 2003 ; 21: 407-13$.

9. Ziegenhagen MW, Benner UK, Zissel G, Zabel P* Schlaak M, Muller-Quernheim I. Sarcoidosis:" TN"alpha release from alveolar macrophages and serum level of $\mathrm{SL}$-2 $2 \mathbb{R}$ are prognostic narkers. Am I Respir Crir Care Med 1997;156:1586-92.

10. Grutters JC, Fellrath J-M, Mulder L, Janssen $\mathbb{R}_{n}$ wan den Bosch JMM, van Velzen-Blad H. Serum SIL2R measurement in sarcoidosis patients: a clinical evaluation. Chest 2003;124:186-95.

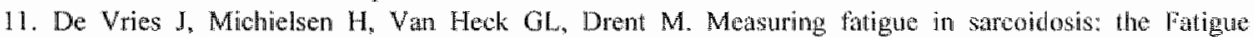
Assessment Scale (FAS). Br W Health Psychol 2004, in press.

12. Flatz $\mathrm{G}$. Enhanced binding of FAD to glutathone reductase in G6PD deliciency. Nartwe 1970;226:755.

13. Yawata $Y$, Tanaka KR. Bffect of metabolic stress on activation of glutathione reductase by FAD in human ted cells. Experientio 1971;27:1214-5.

14. Drent M, Jacobs JA, De Vries J, Lamers RJS, Liem IH, Wouters EFM. Does the cellular bronchoalveolar lavage fluid profile reflect the severity of sarcoidosis? Eur Rospry J1999;13:1338-44.

15. Sato H. Grutter JC. Pantelidis P. Mizzon AN. Almad T, Wan Houte AJ, Lammers J-WJ, van den Boseh JMM, Welsh KI, Du Bois RM. HLA-DQBI*0201; A Marker for Good Prognosis in British and Duth Patients with Sarcoidosis. Am J Respir Cell Mol Biol 2002;27:406-12.

16. Pielinaltho A. Furuya $K$, Yamaguchi $E$, Kawakami $Y$, Selroos $O$. The angiotensin-converting enzyme DD gene is associated with poor prognosis in linnish sarcoidosis palicnts. Eur Respir J 1999:13;723-6.

17. Maliarik MJ, Rybicki BA, Malwitz E, RG, Major M, Popovich J Jr, lannuzzi MC. Angiotensin-tonverting enzyme gene polymorphism and risk of sarcoidosis. Am I Respip Crir Care Med 1998; 158:1566-70

18. Maliarik MI, Chen KM, Major ML, Sheffer RG, Popovich J Jr Rybicki BA, lannuzzi MC. Analysis of HLA-DPB 1 polymorphisms in African-Americans with sarcoidosis. Am I Respor Crit Care Med $1998 ; 158: 111-4$.

19. Shama P', Smith I, Maguire O. Stewart S, Sheerson J, Brown MJ. Clinical value ol ACE genotyping in diagnosis of sarcoidosis Lancet 1997;349:1602-3.

20. MoGrath DS, Goh N, Foley PJ, Du Bois RM. Sarcoldosis: genes and microbes-soil or seed? Sarcoidosis Fase Diffuse Lung Dis 2001;18:149-64.

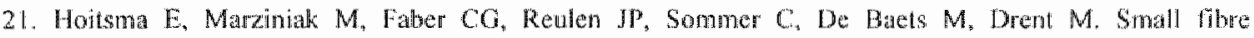
netropathy in sarcoidosis. Lance 2002;359:2085-6.

22. Jain M, Brenner DA, Cui L, Lim CC, Wang B, Pimentel DR, Koh S, Sawyer DB, Leopold JA, Handy DE. Loscalzo J. Apstein CS, Liao R. Glucose-6-phosphate delyydrogenase modulates cynosolic redox status and contractile phenolype in adult cardiomyocytes. Circ Res 2003;93:9-16. 
23. Dran $M$ Gorgels AP, Dast A. Cardiac falure associated with G6PD deficiency. Circ Res 2003, $93(8): 75$

24. Garcha-Nogales P, Amelda A. Bolanos JP. Peroxyntrite protects newrons against nitric oxide-mediated apoptosis. A key role lor glucose-6-phosphate dehydrogenase activity in neuroprotection. $f \mathrm{Bin} / \mathrm{CHew}$ $2003: 278 \div 864 \times 74$

25. Garcia-Nogales P. Almedda A, Fernandez L, Medina $\mathrm{MM}$, Bolanos JP. Inducton of glucose-6-phosphate detrydrogenase by lipopolysactharids contributes to preventing nitric oxide-mediated glutathone depletion in euflured rat astrocytes. J Newrochen 1999;72:1750-8.

26. Drent $M$, vatn den Berg $R$, Haenen GRMM, wan den Berg H, Wouters EFM, Bast A. NF-KB activation in sarcoüdowis. Sancoidosis Vasc Dofuse Lang Dis $2001 ; 18: 50-6$.

27. Abdallah $A$, sato $\mathrm{A}$, Grutters JC, Veeraraghavan $\mathrm{S}$, Lympany $\mathrm{BA}$, Ruwen H, wan den Bosch JMM, Wells AU, Du Bois RM, Welsh KI. Mibibitor kappa B-alpha (IkappaB-alpha) promoter polymorphisms in UK and Dutch sarcoidosis. Genes lom $2003 ; 4: 450$. 4 .

28. Shaina OP. Vikamin D, calcium, and sarcoidosis. Ches 1996;109.535-9.

29. Sabounchi-Schut $\mathrm{F}$, Astrom J Hellman U. EK fund A. Grunewald J. Changes in bronchoalveotar lavage Tuid proteing in sarcoidosis: a protaomics approach . Eur Respur $J 2003 ; 21: 414-20$. 


\section{Chapter 10}

\section{Samenvatting}




\section{Samenvatting}

\section{Sarcoidose}

In HOOFDSTUK $\mathbb{l}$ is een inleiding in sarcoïdose (ook wel bekend als de ziekte van Besnier-Boeck-Schaumann), een aandoening waarvan de oorzaak nog niet bekend is gegeven. Sarcoïdose kan zich op allerlei plaatsen in het lichaam manifesteren maar treedt het meest op in de longen (90\%). De aandoening treft vooral volwassenen tussen de 20 en 40 jaar. Naar schatting hebben in Nederland ongeveer 40 van de 100.000 inwoners sarcoildose.

Het kenmerk van sarcoïdose is een granuloom ofwel een chronische ontstekingshaard. Dit is een opeenhoping van immuncellen, zoals (alveolaire) macrofagen en geactiveerde T-lymfocyten, in de aangedane weefsels. Hoewel tot op heden geen eenduidige oorzaak is gevonden, suggereert het ziektemechanisme dat er sprake is van én of meerdere oorzaken van buiten het lichaam in samenhang met een erfelijke aanleg.

Afhankelijk van onder anderen welke orgaansystemen zijn aangetast, kunnen patiënten met sarcoïdose zich met allerlei klachten aandienen, zoals kortademigheid, oogproblemen, huidafwijkingen, gewrichtsklachten, duizeligheid, hoofd en/of spierpijn. Ook zijn er patiënten met niet-specifieke klachten, zoals algehele malaise, gewichtsverlies en koorts. De meest gerapporteerde klacht is echter moeheid. Deze kan lang blijven bestaan, zelfs nadat tekenen van ziekteactiviteit genormaliseerd zijn.

Het verloop van sarcoïdose is onvoorspelbaar. Een variant, het syndroom van Löfgren gaat bijvoorbeeld gepaard met koorts, huidafwijkingen en/of gewrichtsklachten. Deze vorm heeft een acute presentatie en in het algemeen een gunstig verloop. Wanneer sarcoïdose zich manifesteert in het hart, het centrale zenuwstelsel en/of met uitgebreide longafwijkingen zijn de vooruitzichten ongunstiget.

Voor de begeleiding van sarcoïdosepatiënten en het inschatten van de prognose is het belangrijk dat er een duidelijk beeld wordt verkregen van de omvang van de ziekte. Deze omvang wordt onder meer vastgesteld met behulp van laboratoriumonderzoek, beeldvormende technieken, longfunctietesten, visueel onderzoek van de luchtpijp (bronchoscopie) en een bronchoalvolaire lavage (het spoelen van een gedeelte van de long).

Aangezien de oorzaak van sarcoïdose nog steeds niet bekend is, bestaat de behandelling in het algemeen uit symptoombestrijding die bij milde klachten bestaat wit het gebruik van eenvoudige ontstekingsremmers en bij een ernstiger verloop uit immuunsuppressiva (zoals o.a. prednison). Verder zijn leefregels met betrekking tot het leren omgaan met de moeheid van groot belang.

\section{Evaluatie van markers om de ernst van sarcoïdose te voorspellen}

In het algemeen worden gedurende een ontstekingsreactie door de lever in zeer korte tijd grote hoeveelheden C-reactive protein (CRP) en serum amyloid-A (SAA) aangemaakt. Beide eiwitten worden dan ook acute fase eiwitten genoemd. Bij bepaalde 
dandoeningen is de productie niet explosief maar er vindt wel een constant licht verhoogde producte van deze eiwitten. CRP is belangrik voor de initiatie van het oprumen van bacterien (fagocytose). SAA zorgt voor het beperken en repareren van toegebrachte schade aan de weefsels (door bijwoorbeeld bacteriën). Als gevolg van bepalde ontstekingsreacties, zoals sarcoïdose, worden T-lymfocyten heel sterk gestimuleerd tot delen. In dat geval komen veel van de zogenaamde $\mathrm{LL}-2$ receptoren (IL2R) aan hun oppervlak woor, die ertoe bijdragen dat deze deling van de T-lymfocyten verder wordt gestimuleerd. Deze IL 2R komen deels vrij en zijn in de circulatie meetbaar als oplosbare (soluble) interleukin-2-receptoren (sIL2R). Speciale cellen (epithelioid cellen) die deel uit maken van granulomen bij sarcoidose zijn ook in staat angiotensinconverterend enzyme (ACE) te produceren en deze is ook in de bloedbaan te meten.

Tot op heden is er geen goede marker om de ernst van sarcoidose te bepalen. Daarom werden in het eerste deel van dit proefschrift laboratoriumparameters SIL2R, $A C E$, CRP en SAA, geèvalueerd als potentiele markers bij sarcoïdose.

Voordat een parameter in de dagelijkse praktijk toegepast kan worden als marker, dient deze zorgvuldig onderzocht te worden (HOOFDSTUK $2 \mathrm{t} / \mathrm{m} \mathrm{4}$ ). Hierbij spelen twee factoren een essentiele rol; ten eerste moet de meetmethode betrouwbaar zijn en ten tweede dienen patienten in verschillendle, goed te onderscheiden, groepen te worden ingedeeld (bijvoorbeeld, actief/niet-actief, ernstig/niet-ernstig verloop).

Betreffende het eerste punt, werd in HOOFDSTUK 2 en 3 met name veel aandacht geschonken aan de evaluatie van de CRP methodieken. De huidige toegepaste CRP methodiek bleek ongeschikt te zijn voor het meten van lage concentraties en verder extreem gevoelig voor troebeling in het bloed, veroorzaakt door (bijvoorbeeld) verhoging van trygliceriden (vetten) in niet-nuchter afgenomen bloedmonsters. Aangezien uit eerdere studies is gebleken dat CRP een rol kan spelen bij de beoordeling van de emst van sarcoidose, werd een betrouwbare methodiek gezocht voor het meten van lage concentraties.

In HOOFDSTUK 4 zijn de laboratoriumtechnische aspecten van de SAA en sIL2R geẻvalueerd, omdat het nieuwe bepalingen betreft. De referentiewaarden voor sIL $2 R$ bleken niet afhankelijk te zijn van leeftijd en geslacht. De referentiewaarden voor SAA bleken iets hoger te zign bij vrouwen. Bovendien werd een relatie met leeftijd gevonden, namelijk iets oudere mannen bleken iets hogere waarden te hebben dan de jongere manuren.

Het onderscheiden van patiënten groepen (actief/niet-actief, enstig/niet-ernstig verloop) is in relatie tot sarcoüdose niet eenvoudig. Noch voor de activiteit, noch voor de ernst is er exn goede definitie beschikbaar.

In HOOFDSTUK 5 werd een studie opgezet waarbij aan de hand van internationale richtlijnen criteria zijn gedefinieerd on patiënten in de groepen "ernstig" en "nietanstig" in te delen. Deze indeling vond plaats op basis van de an- of afwezigheid van longlunctiestoomissen. Deze criteria waren zo gedefinieerd dat ze eenduidig te interpreteren en toe te passen zijn. Uit de studie is gebleken dat van de eerder genoemde laboratorimparameters, slL2R de meest geschikte marker voor het voorspellen van de ernst van sarcoildose is. Opvallend genoeg bleek dat $\mathrm{ACE}$, de klassieke sarcoïdose marker, niet bruikbaar is om ernst te voorspellen. 


\section{Het voorspellen van moeheid}

Uit eerdere studies is gebleken dat moeheid een belangrijk symptoom is van patiënten met sarcoïdose. In HOOFDSTUK 6 werd gekeken of de bovengenoemde laboratoriumparameters in staat zijn om moeheid bij sarcoïdose te voorspellen. Geen van de geëvalueerde laboratoriumparameters, noch de gebruikte longfunctieparameters, bleken goede markers van moeheid te zijn. Alleen minder objectieve hulpmiddelen. zoals vragenlijsten, bleken in staat moeheid te voorspellen.

\section{Oxidatieve stress en sarcoïdose}

Naar aanleiding van eerdere studies werd in het tweede deel van het onderzoek gekeken of oxidatieve stress, direct of indirect, mogelijk een rol speelt bij sarcoïdose. Oxidatieve stress is een toestand waarbij er geen goede balans bestaat tussen de vorming (prooxidatieve werking) en de eliminatie (anti-oxidatieve werking) van toxische zuurstofverbindingen.

Twee aspecten die met de gevoeligheid voor oxidatieve stress te maken hebben werden onderzocht.

In HOOFDSTUK 7 werd gekeken of een bepaald enzym te weten G6PD, in staat is om voor voldoende anti-oxidatief (reducerend) vermogen te zorgen. Een enzym is een eiwit dat chemische reacties doet versnellen. G6PD zorgt dat er voldoende van een bepaald stof (anti-oxidlatief vermogen) dat afgekort NADPH heet, aangemaakt wordt. Een genetische of biochemische verandering van G6PD heeft tot gevolg een verlaging van NADPH, wat G6PD-deficiëntie wordt genoemd. In Nederland wordt G6PD-deficiëntie vastgesteld met behulp van de zogenaamde "chroom-inhibitie test". De test berust op het principe dat een enzym, het glutathione reductase (bijna) volledig geremd wordt door chromaat in normale rode bloedcellen maar niet in G6PD-deficiënte cellen.

Tijdens het onderzoek bleek dat bijna één derde wan de vrouwelijke sarcoïdose patiënten en slechts één mannelijke patiënt verlaagde NADPH waarden hadden (Hoofdstuk 7). Er konden echter geen mutaties in het G6PD-gen worden gevonden. De chroom-inhibitie test bleek minder geschikt voor screening op G6PD deficiëntie ondat die veel fout positieve uitslagen opleverde. De door deze test angetoonde veriaagde NADPH concentraties is een aanwijzing dat de oxidative stress een rol speelt bij sarcoïdose. Toekomstige studies dienen de klinische relevantie verder te evalueren en mogelijke therapeutische consequenties te onderzoeken.

In HOOFDSTUK 8 werd gekeken of twee puntmutaties (polymorfismen), in het gen caderend voor het enzym myeloperoxidase (MPO), geassocieerd zijn met sarcoïdose en of ze gerelateerd zijn aan een ernstiger verloop.

MPO is een enzym dat schadelijke zuurstof verbindingen kan genereren en is een belangrijk enzym in een bepaalde soort witte bloedcellen, de neutrofielen. Eerder is aangetoond dat een toename van het aantal neutrofielen in de longen een indicatie is voor een slechtere prognose van sarcoïdose en een verhoogde kans op het ontwikkelen van longfibrose. Dit zou kunnen samenhangen met de hoeveelheid MPO die door deze cellen geproduceerd worden (het niveau van MPO expressie) en haar pro-oxidatieve werking. Twee verschillende functionele polymorfismen werden bekeken in de 
promotor van het MPO gen, namelijk de $-463 \mathrm{G} / \mathrm{A}$ and $-129 \mathrm{G} / \mathrm{A}$. Er werd werondersteld dat een verminderde aanmak van dit enzym een "beschermend" effect kan hebben op de ontsteking bij sarcoudose, en zodoende een minder ernstig verloop kan geven. Echter, er werd geen verband gevonden tussen dit polymorfisme en sarcö̈dose. Bovendien werd er geen verschil in de ernst van sarcoïdose emst tussen dragers van dit polymorfisme en de personen die dit polymorfisme niet hebben.

Sarcoildose is een intrigerende aandoening aangezien er ondanks grote onderzoeksinspanningen nog veel vragen onbeantwoord zijn, met name wat betreft de mogelijke oorzaken, het woorspellen van het ziekteverloop en de waarde van laboratoriumonderzoek in de diagnostiek en follow-up. Tevens is er nog geen adequate therapie voorhanden. Gezien het feit dat de oorzaak nog niet bekend is, bestaat de behandeling vooralsnog voornamelijk uit symptoombestrijding.

Toekomstig onderzoek, met name in de richting van genoom onderzoek en proteomics (eiwit profilering), zal misschien antwoord kunnen geven op de vele openstaande vragen. 
Chapter 11

\section{Sažetak}

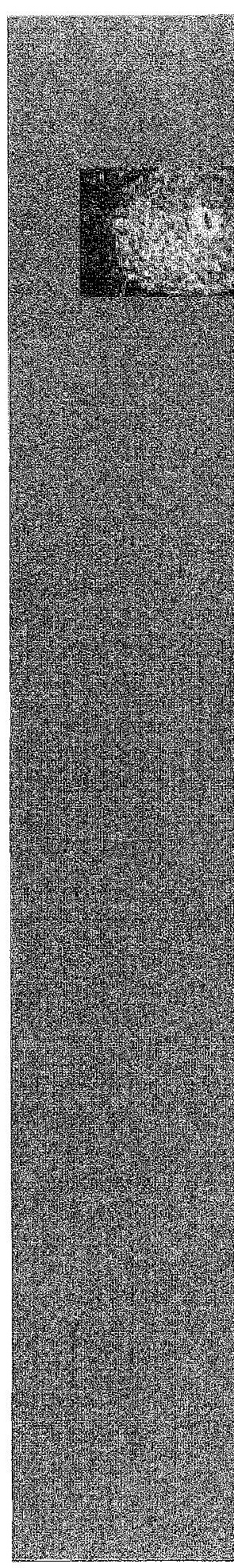


136 Chmos h 


\section{Sažetak}

\section{Sarkoidoza}

U POGLAVLJU \& dat je uwod u sarkoidozu (bolest poznata i pod imenom BesnierBoeck-Schaumann-ova bolest). Etiologija ove bolesti nije poznata. Zahvaca razlicite organe i tkiva, ali pretežno pluća, u $90 \%$ sluçajeva. Najčsce obolijevaju mlade osobe u dobi ad 20 do 40 godina. Sarkoidoza se javlja u otprilike 40 na 100.000 ljudi, premda taj broj varira ovisno o zemljopisnom podrucjü.

Glawno obilježje sarkoidoze su granullomi odnosno kronična upalna zarista. Stvaraju se kao posljedica nakupljanja upalnih stanica u oboljelim tkivima, a posebno bijelih krvnih stanica, kao sto su makrofagi i aktivirani T-limfociti. Premda kod sarkoidoze uzzoćnik bolesti nije poznat, mehanizam bolesti sugerira da bi taj uzročnik ipak morao biti vanjski faktor u kombinaciji s nekim genetskim faktorom.

Simptomi s kojima se bolesnici javljaju ovise o organu koji je zahvaćen (otezano disanje, kašalj, očni problemi, promjene na koži, zglobovima, vrtoglavica te glavobolja i/li bol u mišcima). Bolesnici se također mogu tužiti na nespecifične tegobe kao sto su opća slabost, gubitak na težini i povišena tjelesna temperatura. Najčesće se tuže na umor, simptom koji je vrlo teško objektivizinati, a zaostaje cak i nakon sto su se ostali parametri aktivnosti normalizirali.

Tijek sarkoidoze varira. Tako akutni oblik sarkoidoze, poznat jos i pod imenom Löfgrenov sindrom, koji se manifestira kao kombimacija povišene tjelesne temperature, bolova u zglobovima i specifičnih kožnih promjena (nodozni eritem), općenito ima povoljniji tijek. Sarkoidoza srca, središnjeg živčanog sustava ili vrlo prosirena plućna sarkoidoza imaju nepovoljan tijek i prognozu.

Za praćenje bolesnika i procijenu prognoze vrlo je važno dobiti jasnu kliničku sliku. Proširenost bolesti obično se procjenjuje pomoću laboratorijskih pretraga, rentgenoloških i CT pretraga, testova plućne funkcije, vizualnog pregleda dušnika (bronhoskopija) te bronhoalvolarnog ispiranja (aspirirana fiziološka otopina nakon pranja plućnog režuja, koja daje informacije o vrsti i kolicini upalnih stanica).

S obzirom da uzrok sarkoidoze jos uvijek nije poznat, terapija se uglavnom sastoji u olaksavanju simptoma u slučaju blažih tegoba (ne-steroidnim inhibitorima upale) illi se $u$ slučaju tezih tegoba koriste sredstva koja inhibiraju cjelokupni tjelesni obrambeni sustav (kao npr. prednizon). Osin toga, promjena načina živola i pridržavanje odredenih pravila je jako važno za olaks̆avanje tegoba kao sto je umor.

\section{Evaluacija markera sarkoidoze u procijeni težine bolesti}

U upalnoj reakciji jetra obično proizvodi vellike količne C-raktivnog proteina (CRP) i serum amiloida $\mathrm{A}$ (SAA). Oba proteina se jos nazivaju i proteini akutne lase. Kod nekih oboljenja ta proizvodnja ipak nije eksplozivna, nego je konstantno blago povišena. CRP je važan u inicijaciji procesa uništavanja bakterija ili nekog dnugog uzrocnika upale (fagocitoza). SAA se brine za to da upala bude ogranicena i da dode do reparacije (popravka) tkiva. U nekim upalnim reakcijama, kao što je sarkoidoza, T-limfociti se 
ubrzano dijele i umnozavaju. Pri tome se na površini T-limfocita javljaju receptori, tzv. IL 2-receptori (IL 2R), koji omogucuju to umnožavanje. Jedan dio tog IL2R receptora se oslobada i moze se mjeriti u cirkulaciji, i naziva se topljivi IL-2R (sIL2R). Specijalne stanice (epittioidne stanice), koji takoder cine granulom, su u stanju proizvoditi anglotenzin-konvertirajuci enzim (ACE), koji je takoder mjerljiv u cirkulaciji.

Do danas ne postoji niti jedat laboratorijski parametar koji bi se mogao koristiti za procijenu tezine bolesti. Radi toga su u prwom djelu ove dizertacije, llaboratorijski parametri kao sto su sIL2R, ACE, CRP i SAA, bili evaluirani kao potencijalni markeri sarkoidoze.

Prije nego sto se neki parametar može primjeniti u dijagnostici, mora se temeljito ispitati. Pri tome su jako bitna dva faktora: 1. metoda koja se koristi za mjerenje doticnog parametra mora biti pouzdana (POGLAVLJA 2 do 4) i 2. bolesnici se moraju moći svrstati u dvije razlicite grupe (npr. s aktivnom nasuprot inaktivnom bolešcu, ill bolesnici s težm oblikom bolesti nasupot onilh s blažim oblikom bolesti).

Sto se tič prvog zahtjeva, L POGLAVLIIMA 2 i 3, osobita je pažnja billa posvecena evaluaciji razlicitih CRP metoda. Dosadasnja, općenito prihvacena CRP metoda pokazala se sasvim nepouzdanom za mjerenje niskih koncentracija i ekstremno osjetlijua na zamucenost uzorka. S obzirom da su prijašnje studije pokazale da su niske CRP koncentracije tipične za sarkoidozu, bilo je potrebno nacil metodu kojom bi se niske CRP koncentracije mogle pouzdano mjeriti.

U 4 POGLAVLJU SAA i sIL2R su bili evaluirani budući da pretstawljaju nove mjerne metode. sIL2R referentne vrijednosti pogazale su se neovisnima o životnoj dobi i spolu. Nasuprot tome, SAA referentne vrijednosti su se pokazale višma u žena. Osim toga, u starijih muskkilh osoba nadene su više SAA vrijednosti nego u mladih muških osoba.

Što se tice drugog zahtjeva, situacija je složenaja. Bolesnike sa sarkoidozom nije lako svrstati u grupe (bolesnike s aktivnom nasuprot onih $s$ inaktivnom bolešcu, ili bolesnike $s$ težim oblikom bolesti nasuprot onih s blažim oblikom bolesti). Razlog tome je da nuti za aktivnost niti za "težinu" bolesti ne postoje jasno definirani kriteriji.

U 5 POGLAVLJU, da bi izveli studiju diagnostičke točnosti za čatiri gore navedena laboratorijska parametra, sami smo definirali kriterije kako bi bolesnike svrstali u grupe "tezi oblik bolest" nasuprot "blaži oblik bolesti", na temelju internacionalnih prepruka. Ta podjela je učnjena na temelju prisutnosti tj. odsutnosti plućnih poremećaja. Kriteriji su tako definirani da se daju jednoznaéno interpretirati i primjeniti. Pokazalo se da je od evaluiranih parametara, sIL2R najpouzdaniji prediktor težine bolesti, dok se tradicionalno prihvacen i korišten ACE pokazao manje pouzdanim.

\section{Predikcija umora}

Iz prijasnjih studija pokazalo se da je umor jedan od najcescih nespecificnih simptoma u bolesnika sa sarkoidozom, koji je teško objektivno mjeriti. U 6 POGLAVLJU, cilj je bio vidjeti da li neki od parametara upale, evaluiranih u prethodnom poglawlju, je u stanju statisticki predvidjeti umor. Niti jedan od evaluiranih laboratorijskih parametara ili parametara plucne funkcije, bilo pojedinačno ili u kombinaciji, nije se pokazao dobrim u predviđanju umora. Radi toga se još uvijek savjetuje korištenje psiholoških upitnika, premda manje objektivnih sredstava, u svihu evaluacije takvih nespecifičnih simptoma. 


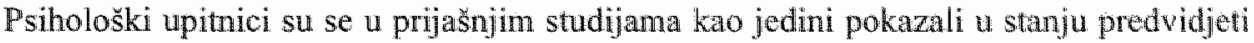
umor.

\section{Oksidativni stres i sarkoidoza}

Cilj drugog dijela ove dizertacije, bio je istraziti kakvu ulogu ima, bilo direktno ili indirektno, oksidativni stres u sarkoidozi. Oksidativni stres je stanje neravnoteze izmedu stwaranja (pro-oksidativnog djelovanja) i eliminacije (anti-oksidativnog djelovanja) toksičnih kisikovih spojeva. Dva aspekta, koja su u vezi s osjetljivošcu na oksidativmi stres, su bila istražena.

U 7 POGLAVLJU predmet istražixanja bila je glukoza-6-fosfat dehidrogenaza (G6PD). G6PD je enzim odgovoran za opskrbu stanica dovoljnim kolicinama anti-oksidativnog spoja, nikotina-adenina-dinukleotid fosfata (NADPH). Genetske ili biokemijske promjene u G6PD imaju za posljedicu sniženje koncentracije NADPH, sto se jos ponekad naziva i G6PD-deficijencija. U Nizozemskoj se G6PD-deficijencija odreduje biokemijski, pomoću indirektnog testa inhibicije GR pomoću kromata (tzw. kromatinhibicijski test). Abnomalni rezultat sugerira snižzenu celularnu koncentraciju NADPH. Gotovo trecina ženskih pacijenata i jedan muški pacijent sa sarkoidozom su imali abnormalne rezultate kromat-inhibicijskog testa. Usprkos tome, samo je kod jednog pacijenta rezultat biokemijskog testa mogao biti potvrden genetskom mutacijom u G6PD genu. Pokazalo se da kromat-inhibicijski test ne može biti primjenjen kod pacijenata sa sarkoidozom za dijagnosticiranje G6PD deficijencije zbog visokog postotka lažno-pozitivnih rezultata. Ipak, snizena celularna koncentracija NADPH upućuje na prisutnost intracelularnog oksidativnog stresa. Klinicka relevancija te činjenice se mora dalje evaluirati kao i njezin utjecaj na terapiju.

U 8 POGLAVLJU, bilo je istraženo da li dvije tockaste mutacije (polimorfizmi) utjecu na ekspresiju gena koji kodira za enzim mijeloperoksidazu (MPO) pri sarkoidozi, te da li prisutnost polimorfizma ima utjecaja na prezentaciju ("težinu") bolesti. MPO je enzim koji je u stanju generirati toksiěne kisikove spojeve i najobuhvatniji je enzim bijelih krvnih stanica (neutrofila). Vec prije je pokazano da porast broja neutrofila u plucima najavljuje lošiju prognozu i povećanu vjerojatnost za razvitak plucne libroze. Ta cinjenica je vrlo vjerojatno u vezi sa količinom MPO koju stanica proizvede (sa nivoon MPO ekspresije) i njezinog pro-oksidativnog djelovanja. Radi toga su predmet istraživanja bila dva funkcionalna polimorfizma: $-463 \mathrm{G} / \mathrm{A}$ i $-129 \mathrm{G} / \mathrm{A}$ u promotonu gena koji kodira enzim mijeloperoksidazu (MPO). Veza izmedu polimorfizana i sarkoidoze nije bila utvdena. Osin toga nije bilo nikakve razlike u klinickoj slici izmedu nositelja i onih koji nisu nositelji tih dvaju polimorfizama.

\section{Zaključak}

Sarkoidoza je interesantna bolest budući da usprkos svim istraživackim naporima jos preostaje puno otvorenih pitanja, prije svega onih koja se tiču uzroka bolesti, predvidanja tijeka bolesti i vrijednosti laboratorijskih istraživanja u dijagnostici i slijeđenju tijeka bolesti. Budući da uzrok još uvijek nije poznat, nema adekvatne terapije, već se ona uglavnom sastoji u suzbijanju simptoma. Buduća istrazivanja, 
osobito istraživanja genoma te profilianja bjelančevina pomoću masene spektrometrije (proteomics), možda ce dati odgovore na neka od th pitanja. 
Dankwoord 


\section{Dankwoord}

Bij het verrichten van het onderzoek en de totstandkoming van een proefschrift is hulp van anderen altijd onontbeerlijk. Uitdrukkelijk wil ik de sarcoidosepatienten bedanken, aangezien zij steeds weer erg enthousiast medewerking hebben willen verlenen aan de in dit proefschrift beschreven onderzoeken.

Verder wil ik alle medewerkers van de afdelingen Klinische Chemie en Longfuncrie van het academisch ziekenhuis Maastricht hartelijk bedanken voor alle steun en inbreng. Toch wil ik een aantal mensen nog even speciaal noemen.

Beste Marja, (Prof, dr. Marja P. van Dieijen-Visser, promotor). Jij was degene, die mij steeds wist te stimuleren en motiveren met je altijd positieve instelling. Jouw wetenschappelijke benadering, pragmatische manier van werken, relativeringsvermogen en de grote rust die je altijd weet uit te stralen -naar mij, maar ook naar anderen - zijn voor mij een groot voorbeeld.

Beste Marjolein, (Dr. Marjolein Drent, co-promotor). Met je onuitputtelijke inzet, enthousiasme en snelheid, waarmee je reacties op mijn ideeën en wetenschappelijke artikelen wist te produceren, heb je me altijd weten te verbazen.

Ik ben jullie beiden erkentelijk voor het vertrouwen dat jullie in mij gesteld hebben om mij dit onderzoek te laten doen. Ook allerlei gesprekken buiten het werk om heb ik enorm gewaardeerd.

Voor de analytische hulp onmisbaar bij de diverse onderdelen van dit proefschrift wil ik in het bijzonder Riet Schwitz en Kim Herzberg bedanken voor alle inbreng en zorgvuldigheid. Verder wil ik Armand Gubbels hartelijk danken voor zijn bijdrage. Het opbouwen van de zogenaamde G6PD-file was niet mogelijk geweest zonder de tomeloze inzet en zorgvuldigheid van Peral Wijnen, waarvoor mijn dank. Daarnaast wil ik Dr: Otto Bekers en Dr. Paul Menheere danken voor de wetenschappelijke steun tijdens de onderzoeksperiode. Serva Rozenhout, ik had het gevoel dat ik je toch nog even apart moest noemen, dus bij deze...

Een speciaal woord van dank wil ik richten tot mijn "collega-onderzoekers" en toenmalige klinisch-chemici in opleiding. Met name Jart Diris, mijn eerste kamergenoot, voor talloze computer- en taaltips, het enthousiasme en de zorg voor de goede muziek op de juiste momenten. Robert Op den Buijsch, ook een langere tijd mijn kamergenoot bedankt voor je hulp en inbreng. Chris Hackeng bedankt voor allerlei handige tips rondom de promotie maar ook al voor de opleiding. Johon De Vries, jouw hulp rond G6PD heb ik enorm gewaardeerd. Jaap Bakker bedankt woor allerlei tips en voor alle plagerijen (dat zorgde voor een vrolijke sfeer op onze kamer). Eirenne Michielsen, jouw dank ik hartelijk voor alle hints voor de stellingen, maar mel name voor vriendschap. Ik dank jullie allen voor alle medeleven en steum maar vootal voor het creëren van een prima werksfeer.

Van de Longafdeling wil ik in het bijzonder, Dr. Rob Lamers (voor het beoordelen van röntgenfoto's), Merinke Lenters (die mij met haar klinische kennis vooral in de eerste fase van mijn promotie veel heeft bijgestaan), Poul Bongaerts en zijn team (bij het verzamelen van de longfunctie data), Bart Kessels en Esther Ten Hoor danken voor hun bijdrage. Tevens gaat mijn dank uit naar Prof. dr. J. Verschakelen van het Universitair Ziekenhuis Gasthuisberg in Leuven, die samen met Dr. Rob Lomers mogelijk gemaakt 
heeft dat een HRCT-scoringssysteem in de evaluatie van de patiënten gebnikt kon worden.

Alle leden van de beoordelingscommissie Prof dr. A. Bast look mijn dank woor een aantal stimulerende "brainstorm" sessies), Prof. dr. E.F.M. Wouters, Prof. dr. P.M. van den Bergh-Loonen en Dr. J.M.M. van den Bosch dank ik voor hun deelname. Prof. dr. R.M. du Bois, I am very honoured that you are so kind to participate to the Assessment Committee of this. PhD thesis and I wish to express my appreciation to you.

Prof. dr. Dirk Roos, Mortin De Boer en Herma Vuil vamuit CLB in Amsterdam, wil ik nog eens extra bedanken voor al hun medewerking bij het puzzelen rondom G6PD. Prof. dr. Ian-Willem Cohen-Tervaert, Dr. Peter Heeninga, Bram Rutgers en verdere medewerkers van het immunologisch laboratorium dank ik voor alle inzet rondom het bepalen van MPO polymorfismen en het opschrijven van een helaas "megatief" artikel, wat niet altijd meeviel.

Dr. P.G.H. Mulder, dank voor uw inzet bij de statistische analyses, voor de altijd duidelijke uitleg en allerlei macro's. Uw bijdrage was ontzettend leerzaam voor mij.

Dr. J. de Vries, dank voor je enthousiasme en alle hulp in de verschillende fases van nijn promotic.

Tiny Wouters, hartelijk bedankt voor de steun, voor het verzorgen van de lay-out van dit proefschrift maar ook voor allerlei andere tips rondom de promotie. Dr. Frank van der Sande dank ik hartelijk voor de Engelse tallcorrecties en mevrouw $M$. Elfferich, voor het zetten van de punten op de i's. Hens, hartelijk dank voor het maken van het omslag. Dr. Peros-Golubicic, wama se specijalno zahvaljujem za vilo ugodnu suradnju, te za citanje i korekciju hrvatskog sažetka ove dizertacije.

Hoewel ze niet rechtstreeks hebben bijgedragen aan de tot standkoming van dit proefschrift, toch wil ik tevens mijn voormalige collega's en begelleiders op de afdeling NMR Spectroscopie danken voor hun bijdrage aan mijn vorming tot onderzoeker.

Beste Elske en Sonja, mijn paranimfen. Ik ben echt zeer vereerd met jullie steun als paranimf. Jullie zijn mij heel veel waard.

Buiten het werk om, mijn ouders (Mama i tata, hvala za sve!), schoonouders, famillie en vrienden dank ik voom alle steun.

Ten slotte, Mourice, bedanken voor alles wat je voor mij betekend hebt in de afgelopen jaren is hier in woorden niet uit te drukken. De totstandkoming van dit proefschrift is ook jouw verdienste. I $k$ heb dan ook vertrouwen dat we toekomstige "uitdagingen" die op onze weg komen op welk terrein dan ook met inzet van ons beiden zullen aankunnen. 


\section{Curriculum vitae}




\section{Curriculum vitae}

Snježana Kos was born on April 10 ${ }^{\text {th }}, 1973$ in Zagreb (Croatia). After she finished secondary school in 1991, she started with her academic education on the faculty of Pharmacy and Medical Biochemistry at the University of Zagreb. There she specialized in Medical Biochemistry and graduated in February 1996. In September 1996 she started with the study of Health Sciences at the University of Maastricht. She graduated in September 1998 specializing in Biological Health Sciences. From October 1998 she worked on the research project of protein translation initiation under supervision of Prof. dr. R. Boelens at the Department of Biomolecular NMR of the Bijvoet Center at Utrecht University. In January 2001 she started as a researcher at the Department of Clinical Chemistry at the University Hospital Maastricht under supervision of Prof. dr. M. P. van Dieijen-Visser and Dr. M. Drent (Department of Respiratory Medicine). The result of that work is presented in the present thesis. She is currently engaged with the training in Clinical Chemistry in the same hospital. 


\section{List of publications}




\section{List of publications}

1. Siljander P., Fandale RW, Feige MA, Comfurius P, Kor S, Bevers EM, Heemskerk JW. Platelet Adhesion Enhances the Glycoprotein VI-Dependent Procongulant Response. Artertowch Thromb Vare Biot $2001: 21: 618-27$.

2. Rohhkraniz-Kos S, Schmitz MP.J, Bekers O, Menheere PPCA, van Diejen-Visser MP. High Sensilvity CReactive Protein Methods Examined. Clin Chem 2002;48:359-62

3. Rorhkrantz-Kos $S$, Drent M, Vuil H, De Boer M, Bast A, Wouters EFM, Roos D, van Dieijen-Visser Ml. Decreased redox state in red blood cells from patients with sarcoidosis. Sarcoidosis Vase Difure Lumg Dis $2002 ; 19: 114-20$.

4. Rothkrantz-Kos $S_{\text {, Bekers }}$, Gubbels A. Drent M, Schmiz MPJ, wan Dieijenm Visser MP. Evaluation of two new high-sensitivity C-reactive protein methods. Ann Clin Biochem 2003;40:398-405.

5. Drent M, De Vries J, Lenters M, Lamers R, Rothkrantr-Kos S. Wouters EFM, van Dieijen-Visser MP. Verschakelen JA. Sarcoidosis: assessment of disease severity using HRCT. Eur Radiol 2003:13:2462-71.

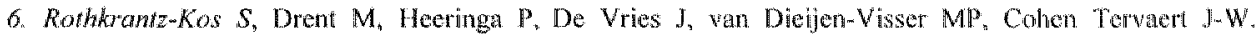
Myeloperoxidase promotor polymorphisms in sarcoidosis. Eu" J Intern Med 2003; 14:296-301.

7. RothkrantzmKos S, van Dieijen-Visser MP, Mulder PGH, Drent M. Usefulness of inflammatory patameters to depict respiratory functional impairment in sarcoidosis. Clin Chem 2003;49:1510-7.

8. De Vries J, Rothkrantz-Kos $\$$, van Dieijen-Visser MP, Drent M. The relationship between fatigue and clinical parameters in acute pulmonary sarcoidosis. Sarcofdosis Vasc Diffuse Lung Dis 2004:/n prew.

9. Ronhkrantz-Kos $S$, Drent M, Schmitz MPJ, Menheere PPPC, van Dieijen-Visser MP. Aralytical evaluation and determination of reference values of soluble interlleukin-2-receptor and serum anyloid-A. Stubmithed. 